\title{
Three-Dimensional Carbon Materials for Efficient Oxygen and Hydrogen Electrocatalysis
}

Ana Belen Jorge*, Rhodri Jervis, Arun Prakash Periasamy, Mo Qiao, Jingyu Feng, Linh Ngoc Tran, Maria-Magdalena Titirici*

Dr. A. B. Jorge; Dr. A. P. Periasamy; L. N. Tran

Queen Mary University of London, School of Engineering and Materials Science, Materials Research Institute, Mile End Rd, E1 4NS, United Kingdom

Dr. R. Jervis

University College London, Department of Chemical Engineering, Electrochemical Innovation Lab, Torrington Place, WC1 0AJ, United Kingdom

Dr. M. Qiao; J. Feng; Prof. M. Titirici

Department of Chemical Engineering, Imperial College London, South Kensington Campus SW7 2AZ, United Kingdom

E-mail: titirici@imperial.ac.uk; $\quad \underline{\text { a.sobrido@qmul.ac.uk }}$

Keywords: 3D porous carbons, electrocatalysis, oxygen evolution, oxygen reduction, hydrogen evolution

\begin{abstract}
Sustainable energy production at an acceptable cost is key for its widespread application. At present, noble metals and metal oxides are the most widely used for electrocatalysis, but they suffer from low selectivity, poor durability and scarcity. Because of this, metal free carbons have become the subject of great interest as promising alternative electrocatalysts for energy conversion and storage devices, and remarkable progress has been accomplished in the advance of metal free carbons as electrocatalysts for renewable energy technologies. Particularly interesting are three-dimensional (3D) porous carbon architectures, which exhibit outstanding features for electrocatalysis applications, including broad range of active sites, interconnected porosity, high conductivity and mechanical stability. This review summarizes the latest advances in $3 \mathrm{D}$ porous carbon structures for oxygen and hydrogen electrocatalysis. The structure-performance relationship of these materials is consequently rationalized and perspectives on creating more efficient 3D carbon electrocatalysts are suggested.
\end{abstract}




\section{WILEY-VCH}

\section{Introduction}

The core of energy conversion and storage technologies such as metal-air batteries, fuel cells and water electrolysers, relies on a series of electrochemical processes, namely the oxygen evolution reaction (OER), oxygen reduction reaction (ORR) and hydrogen evolution reactions (HER), usually catalysed by noble metals (Pt for ORR and HER, and Ir / Ru for OER) or their alloys. However, their high cost and poor stability have impeded their commercial deployment in large-scale applications, although it is worth noting that platinum still exhibits unbeatable ORR catalytic activity in acidic media and most currently available commercial electrochemical technologies use precious metal catalysts. Research efforts have focused on the design and development of electrocatalysts based on transition metals and their compounds/alloys, including oxides, chalcogenides and hydro(oxy) oxides, among others. ${ }^{[1-3]}$ Although most of the transition metal electrocatalysts are stable, some of them are prone to gradual decomposition through oxidation, and agglomeration when exposed to air, and are often electrochemically unstable at high potentials in acidic media, degrading via dissolution and agglomeration mechanisms such as Ostwald ripening. ${ }^{[4]}$

In the quest for novel metal free efficient electrocatalysts, carbon materials have positioned themselves at the forefront as serious contenders to replace noble metal based electrocatalysts in energy devices. This means a notable shift from their initial, more passive, role as supports for metal nanoparticle catalysts to have an active part in the electrocatalytic process. If we have a look at literature in the last decade, we can see that significant advances have been made in the synthesis and application of nanostructured carbons for energy. ${ }^{[5-15]}$ Carbon materials are low-cost, easy to tune, present good electrical and thermal conductivity, and mechanical strength, as well as the potential to have high surface area morphologies. In recent years, carbon materials (i.e., graphene, carbon nanotubes, graphitic arrays, and other nanostructures) have been developed as promising cost-effective alternatives for promoting oxygen and hydrogen electrocatalysis in energy technologies. ${ }^{[16-18]}$ In particular, three dimensional (3D) carbon architectures, with tunable porous structures, offer extraordinary mass and electron transport capabilities, which are extremely attractive for electrocatalysis in energy conversion and storage systems. ${ }^{[14,19,20]}$ In the last decade, major breakthroughs in the field of metal free carbon electrocatalysts have been achieved, ${ }^{[16,21-31]}$ making the creation of a new generation of energy devices based in cost-efficient sustainable metal free carbons possible (Figure 1). ${ }^{[32]}$ 


\section{WILEY-VCH}

The remarkable number of molecular symmetries and dimensions, ranging from zerodimensional (0D) carbon dots, through one dimensional (1D) carbon nanotubes (CNTs), twodimensional (2D) graphene sheets, to 3D nanodiamonds, provide the perfect platform for building new 3D architectures with interconnected porosity and active sites. The possibility to easily alter the surface chemistry of the carbon structures and doping can lead to the creation of additional active sites. Carbons, then, become a great platform to rationally design a new generation of cost-effective 3D assembled electrocatalysts for energy storage and conversion devices.

Doping and co-doping metal free carbon catalysts with different heteroatoms (N, B, P, S, O) has been found to be an efficient way to further improve the electrocatalytic activity of carbon catalysts. ${ }^{[27,29]}$ However, there is still a considerable ongoing debate about the actual role of the dopants, their chemical configuration and defects in the catalytic activity. ${ }^{[33]}$ Along with the rapid developments in heteroatom doping of carbon structures, hybridization with other metal free compounds has also been explored as an effective way to increasing the number of active sites and hence improving the performance for electrocatalysis.

This review paper summarizes the latest trends in the design of 3D porous metal free carbon materials for oxygen and hydrogen electrocatalysis, showing important breakthroughs in the field, and the challenges carbon materials still to overcome to become the catalysts of choice in commercial energy conversion and storage devices.

\section{Advantages of 3D porous carbons for electrocatalysis}

Regardless of the wide range of carbon molecular architectures, graphene nanosheets and carbon nanotubes (CNTs) possess a common building block with conjugated alternating C-C and $\mathrm{C}=\mathrm{C}$ bonds responsible for the delocalization of $\pi$ electrons in their structure. 3D porous carbon materials present many obvious advantages over zero-dimensional (OD) carbon dots, 1D nanotubes and 2D graphene, particularly for catalysis. These include a large surface area with many exposed catalytically active sites, edge-located active sites proved to be more active than the ones on the surface or bulk, ${ }^{[34,35]}$ a multidimensional conductive network with excellent electrical conductivity (both in plane and through plane), good mechanical strength, and large volume to allow electrolyte diffusivity and accommodate the electrolyte/reactant diffusion process (Figure 2). ${ }^{[36,37]}$ Maximising the size of the so-called triple phase boundary where electrons, reactant and electrolyte meet and reaction can take place, is a general goal in design of electrodes for electrocatalytic energy storage and conversion devices, from solid 


\section{WILEY-VCH}

oxide fuel cells with ceramic electrolytes, to lithium ion batteries with a combination of solid state and liquid diffusion processes. Carbon-based electrocatalysts for low temperature fuel cells, electrolysers and metal air batteries also require a large triple phase boundary to operate at high current densities and with good efficiency, and so design of the microstructure of the catalysis is also critical here. Overall, 3D hierarchical interconnected porosity and conducting pathways spawned within a 3D porous network provide significant improvements in structural, electrical and textural properties, facilitating electron, gas and mass transport during the course of the electrocatalytic process. ${ }^{[38]}$

\section{Designing 3D porous carbons for electrocatalysis}

The methods that have been most widely used for the preparation of $3 \mathrm{D}$ porous carbons, particularly the methods that enable to have the creation of interconnected macro (micro/meso) pores to achieve the performance improvements in the oxygen and hydrogen electrocatalysis are discussed below, considering that the created hierarchical pores have the major roles to play in the charge transport and the mass transfer in such electrocatalytic reactions. The fabrication of self-supporting 3D macroporous films through the electrospinning and the $3 \mathrm{D}$ printing techniques are also discussed.

3.1. Hard and soft templating. Since the pioneering works on wet chemistry synthesis of silica $\left(\mathrm{SiO}_{2}\right)$ nanoparticles ${ }^{[39]}$ and mesoporous $\mathrm{SiO}_{2}$ discovery ${ }^{[40]}$, the use of nano- and mesoporous $\mathrm{SiO}_{2}$ templates to produce $3 \mathrm{D}$ porous carbons via hard-templating has gained considerable momentum, and many carbon structures with ordered mesopores using silica templating have been reported. ${ }^{[41-45]}$ Porous structures play a vital role in regulating the exposure of active sites and the diffusion of reactants and electrolytes. ${ }^{[31,46-53]}$ Macropores have been shown to provide effective mass transport pathways, while mesopores and micropores offer a large surface area increasing the accessibility of reactants to the active sites and the number of active sites per geometric surface area of the electrode, ${ }^{[54,55]}$ therefore hierarchical porosity becomes critical for electrocatalysts. Zeolites have also been used to create $3 \mathrm{D}$ porous carbon structures. ${ }^{[56,57]}$ The structures of over 10 ZIF template carbons (ZTCs) have been successfully predicted, opening the doors to a variety of possible $3 \mathrm{D}$ carbon structures available. ${ }^{[58]}$ Metal oxide nanoparticles are another example of hard templating that have been extensively employed to generate hierarchical structures with uniform porosity and well defined topologies. ${ }^{[59]}$ Template chemical vapour deposition (CVD) of graphene from the gas phase onto metal templates can be employed to successfully produce graphene sponges, by selective dissolution of the metallic 


\section{WILEY-VCH}

foam in strong acids. ${ }^{[60,61]}$ Template CVD enables precise control over the pore architecture of the sponges. ${ }^{[62]} \mathrm{CVD}$ can also be combined with other template methods to prepare 3D carbon nanostructures, such as salt templating. For example, a 3D hierarchical structure consisting of 2D N, S co-doped carbon sheets ${ }^{[63]}$ and 2D / 3D carbon hybrid structures ${ }^{[64]}$ was prepared through a combined CVD and salt templating approach. A pyrolysis step followed by the removal of the template using strong acids is always required when using hard templates.

Soft templating has the advantage of being able to create a porous structure through the removal of the template simultaneously during the carbonisation process. ${ }^{[65-67]}$ This makes it more convenient than hard templating as we do not any longer need an extra step to remove the template. However, the control over the pore size becomes more challenging when using soft templates. Surfactants, polymers and metal salts are examples of soft templates. In the case of metal salt templates, such as $\mathrm{NaCl}$ and $\mathrm{KCl}$, cubic crystallites are generated, which can only lead to the creation of macropores, making it necessary to combine them with other methods to produce meso- and micropores. ${ }^{[68,69]}$ Hard and soft templates can also be applied in one-pot synthesis to create $3 \mathrm{D}$ connected network. ${ }^{[70]}$

\subsection{Self-sacrificial templating. Templates can serve as the carbon precursor at the same time} that they are creating porosity. Recently, MOF derived mesoporous carbon structures, carbide derived carbon and onion-like carbon structures have been prepared by solution-based chemical processes, condensation, and coordination reactions. ${ }^{[23,71-78]}$ Porous covalent organic frameworks (COFs) are also self-sacrificial templates employed to produce carbons with controllable structure and multi-chemical functionality. ${ }^{[79,80]}$ Bacterial cellulose, plant biomass and melamine sponges are ideal self-sacrificial precursor and templates for 3D carbons. ${ }^{[81-86]}$

\subsection{Assembly of $3 D$ carbon nanostructures. Graphene and graphene oxide (GO) nanosheet} dispersions are a good choice for fabricating 3D porous carbon electrodes. The nanosheets can self - assemble into highly porous sponges through hydrothermal or chemical methods, or via the use of spacer molecules to aid as scaffolds for the nanosheets, that can be electrospun into to form mats, cross-linked into low - density porous beads, vacuum filtered into films or spray dried into 3D crumpled particles. ${ }^{[87-98]}$ Additives such as hydrogen peroxide and acetic acid can promote the production of pore structure and reduction of GO. The size of graphene nanosheets also plays a critical role in controlling the structural and mechanical properties of the $3 \mathrm{D}$ graphene sponge. ${ }^{[99]}$ Unfortunately, the rGO foam prepared by hydrothermal methods usually exhibits low electrical conductivity $\left(\sim 114.7 \mathrm{~S} \mathrm{~m}^{-1}\right){ }^{[100]}$ Therefore, post-pyrolysis treatments have been introduced to increase the electrical conductivity and hence, facilitate the 


\section{WILEY-VCH}

performance of active sites during the electrocatalysis process. ${ }^{[101,102]}$ Small molecules, such as glucose and chitosan, and larger ones such as ovalbumin have been used as precursors for the synthesis of carbogels via hydrothermal carbonization, followed by activation treatment to further facilitate hierarchical structuring with high surface area and variety of pore sizes. ${ }^{[59,103]}$ Controlled porous morphology and heteroatom doping can be obtained in the presence of acid molecules that catalyse the polymerization process.

Macromolecule cross-linking assisted synthesis is also a promising method for creating gelation-based 3D graphene or reduced graphene oxide (rGO) structures. ${ }^{[104]}$ The traditional CVD method is a powerful technique to grow carbon nanostructures such as 3D nanorod arrays, ${ }^{[105,106]}$ nanotubes, ${ }^{[107]}$ and nanofibers. ${ }^{[108]}$ It has recently been demonstrated that graphene-CNT integrated 3D nanomaterials with a pillared structure can be produced by singleor multistep chemical vapour deposition processes, and even through solution self-assembly. ${ }^{[53 \text {, }}$ ${ }^{109-112]}$ It is worth noting that while bottom up approaches such as CVD can produce highly controlled materials with hierarchical porous structures and tunable properties, it is unlikely to be deployed at scale for mass production of electrocatalysts in 3D.

Flexible freestanding metal free electrocatalysts of P-doped graphitic carbon nitride $\left(\mathrm{g}_{-} \mathrm{C}_{3} \mathrm{~N}_{4}\right)$ growing on carbon cloth have been reported. ${ }^{[33]}$ This was achieved by mildly oxidizing the surface to facilitate its interaction with melamine ( $\mathrm{N}$ source) and phytic acid ( $\mathrm{P}$ source), followed by self-assembly and carbonization.

3.4. 3D porous carbon macrostructures. 3D printing has received increasing interest in the last decade ${ }^{[113-118]}$ due to its flexibility and ability to design functional devices which can integrate catalytic functional materials. ${ }^{[119,120]}$ Periodic graphene aerogel microlattices with designed macroscopic architectures were created using the 3D printing technique, by developing a printable graphene-based ink (Figure 3). This method enabled excellent control of pore morphology while maintaining the characteristic advantages of graphene nanosheets. ${ }^{[121]}$ The addition of fiber laser to mill the graphene structure to create graphene foams using 3D printing enabled control of thickness, shape and further refining of the 3D macrostructure. ${ }^{[122]}$ In particular, the use of $3 \mathrm{D}$ printing to develop graphene aerogels, ${ }^{[123]}$ neat porous carbon aerogels, ${ }^{[124]}$ MOF-derived hierarchically porous frameworks, ${ }^{[17]}$ carbon fiber reinforced thermoplastic composites, ${ }^{[125]}$ and $\mathrm{LiFePO}_{4} / \mathrm{GO}$ based interdigitated electrodes ${ }^{[116]}$ with controllable geometries and sizes at micrometre scales have been widely explored. 3D printing can process $3 \mathrm{D}$ porous carbon structures of $10 \mu \mathrm{m}$ thick or thicker with very quick drying 


\section{WILEY-VCH}

time. ${ }^{[126-129]}$ Some 3D printed electrodes have been used in $\mathrm{Li}^{-} \mathrm{O}_{2}$ batteries ${ }^{[116]}$ and are attracting tremendous interest, though the application of 3D printed electrodes in electrocatalysis is still in its infancy. ${ }^{[36,130]} 3 \mathrm{D}$ printed electrode use in electrocatalysis might be hampered, though, by the development of an appropriate ink and printing scheme for abundant active sites generation. Other major printing techniques, such as inkjet printing, screen printing, and transfer printing, have also been commonly used for depositing nanostructured carbons onto substrates of varying size, surface energy, and flexibility for energy applications.

Electrospinning is also an effective way to create 3D porous self-supporting macrostructures of metal free carbons with control over porosity, fiber size and alignment. ${ }^{[131-133]}$ Electrospinning draws out small fibers of polymer solution using a high voltage, and so polymers with a wide variety of chemistries and heteroatoms can be used in the process, before a carbonisation step to introduce electrical conductivity. This technique represents an excellent choice for designing hierarchically porous structures, with the possibility to combine hard and soft templates, and introduce multiple heteroatoms or functionalities.

\section{Heteroatom doping, defects and hybridization.}

Since the discovery in 2009 that showed that a metal free compound, consisting of N-doped vertically aligned carbon nanotubes, could act as electrocatalyst to potentially replace Pt for the ORR in alkaline fuel cells, exhibiting high catalytic performance, and long-term durability, ${ }^{\text {[29] }}$ many research groups from all over the world have reported other active metal free catalysts with remarkable activities, not only for ORR but also for the OER, HER and many other reactions of interest. Combined experimental measurements and DFT calculations revealed that $\mathrm{N}$-doping was responsible for the improved ORR. Since we only have carbon atoms in a pure graphene structure, the charge and spin density are homogeneously distributed, and graphene can be thought of as a zero band gap semiconductor. This translates into materials that are usually non-active for catalyzing electrochemical processes. Due to the difference in electronegativity, doping with heteroatoms induces charge transfer from neighbour carbon atoms, hence facilitating chemisorption of reactants as well as changing the local density of states and electronic structure. ${ }^{[29,134]}$ These studies have included not only $\mathrm{N}$, but also other heteroatoms including $\mathrm{B}, \mathrm{S}, \mathrm{P}$ and $\mathrm{O}$, and can be broadly divided into more electron withdrawing $(\mathrm{N}, \mathrm{O})$ and electron donating $(\mathrm{B}, \mathrm{P})$, with $\mathrm{S}$ having an almost identical electronegativity to $\mathrm{C}^{[31,135]}$ The possibility to alter and control the electronic and catalytic 


\section{WILEY-VCH}

properties by just introducing other heteroatom species, have made carbon materials extremely attractive for energy applications. ${ }^{[12,90,116,136]}$

However, there is still a debate in the literature whether all these heteroatoms play a role in electrocatalysis and what the corresponding mechanism are. A comprehensive review on the role of different heteroatoms within carbon materials for different electrocatalytic reactions can be found in reference. ${ }^{[137]}$

Perhaps the most studied dopant for carbon is nitrogen. $\mathrm{N}$ is more electronegative than $\mathrm{C}$ and so can remove charge density from neighbouring carbon atoms and introduces n-type doping behaviour. Due to the similar bond length of C-C and C-N, N doping in graphene layers can occur with minimal distortion of the carbon structure. Significant effort has been devoted towards finding out what type of nitrogen (pyridinic, pyrrolic, graphitic or oxidized) is responsible for the active site in $\mathrm{N}$-doped carbons for ORR, without consensus to date. ${ }^{[28,138 \text {, }}$ ${ }^{139]}$ Some studies suggest that pyridinic nitrogen is the active site for ORR, via creation of Lewis basic sites and subsequent activation of the neighbour carbon. ${ }^{[139]}$ Other works indicated that graphitic nitrogen is the one promoting the activity, instead. ${ }^{[31,140,141]}$ Moreover, there is not positive correlation in the literature between $\mathrm{N}$ concentration for $\mathrm{N}$-doped carbon catalysts and their activity for the ORR, which is inconsistent with the mechanism of activation proposed. This has been attributed to either a decrease in electronic conductivity due to an excess of $\mathrm{N}$, or that an additional effect is responsible for the ORR catalysis. ${ }^{[33]}$ Part of the source of debate and ambiguity over the nature of the active site in $\mathrm{N}$-doped carbons comes from the difficulty in synthesizing model catalyst systems with only single $\mathrm{N}$ environments, though very recent advances in this area are pointing towards the pyridinic $\mathrm{N}$ being more crucial than graphitic $\mathrm{N}$, which is discussed in more detail in the ORR section of this review.

As well as N, B is a popular heteroatom dopant and due to its lower electronegativity than C, acts as a charge donator to the graphene structure, resulting in p-type behaviour, which can be advantageous for electrocatalysis. B-doping can also lead to enhanced electronic conductivity, which is key for active catalysis of all electrochemical reactions. ${ }^{[142]}$ Contrary to $\mathrm{N}$ or $\mathrm{B}$, the electronegativity of $\mathrm{S}$ is almost identical to that of $\mathrm{C}$ and, subsequently, doping with $\mathrm{S}$ does not have much effect in changing the localized charge density of the graphene structure. Additionally, the $\mathrm{S}-\mathrm{C}$ bond is $25 \%$ longer than the $\mathrm{C}-\mathrm{C}$, and so $\mathrm{S}$ doping can have a significant distortion effect on the structure. ${ }^{[143]} \mathrm{P}$ has a significantly different doping effect than $\mathrm{N}$, despite having the same valence electron arrangement, as it is less electronegative than $\mathrm{C}$ and therefore 


\section{WILEY-VCH}

is electron donating. $\mathrm{P}$ tends to form $\mathrm{sp}^{3}$ hybridisation with $\mathrm{C}$, resulting in pyramidal $\mathrm{PC}_{3}$ clusters that protrude from the graphene plane and a subsequent reduction in electronic conductivity.

As well as the ORR, HER and OER are important electrocatalytic reactions for water electrolysis, and heteroatom doping is a vital route to metal free active catalysts. The doping strategy for catalysts for HER and OER is centered around tuning the absorption energy of reaction intermediates such as $\mathrm{H}^{*}, \mathrm{HO}^{*}, \mathrm{O}^{*}$ and $\mathrm{HOO}^{*}$, with the goal of generating materials that there close to the peak of the volcano plot for the activity towards the respective reactions. Again, heteroatom doping can alter the local density of states and tuning of the electronic properties of metal free catalysts is possible to enhance the activity towards the HER or OER. Unlike for the ORR, catalyst for the HER and OER often operate at large negative or positive potentials, respectively, and so stability of these materials is more of a concern than for ORR, particularly for OER catalysts in acid where the operating voltage can get above the stability limit for carbon of $1.8 \mathrm{~V}$ vs RHE. As heteroatom doping normally substitutes a carbon atom in the chemical structure, as opposed to the metallic nanoparticles adsorbed onto the support surfaces in traditional electrocatalysts, it represents inherent structural robustness, and often leads to more stable catalysts in long term testing.

Co-doping, often with $\mathrm{N}$ as one of the heteroatoms, is a popular strategy to improve the activity of metal free electrocatalysts, with elements such as S, P, B, Si, F, and all explored as strategies in recent years. Co-doping is largely considered to have a synergistic effect, whereby a neighbouring heteroatom increases the ease of co-ordination of reactant molecules near the active site, or contributes electron donation or withdrawal from the charge density of the active site. Very recent work on CNT co-doped with N and S suggest, however, that rather than having a synergistic effect, the $\mathrm{S}$ simply acts to promote the formation of pyridinic $\mathrm{N}$ over other $\mathrm{N}$ environments and improves the activity accordingly. B, another popular co-dopant is still not fully understood in terms of its role in enhancing active sites ${ }^{[144]}$, and more work needs to be done to fully elucidate the effect of co-doping on the mechanisms of metal free electrocatalysts. In general, the further complication of model systems when 2 or more co-dopants are introduced to the graphene structure means that true mechanistic understanding of these materials is still an active area of research, and there is much debate in the modern literature. The effect of codoping can also lead to synthetic constraints on the materials; for instance, specific spacing between heteroatoms might be desired for good performance ${ }^{[145]}$, or confined ratios of atoms in the material, which represents significant experimental challenges for improving the catalytic 


\section{WILEY-VCH}

activity for different co-doping systems. Detail of specific insights for each reaction is given in the corresponding section of this review. Ternary plots are provided in Figure 4 showing how each type of $\mathrm{N}$, particularly, the pyridinic-, pyrrolic-, and the graphitic- $\mathrm{N}$ affect the performance of metal-free carbon catalysts in ORR (Figure 4). The data are presented in the supporting information (Table S1). The Pyridinic N and the Graphitic N are the most active Nsites, with a contribution of $\sim 30 \%$ and $\sim 50 \%$, respectively, for the ORR performance in alkaline and acid.

Finally, an emerging field in metal free electrocatalysts is the effect of defects in the carbon structure on the activity toward electrochemical reactions, with some recent studies suggesting that this could allow purely carbon catalysts to achieve acceptable performance. Interruption of the $\pi$ conjugated $\mathrm{sp}^{2}$ network of carbon atoms can introduce localised charge and spin polarisation in the same way that heteroatom doping can on neighbouring carbon atoms. ${ }^{[27,146]}$ The nature of edge defects is also important, with Deng et al. finding that armchair type edges in graphene nanoribbons were inactive towards the ORR, whereas zig-zag edges showed activity with low energy barriers for the mechanistic steps of the ORR. ${ }^{[147]}$ Wang et al. ${ }^{[148]}$ recently discovered that intrinsic carbon defects could lead to high activity for $\mathrm{CO}_{2}$ reduction, concluding that $\mathrm{sp}^{2}$ defects (pentagonal and octagonal) were more important than edge defects, and that perhaps the importance of heteroatom doping in metal free catalysis needs to be rethought. Very recent work from Jia et al. ${ }^{[34]}$ selectively created edge pentagonal defects in highly ordered pyrolytic graphite (HOPG) by removing pyridinic $\mathrm{N}$ atoms and showed excellent activity towards the ORR, again suggesting that the importance of heteroatom doping might be over stated in the previous understanding of the community. Tang et al. ${ }^{[149]}$ discuss the effect of defects in $\mathrm{N}$ doped carbons, synthesising $\mathrm{N}$ rich structures via deflagration, and then partially removing some of the $\mathrm{N}$ to leave a highly defective carbon structure, but with some remaining heteroatom doping, and resulting in a electrocatalyst that is only slightly less active towards the ORR than Pt/C in alkaline. Recent advances in understanding of the role of intrinsic defects in the graphene layers of metal free electrocatalysis show promise for these materials and will likely bring a rapid rise in work in the area (Figure 5).

Carbons with defects and dopants, so called heteroatom doped defective carbons were created through N, S, B, and P doping. ${ }^{[150,151]}$ Some heteroatoms were removed from dopant sites with heating under nitrogen atmosphere to create point defects (hole, zig-zag edge, armchair or pentagon rings, Stone-Wale defect, single vacancy, double vacancy) or line defects (grain boundary). ${ }^{[152]}$ Such defects and dopant sites were used for the catalysis of both oxygen and 


\section{WILEY-VCH}

hydrogen electrocatalysis, therefore, clear identification of the active sites is important. ${ }^{[152]}$ Carbons at the edges are found to be more active for ORR, compared to those near basal planes. ${ }^{[153]}$ Particularly armchair edges next to graphitic $\mathrm{N}$ are active for the catalysis of both oxygen and hydrogen, ${ }^{[154]}$ indicating that the point defects are playing major roles in these reactions. How exactly were these active sites identified from the structures is still under debate. Ambiguity over the roles of defects and dopant sites in oxygen and hydrogen electrocatalysis necessitates the use of standard techniques (X-ray absorption near edge structure, extended Xray absorption fine structure, and high-angle annular dark-field scanning transmission electron microscopy $)^{[34,155]}$ for the precise identification of active sites.

\section{Best Practice for Oxygen and Hydrogen Electrocatalysis}

Consistent and accurate measurements of metrics (onset potential, overpotential, halfwave potential, limiting current density and exchange current density) through good electrochemical practice is vital when vastly different catalysts are being compared and new materials are emerging at such a fast rate. Many guides to best practice in using rotating disc electrode (RDE) or rotating ring disc electrode (RRDE) to evaluate catalysts exist, ${ }^{[156-161]}$ though their advice is not always followed in the literature as evidenced by recent articles on common pitfalls in electrochemical catalyst evaluation. ${ }^{[162,163]}$ Considering the impact of catalyst loading on the amount of peroxide intermediate seen in RRDE experiments, it is recommended that evaluation of all new catalysts should be made with loading ranges from $40-800 \mu \mathrm{g} \mathrm{cm}^{-2}$ before any conclusions about the 4-electron pathway are made. ${ }^{[164]}$ It is important to use a very thin film of catalyst to avoid masking the peroxide production that could be quenched in the catalyst layer, ${ }^{[160]}$ and a catalyst layer $<25 \mu \mathrm{m}$ is therefore recommended for accurate electrochemical evaluation. With the increasing interest in metal free catalysts and therefore focus on testing in alkaline environments, the need to standardise procedures in alkaline is clear ${ }^{[165]}$ and considerations such as catalyst layer thickness and even binder,${ }^{[166]}$ reference electrode ${ }^{[162]}$ and counter electrode should be carefully selected. The platinum counter electrode is prone to dissolution in acid, and therefore, it should be replaced with the graphite electrode to avoid any trace level contamination from the Pt. As sulphate anions are known to adsorb on Pt surfaces, perchloric acid is recommended for the ORR performance tests in acid, and it is also suggested for the porous carbons. Metal free catalysts can sometimes contain trace amounts of metal, ${ }^{[167]}$ perhaps from the synthesis steps that can be the sole cause of electrochemical activity, and so care should be taken to ensure there are no trace metals if claiming ORR catalysis in metal free materials. ${ }^{[168]}$ The electrolyte $(\mathrm{KOH})$ can contain some metals $(\mathrm{Fe})$ in ppm levels as well, 


\section{WILEY-VCH}

perhaps leached from the catalysts used in its preparation steps, therefore, electrolytes should be screened for trace metals with inductively coupled mass spectroscopy (ICPMS) and purified where possible. ${ }^{[167,169]}$ It is important that the intrinsic ORR current alone (obtained in $\mathrm{O}_{2}$ saturated electrolyte) must be considered for the performance evaluation and therefore, it should be subtracted from the background current (obtained in $\mathrm{N}_{2}$ saturated electrolyte) to eliminate the capacitive current contributions. The Tafel slopes and the exchange current density for both oxygen and hydrogen electrocatalysis should be determined after correcting the mass-transfer effects. It is preferred to determine the electron transfer numbers from the RRDE measurements, compared to the RDE measurements, as it reduces the errors in calculations. The use of lugging capillary for all the polarization tests is suggested to minimize the ohmic drop (IR drop), and the IR compensation is recommended for the correction of current data obtained from the $\mathrm{R}(\mathrm{R}) \mathrm{DE}$ measurements. The stability of the catalyst should be tested either in the form of their retention of activity after many cycles (upwards of 10,000) or prolonged voltage holds (>10000s). Although tolerance to $\mathrm{MeOH}$ is often a metric that is used to assess the quality of metal free catalysts, it has become abundantly clear that hetero-atom doped catalysts are not active for $\mathrm{MeOH}$ oxidation, and so do not suffer voltage loss due to $\mathrm{MeOH}$ crossover, exemplified by the majority of recent examples in the literature. ${ }^{[75,156,165,170-184]}$ It is apparent that this is now a largely meaningless metric for metal free catalysts, and all non PG M materials should be assumed to have good tolerance to $\mathrm{MeOH}$ crossover. Likewise, many metal free catalysts show inherent cycling stability compared to $\mathrm{Pt} / \mathrm{C}$ or metal containing doped carbons, which, while being of great value, should no-longer be considered 'remarkable' in today's literature, as it has been demonstrated many times over. The most essential metrics (active site density, electrochemical surface area and roughness factor) to evaluate the electrocatalytic performance of porous carbons should be estimated with great care. For example, the double layer capacitance of a porous carbon-based catalyst should be normalized with reference to a standard flat carbon surface, and doing so will not overestimate or underestimate the electrochemical specific surface area. Unlike that for ORR, stability of the catalyst for OER is affected by carbon oxidation reactions. Particularly carbon oxidation (corrosion) reactions change the surface oxygen content at high-voltage holds, therefore, the OER activity should not be over rated, and current contributions of carbon oxidation reactions should be determined electrochemically and corrected from the curves of OER polarization. ${ }^{[166]}$ XPS can be used to evaluate the surface oxygen content attributable to the reactions of carbon oxidation. Hydroquinone/quinone system is an indicator of carbon corrosion, and with negligible increase of current for hydroquinone/quinone peaks at $0.6 \mathrm{~V}$ vs. RHE with high-voltage holds means 


\section{WILEY-VCH}

that the catalyst is resistant to carbon corrosion. ${ }^{[153]}$ This test could be conducted to monitor the carbon corrosion on a porous carbon electrode surface.

\section{3D carbons for the oxygen reduction reaction (ORR)}

The ORR is a major focus of electrocatalysis, being vital to the efficient operation of fuel cells $^{[162]}$ and metal-air batteries. ${ }^{[163]}$ The ORR requires the breaking of a strong O-O bond and four coupled proton and electron transfers, meaning that the reaction mechanism is complex and can proceed via undesirable side reactions, leading to high activation overpotentials and, ultimately, low performance in working devices. For this reason, the state-of-the-art ORR catalysts have historically been based on Pt or Pt group metals (PGMs) as they provide a high enough activity for reasonable reaction rates, especially in acidic media. As these materials tend to be costly, much research effort has been placed on reducing the amount of PGMs in ORR catalysts, through strategies such as nano-sizing, alloying or core-shell morphologies, in order to make technologies such as fuel cells economically viable. ${ }^{[185]}$ Despite great progress in this area, ${ }^{[186]}$ a reduction in $\mathrm{Pt}$ to the 'bare minimum' risks poor performance at high current densities and susceptibility to more rapid device performance loss due to corrosion of the catalyst, something that PGM catalysts are prone to under long-duration operation (particularly in acidic media). ${ }^{[187]}$ Therefore, for cost and stability reasons, new catalysts for the ORR are highly sought after. Attention in recent years has focused on transition metal active centers in carbon matrices, especially where the carbon is doped with heteroatoms such as nitrogen, ${ }^{[188]}$ though the presence of metal in these materials leads to significant durability challenges, again, particularly in acidic media, ${ }^{[189]}$ and so a new class of entirely metal free ORR catalysts has emerged in recent years as cost effective, durable and electrochemically selective alternatives to traditional materials. ${ }^{[90,190]}$

In 2009, Dai's group demonstrated for the first time a superior activity of metal free ORR catalysis in alkaline media compared to $\mathrm{Pt} / \mathrm{C}$, using vertically aligned nitrogen doped $\mathrm{CNT}$ arrays and highlighting the role of nitrogen in greatly enhancing the activity over pure CNTs. ${ }^{[29]}$ Since then, much progress has been made in the use of heteroatom doping to enhance the activity of 1D (CNTs) and 2D (graphene) carbons towards the ORR, summarised in the recent review by Shao et al. ${ }^{[191]}$ As well as tuning the electronic structure of the carbon matrix via heteroatom doping, modifying the structure of the nanomaterials is important to enhance surface area, mass transport of reactants and electrical conductivity. Additionally, 1 or 2D catalysts can be difficult to process into working electrodes and may suffer from a lack of mechanical robustness or re-staking of nanomaterials. Therefore, 3D carbon structures 


\section{WILEY-VCH}

including varying porosity have recently been seen as routes to scalable, high performance electrodes for the ORR, including the possibility of free-standing electrodes. ${ }^{[190]}$ Such is the interest in the field of heteroatom-doped carbons for metal free ORR catalysts, the number of publications is rapidly increasing year on year. Several recent reviews give good overviews of the progress in the area, ${ }^{[90,190]}$ and as the publication rate is high, this section will focus mainly on work since those reviews were published, as well as on 3D doped carbons in preference to 1 or $2 \mathrm{D}$.

6.1. Mechanism. The mechanism of the ORR is complex and involves the possibility of multiple adsorption and desorption steps as well as four coupled proton and electron transfers, and for this reason is relatively poorly understood as well as being the limiting factor in the performance of most energy conversion or storage devices that employ the ORR as the reaction on the catalyst. Ramaswamy and Mukerjee ${ }^{[192]}$ showed evidence for an outer-sphere electron transfer in alkaline media, meaning that there is a surface-independent aspect to the mechanism that opens up the possibility of a wide range of catalysts for the ORR at high $\mathrm{pH}$. In this way, there is a kinetic advantage to operating in alkaline media on non-Pt surfaces, as well as the thermodynamic one previously shown by Bilzanac et al. ${ }^{[193]}$ However, they also showed that the outer-sphere process leads predominantly to peroxide as the final product via a 2 -electron pathway. In order to promote the 4-electron pathway, the authors emphasised the importance of facilitating the direct adsorption of molecular $\mathrm{O}_{2}$ on a hydroxyl-free active site, particularly for non-noble metal surfaces that are less capable of further reducing adsorbed peroxide species in a serial 4-electron pathway. ${ }^{[160]}$ Recent advances in electrochemical techniques and the use of the Nabae model have been able to distinguish the direct 4-electron pathway from the serial 4-electron pathway, and $\mathrm{Wu}$ et $\mathrm{a}^{[194]}$ used this to show that Fe-containing $\mathrm{N}$-doped carbons proceed via the direct pathway, as opposed to the serial pathway in the metal free version of the catalyst.

The early work in metal free catalysis of the ORR from Dai's group ${ }^{[29]}$ attributed the increased activity of the $\mathrm{N}$-doping of CNTs to the change in adsorption of $\mathrm{O}_{2}$ from end-on to side-on, or parallel diatomic adsorption, and the subsequent weakening of the O-O bond. ${ }^{[195,196]}$ A recent review from Singh et al. ${ }^{[197]}$ on the active sites and mechanism of the ORR on N-doped carbons sheds light on the desired structures for good activity. $\mathrm{N}$ can exist in the graphitic (three bonds to $\mathrm{C}$ ), pyridinic ( 2 bonds to $\mathrm{C}$ in a six-membered ring) or pyrrolic ( 2 bonds to $\mathrm{C}$ in a fivemembered ring) sites within a carbon matrix, and there was some debate in the literature until recently as to the active site, in part due to the difficulty in producing catalysts that do not have 


\section{WILEY-VCH}

a mix of $\mathrm{N}$ environments and also inhomogeneities in the morphology and degree of graphitisation in the carbon matrix. Though some studies suggested that graphitic $\mathrm{N}$ creates the active site,${ }^{[198,199]}$ the majority showed that catalysts with high amounts of pyridinic $\mathrm{N}$ showed greater activity for the ORR. ${ }^{[200-204]}$ Experiments using model catalyst systems created pyridinic and graphitic N-doped HOPG and showed that the former has higher electrochemical activity for the ORR, and concludes that pyridinic $\mathrm{N}$ creates Lewis basicity on neighbouring $\mathrm{C}$ atoms, which are the active sites. ${ }^{[28]}$ However, we noted from the literature of porous carbons that the major contributions to ORR activity comes from that of graphitic $\mathrm{N}$ than pyridinic-N. Perhaps, major works that we have considered for the construction of ternary plots were of porous carbons with high surface areas (600-2500 $\left.\mathrm{m}^{2} \mathrm{~g}^{-1}\right)$ and high graphitic $\mathrm{N}$ content $(\sim 1.7-\sim 5 \%)$, and change in the ratio of graphitic $\mathrm{N}$ to total $\mathrm{N}$ could be reasons for this trend (Table 1, SI).

The importance of the neighbouring ortho-carbon in pyridinic N-doping to the ORR was also demonstrated by Xing et al. ${ }^{[205]}$ and Wang et al. ${ }^{[206]}$ The negatively charged pyridinic $\mathrm{N}$ creates positive charge in the neighbouring $\mathrm{C}$ which can change the localised density of states and lead to higher activity than that of graphitic $\mathrm{N},{ }^{[207]}$ and so much recent focus in $\mathrm{N}$-doped carbon catalysts is in increasing the levels of pyridinic $\mathrm{N}$ in the graphene sheet, relative to other $\mathrm{N}$ environments, which is not without its challenges and means many routes are bottom-up and not necessarily scalable. ${ }^{[197]}{ }^{[208]}$ Recently, work from Jia et al. ${ }^{[34]}$ selectively removed the pyridinic $\mathrm{N}$ from the edge sites leaving a pentagon defect at the edge of the carbon matrix that was even more active for the ORR than the pyridinic $\mathrm{N}$ in HOPG via micro-electrolytic measurements, opening up the potential for non-doped carbons to show comparable activity via carbon defects.

Density functional theory (DFT) calculations on N-doped graphene also reveal that the 4electron pathway is possible in acid and is attributed to the introduction of $\mathrm{N}$ producing high spin density on the active site of the graphene,${ }^{[209]}$ and can also be used to rapidly screen many dopants for their activity towards ORR. ${ }^{[210]}$ In general, the reaction mechanism of the ORR in acid involving all the adsorbed intermediates is found in the work of Zhang and Xia. ${ }^{[209]}$

\subsection{Single element doped 3D carbons. Many studies on 3D carbon architectures with single} heteroatom doping have emerged in the literature recently, with N-being the overwhelming favourite dopant, with morphologies that can be broadly divided into macro-structures (mesoporous, granular), ${ }^{[156,165,173,194,211-216]}$ aerogels, ${ }^{[170,217,218]}$ nanospheres, ${ }^{[75,149,182,219-221]}$ $3 \mathrm{D}$ structures of $2 \mathrm{D}$ graphene ${ }^{[170,221]}$ or $1 \mathrm{D}$ nanotubes, fibers, ${ }^{[222,223]}$ and more complicated 


\section{WILEY-VCH}

architectures such as honeycomb ${ }^{[184]}$ or brain-like ${ }^{[224]}$ morphologies. A summary of much of the recent literature in metal free ORR catalysis is given in Figure 6 (see Table 1).

Tian et al. ${ }^{[217]}$ developed $\mathrm{N}$-doped aerogels for microbial fuel cell application and found that $\mathrm{KOH}$ activation significantly improved the ORR activity, attributed to the increase of BET surface area, higher pyridinic $\mathrm{N}$ and lower oxygen functional groups (with increasing concentration of $\mathrm{KOH}$ solutions) (Figure 7f). Zhao et al. ${ }^{[170]}$ used GO with a supramolecular self-assembled aggregate that acted as a spacer to prevent restacking, as well as acting as a pore former and source of $\mathrm{N}$, leading to a high surface area and porosity and comparable half-wave potential to $\mathrm{Pt} / \mathrm{C}$ (Figure 7e). Xie et al. ${ }^{[218]}$ recently used a crosslinking of GO to produce very high surface area $\left(1631 \mathrm{~m}^{2} \mathrm{~g}^{-1}\right) \mathrm{N}$-doped graphene aerogels which they claim reduces the diffusion time of $\mathrm{O}_{2}$ in the pores, leading to high ORR activity as claimed by the high limiting current density of over $7.5 \mathrm{~mA} \mathrm{~cm}^{-2}$. However, this is higher than the theoretical limiting current density of $\mathrm{O}_{2}$ saturated $\mathrm{KOH}$ at $1600 \mathrm{rpm}$, as mentioned earlier in this section, and as the onset potential is also significantly lower than $\mathrm{Pt} / \mathrm{C}$, it is possible that the high current is attributable to side reactions or contaminants, and caution should be taken before this material is hailed as the highest activity metal free catalyst for ORR.

Wang et al. ${ }^{[173]}$ produced mesoporous carbons and compared their activation with $\mathrm{KOH}$ and $\mathrm{ZnCl}_{2}$, with the later showing the best activity towards ORR, attributed to creation of a more open pore structure and higher retention of $\mathrm{N}$ doping. However, it was not clear if there are trace metals remaining from the activation that could contribute to the activity. $\mathrm{Mu}$ et al. ${ }^{[215]}$ also used $\mathrm{ZnCl}_{2}$ to activate their carbons with no demonstration of the $\mathrm{Zn}$ XPS signal to confirm the lack of trace metals in the final catalyst, and also inferior electrochemistry to $\mathrm{Pt} / \mathrm{C}$ in alkaline solution. Honeycomb-like structures of hierarchical porosity were synthesised by Tang et al. ${ }^{[184]}$ from dandelion seed and $\mathrm{ZnCl}_{2}$ as an activation agent, again with no XPS to show the lack of $\mathrm{Zn}$ (Figure 7b). They achieved somewhat comparable activity to that of Pt, albeit with a slightly low onset potential shown for Pt in their electrochemical results. However, the performance in a methanol fuel cell was superior to that of $\mathrm{Pt}$, attributable to its lack of poisoning from $\mathrm{MeOH}$ crossover. Li et al. ${ }^{[216]}$ synthesised fluffy mesoporous carbon using a zinc carbonate porogen to deliver hierarchical porosity and propose this method as a general route to good N-doped catalysts from biomass, with similar onset and better half-wave potential (though lower limiting current density) than Pt/C. They demonstrated this process for a vast array of biomass sources from bamboo to soybean and obtained similar onset and half-wave potentials for all materials, though, again, the absence of $\mathrm{Zn}$ in the final material is not proven unequivocally. Similarly, 


\section{WILEY-VCH}

Baohua Zhang et al. ${ }^{[214]}$ used a ferric nitrate pore former to increase the surface area of their mesoporous N-doped carbon with no discussion of trace metals (Figure 7c). Yan Zhang et al. ${ }^{[211]}$ generated their catalyst from Al containing MOFs, but showed that all the Al was removed during pyrolysis by ICP-MS, though the performance in alkaline electrolyte was significantly poorer than $\mathrm{Pt} / \mathrm{C}$. Chen et al. ${ }^{[212]}$ synthesised a hierarchically porous N-doped carbon from biomass and with a melamine treatment to introduce $\mathrm{N}$-doping after carbonisation. They again showed the positive effect of $\mathrm{KOH}$ treatment in the generation of porosity in the catalysts, though they found the optimal concentration of $\mathrm{KOH}$ to be $0.1 \mathrm{M}$, which is lower than other examples in the literature and could lead to cost and environmental benefits in the synthesis of such catalysts. They achieved equal performance to that of $\mathrm{Pt} / \mathrm{C}$ in alkaline media, with a slightly higher half-wave potential, attributed to the interconnectivity of the pores created on $\mathrm{KOH}$ treatment opening up more active sites, as well as the $\mathrm{N}$-doping. This further demonstrates the capability of designing 3D structures to enhance active site availability, and therefore performance in the ORR. Their biomass precursor also contained traces of Si, which remained after pyrolysis, suggesting that this could also be key to the good performance. MOFderived hollow spheres were demonstrated by Chai et al. ${ }^{[75]}$ by using Zn-containing MOFs to create core-shell particles which self-sacrifice to give N-doped hollow spheres. They found a fairly low level of N-doping by XPS (1.92 wt\%), however the ratio of pyridinic and graphitic $\mathrm{N}$ to total $\mathrm{N}$ was the highest for the hollow spheres. They showed comparable performance to Pt in alkaline, with slightly lower onset potential but similar half-wave potential, and claimed the best performance towards the ORR for any MOF-derived N-doped carbons. This good performance is attributed to the high surface area, hierarchical porosity (with a high volume of meso and micropores), and high ratio of pyridinic and graphitic $\mathrm{N}$, again demonstrating the need for both electrocatalytic and mass transport properties to be enhanced.

Liu et al. ${ }^{[222]}$ synthesised N-doped hollow carbon fibers from biomass that showed high pyridinic and graphitic $\mathrm{N}$ content and better activity than those without $\mathrm{N}$-doping, though the electrochemical behaviour was worse than that of Pt/C. Shi et al. ${ }^{[223]}$ also used carbon fibers, but as a support for $\mathrm{N}$-doped nanospheres, and showed outstanding performance with a similar onset and better half-wave potential than that of Pt/C (Figure 7a). Hassan et al. ${ }^{[221]}$ used functional polystyrene microspheres as a sacrificial core to create hollow spheres on carbonisation with higher activity and electron transfer number than those including the core, attributed to greater porosity and surface area. Tang et al. ${ }^{[149]}$ also produced hollow nanospheres 


\section{WILEY-VCH}

with high $\mathrm{N}$-doping and porosity, as well as large numbers of carbon defects in the structure. This led to only slightly poorer performance than $\mathrm{Pt} / \mathrm{C}$ in alkaline media.

Chakraborty et al. ${ }^{[213]}$ used a probe molecule to estimate the number of surface sites on N-doped carbon black, which tracked with the activity of the catalyst, whereas the wetted surface area from the double layer capacity did not follow a trend. This shows promise as a method to accurately characterise the active sites of similar materials.

The kinetic isotope effect was used to study the different mechanisms of ORR on N-doped nanospheres by Eckardt et al. ${ }^{[219]}$, who demonstrated a better half wave potential (but worse onset potential) than $\mathrm{Pt} / \mathrm{C}$ in alkaline for their highest carbonisation temperature sample. They showed that in acid, the first proton transfer is the rate determining step, while in alkaline the first electron transfer is most significant. The selectivity for the 4-electron pathway in acid is poor. Conversely to some of the literature discussed in the mechanism section, they found no link between the amount of nitrides on the surface, even the content of pyridinic $\mathrm{N}$, and linked the improvements in the catalyst to increase surface area, microporosity and active pore edges with temperature, which could act as Lewis base sites.

Lei et al. ${ }^{[224]}$ synthesised brain-like architectures and obtained excellent activity for the ORR in alkaline, with an onset potential of $0.969 \mathrm{~V}$, slightly higher than that of Pt. They attributed the electrochemical performance to the improved mass transfer in the 3D structure and highlighted the need to produce metal free catalysts without using metal-containing precursors. It is often claimed that an acid etching/leaching step is sufficient to remove the metal from the precursors, as in the work of Li et al. ${ }^{[156]}$ who used a single-source precursor of ferric citrate to synthesise $\mathrm{N}$-doped porous carbons, treated with $\mathrm{HCl}$ to remove nanocrystals of $\mathrm{Fe}_{2} \mathrm{~N}$, which they show by X-ray diffraction (XRD) spectroscopy. While it is true that the particles of $\mathrm{Fe}_{2} \mathrm{~N}$ are removed, $\mathrm{XRD}$ is not sufficient evidence to show that there is not still Fe active sites in the catalyst carbon matrix, though XPS results do not show any evidence for surface Fe. Also, via X-ray photoelectron spectroscopy (XPS), they showed that increasing the pyrolysis temperature decreased the amount of pyridinic and pyrrolic-N, but increased the number and size of macropores, attributed to the larger sizes of $\mathrm{Fe}_{2} \mathrm{~N}$ aggregates formed at a higher temperature. This demonstrated a mixed positive and negative effect on the catalyst performance in ORR with increasing synthesis temperature, with the best performance shown for the sample prepared at $600{ }^{\circ} \mathrm{C}$, slightly better than that at $700{ }^{\circ} \mathrm{C}$, and both performing significantly better than that at $500{ }^{\circ} \mathrm{C}$. This shows that there could be a trade-off between producing a 


\section{WILEY-VCH}

hierarchically porous sample and maintaining pyridinic N-content. All samples, however, showed a worse onset and half-wave potential compared to $\mathrm{Pt} / \mathrm{C}$ in alkaline.

Wu et al. ${ }^{[165]}$ used a hard templating method to produce a large amount of macro, meso and micropores in a P-only doped $\mathrm{C}$ (one of the few non-N containing catalysts in recent literature). Though the catalyst performed worse than $\mathrm{Pt} / \mathrm{C}$ in alkaline, with an onset potential of $0.88 \mathrm{~V}$ ), the benefit of the hierarchical porosity over ordinarily structured P-doped carbon was clearly shown. Han et al. ${ }^{[182]}$ produced a high surface area $\mathrm{N}$-doped carbon with multiple directional porosity with similar onset and half wave potentials in alkaline media, and only slightly lower than $\mathrm{Pt} / \mathrm{C}$ in sulphuric acid electrolyte; although sulphate anions are known to adsorb on $\mathrm{Pt}$ surfaces, which is why perchloric acid tends to be used for acidic electrochemical analysis ${ }^{[225]}$. This could perhaps be artificially masking the $\mathrm{Pt} / \mathrm{C}$ performance in these tests.

As well as modifications to the carbon morphology and chemical structure, Qiao et al. ${ }^{[220]}$ showed recently that modification of the layer next to the carbon surface with ionic liquids can greatly enhance the catalyst performance, for both Fe containing and metal free carbons, and in acid and alkaline (Figure 7d). They hypothesise that the ionic liquid layer enhances affinity for $\mathrm{O}_{2}$ adsorption, increasing the diffusion to the active site, and at the same time the hydrophobic nature of the layer helps to expel the product water. The Fe containing catalyst showed better performance than $\mathrm{Pt} / \mathrm{C}$ in alkaline media, with a higher onset and half-wave potential, and though the metal free catalyst is not directly compared with Pt in alkaline, the ionic layer modification shows improvement in activity compared to the $\mathrm{N}$-doped carbon without it, but overall lower performance than that of $\mathrm{Pt} / \mathrm{C}$. They showed that a too-thin layer of ionic liquid did not promote $\mathrm{O}_{2}$ diffusion to the active sites, and that increasing the thickness of the layer had detrimental effects on the activity, attributed to lower electronic conductivity and oxygen diffusion through the layer. They also suggested that thicker layers of ionic liquid become equilibrated with water and hinder the electron transfer, as well as preventing full expulsion of product water and therefore blockage of reactant sites. The hypothesis was developed for the Fe-containing version of their catalyst, but also applied to the metal free $\mathrm{N}$-doped carbons, as they saw a $54 \mathrm{mV}$ (acid) and $14 \mathrm{mV}$ (alkaline) improvement in the half-wave potential on application of the ionic layer. Such modifications of the nature of the solvent environment close to the surface active sites show great promise as routes of fundamental enhancement of the ORR mechanism, and further mechanistic understanding through theory and the use of model catalysts with specific $\mathrm{N}$ environments or carbon defects would greatly enhance the understanding of this phenomenon. 


\section{WILEY-VCH}

Although most recent examples of single-heteroatom doped carbon catalysts have demonstrated their performance in alkaline, there are some examples of use in acidic media ${ }^{[182,219,220]}$ and neutral electrolytes, ${ }^{[217]}$ though they do not compare performance in acid with $\mathrm{Pt} / \mathrm{C}$ (with the exception of Han et al. ${ }^{[182]}$ in the less preferable sulphuric acid medium), and Qiao et al. obtained their best performance vs $\mathrm{Pt} / \mathrm{C}$ in alkaline for their Fe containing catalyst, rather than the metal free. This means we are still a little way off replacing Pt in PEM fuel cells. Nevertheless, there are several examples in the recent literature of better or equal performance to $\mathrm{Pt} / \mathrm{C}$ in alkaline electrolytes ${ }^{[75,170,182,212,216,223,224]}$, which bodes well for metal-air batteries and alkaline fuel cells, especially with recent developments in alkaline polymer membranes. ${ }^{[226 \text {, }}$ 227]

Despite great number of efforts being dedicated to creating simple and complicated 3D structures with the use of activating agents and porogens, structures with hierarchical pores and high surface areas (600-1460 $\left.\mathrm{m}^{2} \mathrm{~g}^{-1}\right)$ have clearly emerged as favourites for ORR. The plot of activity to surface area gives a clear relationship that indicates that more porous structures have been prepared, exhibiting low onset and high halfwave potential in alkaline than in acid, meaning that the mass transfer is improved via hierarchical pores (Figure 6a, b). Doping of $\mathrm{P}$ alone to the carbon atoms in $3 \mathrm{D}$ structures resulted in performance worse than $\mathrm{Pt} / \mathrm{C}$. $\mathrm{N}$ has clearly emerged as one of the most efficient dopant sites, that was introduced to the carbon atoms for improving the ORR activity in alkaline than in acid. Pyridinic- $\mathrm{N}$ and graphitic-N sites were active than pyrrolic-N and quaternary- $\mathrm{N}$, suggesting that both producing a hierarchically porous sample and maintaining the content of pyridinic-N $(\sim 30 \%)$ and graphitic $\mathrm{N}(\sim 50 \%)$ is important for achieving the best performance in ORR. The structures with low or very high surface area $\left(600 \mathrm{~g}^{-1}<\right.$ and $\left.1500 \mathrm{~g}^{-1}>\right)$ have showed poor activity (Figure 6c), meaning that the stable active sites and defects have to be introduced to their surfaces for improving the electrocatalytic activity and the stability. The fact that pyridinic $\mathrm{N}$ site protonates in acid to form pyrrolic-N sites could be one reason for the poor activity and stability, meaning that $\mathrm{N}$ composition before and after ORR has to be determined with advanced analytical tools and compared. ${ }^{[228,229]}$ The other reason for low electrocatalytic performance in acid could be due to the adsorption of sulphate anions on the active sites.

6.3. Co-doping for the ORR. In addition to single-heteroatom doping, co-doping of two elements has previously been shown to have an advantageous synergistic effect on performance towards the ORR, though with the exact mechanism remaining elusive. ${ }^{[30,230-233]}$ Indeed, given the number of possible sites in single heteroatom-doped carbons already discussed, the addition 


\section{WILEY-VCH}

of a second heteroatom complicates the picture somewhat. There are many recent examples in the literature of co-doping with $\mathrm{N}$ of various different heteroatoms, including; sulphur ${ }^{[174,176 \text {, }}$ ${ }^{234-237]}$, phosphorous ${ }^{[172,238-241]}$ boron $^{[178,242-244]}$, fluorine ${ }^{[177,245]}$ and iodine. ${ }^{[246]}$

The effect of S doping in N-doped carbons was previously thought to be synergistic, but JinCheng $\mathrm{Li}$ et al. ${ }^{[236]}$ recently showed that the effect is actually down to the contribution of a large pyridinic $\mathrm{N}$ content when $\mathrm{S}$ doping precedes $\mathrm{N}$ doping, obtaining identical performance to $\mathrm{Pt} / \mathrm{C}$ in alkaline. When $\mathrm{N}$ doping was the first step in the synthesis, they found that subsequent $\mathrm{S}$ doping actually induces a performance loss for the ORR due to $\mathrm{S}$ substituting the pyridinic $\mathrm{N}$ preferentially, throwing doubt on the synergistic mechanisms thought to apply to these materials. Nevertheless, several recent examples have shown a positive effect of co-doping in the literature. Daohao Liu et al. ${ }^{[246]}$ showed excellent activity for the ORR in both alkaline and acid (sulphuric and perchloric), and claimed that the key to this activity in acid is the pentagonal edge $\mathrm{S}$ defects, and presents a framework for designer catalysts to greatly improve the activity for acidic PEM fuel cells (Figure 8d). Moreover, the synthetic route used seaweed biomass and followed a low cost and sustainable process. Tong et al. ${ }^{[174]}$ synthesised N/S-doped carbon from Fe-containing methyl orange, with a subsequent acid leaching step which improved the performance, compared to the Fe containing catalysts. They obtained a comparable onset potential but worse half-wave and limiting current than $\mathrm{Pt} / \mathrm{C}$ in $\mathrm{KOH}$, and also tested their catalysts in acid (both sulphuric and perchloric), but with worse performance than $\mathrm{Pt} / \mathrm{C}$, and suspiciously large negative currents at low overpotentials that suggests some sort of contamination in the electrochemical system. Yong-Feng Li et al. ${ }^{[176]}$ used a self-templating route to prepare N/S doped carbons with a honeycomb structure from crab shells, without the use of activating agents, with comparable performance to $\mathrm{Pt} / \mathrm{C}$ in alkaline - though the onset potential appears higher than $\mathrm{Pt} / \mathrm{C}$, the slope of the kinetically controlled region is lower, suggesting some variation in reference electrode potential could have occurred (Figure 8a). Again, high surface areas and hierarchical pore structures are highlights as a reason for improved performance of these catalysts. Cazetta et al. ${ }^{[235]}$ synthesised N/S doped carbon from bone char and egg white, with a silicate precursor route producing the best performing catalyst, but all catalysts showing a distinct two-phase behaviour in the electrochemistry, and not reaching a limiting current. Wang et al. ${ }^{[247]}$ synthesised protein hydrogel networks with tuneable porosity that showed identical performance to $\mathrm{Pt} / \mathrm{C}$ in alkaline, and only slight overpotentials compared to $\mathrm{Pt} / \mathrm{C}$ in perchloric acid (Figure 8c). This demonstrates the potential of $\mathrm{N}$ and $\mathrm{S}$ co- 


\section{WILEY-VCH}

doping to improve the activity in acidic electrolytes, provided the right active sites can be targeted, as well as a preferential hierarchical porosity in the 3D structure.

As well as S, P is a popular co-dopant with N. Computational studies by Gracia-Espino in 2016 ${ }^{[145]}$ investigated the mechanism for ORR on $\mathrm{N}$ and $\mathrm{P}$ doped graphene surfaces under alkaline conditions and concluded that though single atoms of either $\mathrm{N}$ or $\mathrm{P}$ could activate the $\mathrm{C}$ surface, co-doping of both had a significantly stronger synergistic effect. The spacing between the $\mathrm{N}$ and $\mathrm{P}$ is critical, with a spacing of at least $4 \AA$ required to avoid localisation of charge around the carbon atom, suggesting that synthetic routes to N/P doped carbons should aim to have a homogeneous distribution of elements in order to improve the electrocatalytic performance. Alonso-Lemus et al. ${ }^{[238]}$ synthesised N/P doped carbons from chicken manure and activation with $\mathrm{KOH}$ and $\mathrm{H}_{3} \mathrm{PO}_{4}$, with the best performing catalyst in alkaline being that of $\mathrm{KOH}$ treatment ( $0.86 \mathrm{~V}$ onset potential), though $\mathrm{H}_{3} \mathrm{PO}_{4}$ was similar $(0.85 \mathrm{~V})$. Significant amounts of Si were also present in these catalysts due to the precursor used. Sun et al. ${ }^{[239]}$ prepared a N/P doped aerogel with $\mathrm{CsCl}$ (not trace metal shown with ICP-MS) with an inferior onset and half-wave potential to $\mathrm{Pt} / \mathrm{C}$ in alkaline electrolyte. $\mathrm{P} / \mathrm{N}$ co-doping seems to be promising for ORR/OER bifunctional catalysts, ${ }^{[240,241]}$ which are covered elsewhere in this review. Simulation results suggest that the P-N bond is the real active site for OER, while the $\mathrm{N}$ atom next to the edge carbon seems to be responsible for ORR. The P site alone is not active for ORR because it is difficult to remove $\mathrm{OH}$ or $\mathrm{O}$ group from $\mathrm{P}$ than $\mathrm{N}$.

Another popular co-dopant is B. Recent calculations on the ORR mechanism of B and N doped CNTs and nano-ribbons by Zou et al. ${ }^{[144]}$ suggested that N-only doping of CNTs is superior to N/B co-doping. DTF calculations by Kattel et al. ${ }^{[248]}$ on N/B doped graphite show that graphitic $\mathrm{BN}_{3}$ sites are catalytic for 4-electron ORR, and all other sites in N/B doped graphite are likely blocked by intermediates. Thus, increasing these number of sites is desirable for synthesis of N/B doped carbon metal free catalysts. Han et al. ${ }^{[242]}$ recently synthesised a N/B aerogel that showed a more positive onset potential $(0.994 \mathrm{~V})$ than existing N/B doped carbons in alkaline, though still somewhat poorer than $\mathrm{Pt} / \mathrm{C}$ in alkaline. Florent et al. ${ }^{[178]}$ showed that a high volume of small pores that adsorb $\mathrm{O}_{2}$ enhances the ORR efficiency, and that the presence of $\mathrm{B}$ also helps the onset potential, contrary to what was previously shown on B-doped CNTs, ${ }^{[249]}$ though the performance is significantly poorer than $\mathrm{Pt} / \mathrm{C}$ in alkaline. Yu et al. ${ }^{[243]}$ also synthesised N/B doped aerogels and tested them in alkaline as well as acid. The performance was comparable to $\mathrm{Pt} / \mathrm{C}$ in alkaline, and showed significantly greater performance than the single $\mathrm{N}$ or $\mathrm{B}$ 


\section{WILEY-VCH}

heteroatom doped versions of the catalyst. There was also some activity towards the ORR in acid, though with a significant overpotential compared to Pt/C (Figure 4).

Finally, halides have also been used as co-dopants with $\mathrm{N}$ in metal free catalysts. Gong et al. ${ }^{[177]}$ and Akula et al. ${ }^{[245]}$ recently demonstrated N/F co-doped carbons. Gong used electrospinning to produce carbon fibers that can act as freestanding electrodes that showed similar performance to $\mathrm{Pt} / \mathrm{C}$ in $\mathrm{KOH}$ (only a lower limiting current), as well as some activity in sulphuric acid. Akula et al showed that co-doping improved the performance compared to the single heteroatom doped ones, including in a PEM fuel cell test. Liu et al. ${ }^{[246]}$ synthesised N/I doped carbons from hydrogen-bonded organic frameworks (HOFs) and pre-treatment with potassium iodide and shows comparable performance to $\mathrm{Pt} / \mathrm{C}$ in alkaline, though they seem to suggest that this is due to increased $\mathrm{N}$ doping rather than the incorporation of I in the carbon matrix. Further studies of such systems are needed to elucidate the reason for the high performance.

Co-doping has been shown to be a successful strategy to improve the activity of metal free catalysts, with several recent examples in the literature showing similar or better performance than $\mathrm{Pt} / \mathrm{C}$ in alkaline, $[174,176,177,236,243,246,247,250]$ and even promising activity in acidic electrolytes. ${ }^{[174,177,234,243,247]}$ Co-doping not only changes the delocalization of spin or charge density (electronic configuration changes), but also it creates more intrinsic defects in carbon atoms. Therefore, we suggest the use of advanced surface modification methods to introduce the co-doping effect in 3D carbons for increasing the actives sites and introducing the synergistic effect for ORR. Note that the activation of $\pi$ electrons in carbon gets affected if the lone-pair of electrons from $\mathrm{N}$ is neutralised by the vacant orbital of $\mathrm{B}$ that overall affects the co-doping efficiency and the performance in ORR. [Error! Bookmark not defined.] It is therefore important to note that doped heteroatoms such as $\mathrm{N}$ and $\mathrm{B}$ are separately bonded to $\mathrm{C}$ and not bonded with each other.

6.4. Ternary doping for the ORR. A small number of recent papers have also used three heteroatom dopants to improve the performance for the ORR. All contain $\mathrm{N}$ and $\mathrm{S}$, with $\mathrm{P}^{[251 \text {, }}$ ${ }^{252]}$ or $\mathrm{F}^{[180]}$ as the third dopant. Sher Shar et al. ${ }^{[251]}$ used a foam structure generated from GO building blocks to produce a high surface area ternary doped catalyst with an enhanced onset potential (though worse limiting current density) compared to $\mathrm{Pt} / \mathrm{C}$ in alkaline and was attributed to the ternary doping as well as the open structure and access to active sites. Rong et al. ${ }^{[252]}$ used ZIF-8 to synthesise mesoporous carbon with N, S and P doping and tested the materials in alkaline, acid and neutral solutions. They obtained comparable performance in 


\section{WILEY-VCH}

$\mathrm{KOH}$ and only slightly lower half-wave potentials in phosphate buffer solution (PBS) and sulphuric acid. Lv et al. ${ }^{[180]}$ showed identical performance of their porous N, S, F doped carbons in alkaline as $\mathrm{Pt} / \mathrm{C}$, though the limiting current density in their experiments was low for both. They hypothesised that there was a synergistic effect with the $\mathrm{N}$ and $\mathrm{F}$ doping, and that the $\mathrm{S}$ doping polarised the carbon electron density, though more work is needed in general to study the mechanism of ternary doped metal free catalyst for the ORR.

In general, ternary doping is a promising strategy for producing metal free catalysts with similar or better performance to $\mathrm{Pt} / \mathrm{C}$ for the ORR. It also leads to the creation of defects in carbons that can either be a point defect or line defect, although point defects have been widely explored. The acid tolerance of each defect may vary and that depends on the electrolyte in which they are being tested, meaning that there are urgent needs for the creation of 3D carbons with controlled oxidation defects. It is possible to predict through DFT calculations that whether or not an intermediate is formed on a specific defective site, ${ }^{[253]}$ though identifying and monitoring of one or more defective site experimentally is difficult as the defect could degrade in acid with time. Some studies have point out that the carbon atoms with the zig-zag defects, ${ }^{[155]}$ and the graphitic-type-N defects ${ }^{[234]}$ as well as the $\mathrm{S}$ atoms with the pentagon defects are stable in acid, suggesting that introducing the defects to the carbon atoms or the dopants increases their acid tolerance limit and that helps for the continuous monitoring of such defects through the high resolution microscopy. We suggest the use of advanced engineering methods for the defect management in carbon-based materials for both introducing asymmetric electronic distribution and control of electronic structures locally, which could also increase the acid tolerance limit of the porous carbon-based electrocatalysts.

6.5. Device application. A few recent papers test metal free catalysts outside of the threeelectrode $\mathrm{R}(\mathrm{R}) \mathrm{DE}$ environment for use in real devices. Metal air batteries often employ an aqueous $\mathrm{KOH}$ electrolyte, much like that used in the three-electrode testing, and so the environment is less dissimilar to a working device. ${ }^{[223,241,247,250]}$ As metal air batteries need to charge and discharge, they require bifunctional catalysts to act as OER promotors, as well as ORR, and these will be covered later in the review. A few recent papers test their materials in working fuel cells, where the oxidant is delivered in the gaseous phase and there is an ionic conductive membrane between the anode and cathode. This environment is quite different to that tested with the $\mathrm{R}(\mathrm{R}) \mathrm{DE}$ and therefore it is important to test promising catalysts in working devices where possible. Engineering considerations such as pressure, humidity, gas flow manifolds, catalyst layer structure and contact resistances will all have an effect on the 


\section{WILEY-VCH}

performance of a real fuel cell. To fill the gap between the lab scale R(R)DE test and the real device test, GDE set up could be used to evaluate the electrocatalytic performance of 3D carbons. 3D freestanding films and aerogels/hydrogels could be integrated to the floating electrodes and tested in freestanding configuration. ${ }^{[254,255]}$ In freestanding GDE or floating electrode set up, the transfer of reactants through gas phase will be much faster that the R(R)DE set up, and so the convection and reactant transport related issues will be less, meaning that the artifacts caused to the data obtained in a freestanding test configuration will be minimum. The data collected from freestanding configuration can be compared with the data collected from the real device test, and such performance comparisons will be meaningful.

Akula et al ${ }^{[245]}$ tested their N/F co-doped catalysts in a alkaline anion exchange membrane fuel cell (AAEMFC) with $\mathrm{H}_{2}$ at the anode, and showed enhanced performance from the co-doping compared to $\mathrm{N}$ and $\mathrm{F}$ only, however there was a low peak power density of around $13 \mathrm{~mW} \mathrm{~cm} \mathrm{~cm}^{-2}$, which was significantly lower than that of the Pt catalyst membrane electrode assemble (MEA). Tang et al. ${ }^{[184]}$ tested their $\mathrm{N}$-doped carbons for performance in a $\mathrm{MeOH}$ fuel cell and obtained better peak power density of around $1000 \mathrm{~mW} \mathrm{~cm}^{-2}$ compared to $800 \mathrm{~mW} \mathrm{~cm}^{-2}$ for $\mathrm{Pt} / \mathrm{C}$, attributable to the lower $\mathrm{MeOH}$ crossover poisoning. Tian et al. ${ }^{[217]}$ also tested $\mathrm{N}$-doped carbons for performance in a microbial fuel cell, and achieved high peak power densities of nearly 800 $\mathrm{mW} \mathrm{cm}{ }^{-2}$ compared to $600 \mathrm{~mW} \mathrm{~cm}^{-2}$ for Pt/C, also showing benefit for waste water treatment.

\section{3D carbons for the oxygen evolution reactions (OER)}

The OER is a complex but key process for both water electrolyzers and rechargeable metal-air batteries. ${ }^{[12,256-258]}$ The evolution of $\mathrm{O}_{2}$ is typically a kinetically slow multi-step process, requiring the transfer of four electrons and O-O bond formation. ${ }^{[259]}$ This multiple-step reaction is $\mathrm{pH}$ dependent. In acidic and neutral electrolytes, two molecules of $\mathrm{H}_{2} \mathrm{O}$ are oxidized to four $\mathrm{H}^{+}$and one $\mathrm{O}_{2}\left(2 \mathrm{H}_{2} \mathrm{O} \leftrightarrow 4 \mathrm{H}^{+}+\mathrm{O}_{2}+4 e^{-}, E_{a}^{0}=1.23 \mathrm{~V}\right)$. In alkaline electrolyte, four $\mathrm{OH}^{-}$are oxidized into $\mathrm{H}_{2} \mathrm{O}$ and $\mathrm{O}_{2}\left(4 \mathrm{OH}^{-} \leftrightarrow 2 \mathrm{H}_{2} \mathrm{O}+\mathrm{O}_{2}+4 e^{-}, E_{a}^{0}=0.404 \mathrm{~V}\right)$. However, as mentioned, the actual OER process is more complex than the stoichiometric equations, and proceeds through multiple steps. In nature, the OER is catalyzed by the oxygen-evolving complex, which contains a cubane-like $\mathrm{Mn}_{3} \mathrm{CaO}_{4}$ active site. ${ }^{[260]}$ However, in the laboratory, noble metals and noble metal oxides need to be employed instead. Ruthenium and iridium oxides exhibit the best OER performances, but their scarcity and cost limit their application at large scale. ${ }^{[261]}$ Transition metal materials, including perovskite oxides, hydro(oxy)oxides and chalcogenides have been widely investigated as cost-efficient alternatives to noble metal 


\section{WILEY-VCH}

catalysts. ${ }^{[133,262-279]}$ However, these suffer from unwanted degradation processes under real working conditions. In 2013, the first metal free catalyst (nitrogen-doped carbon) that exhibited comparable activity for the OER to non-precious metal catalysts was reported. ${ }^{[22]}$ However, metal free carbon OER electrocatalysts are not as popular in the literature as in the case of ORR carbon materials, perhaps due to the bigger challenges still to overcome for achieving efficient OER. Nonetheless, recently the number of reports have increased, ${ }^{[14,133,253,268-280]}$ and special focus has been given to 3D architectures (nano and macro) and heteroatom doping. Some of these examples are summarized in Figure 9. Though it is the reverse reaction to the ORR, the material requirements for OER can be quite different, as water is a reactant in the process, rather than gaseous $\mathrm{O}_{2}$ and $\mathrm{H}_{2}$ in fuel cells, and so the mass transport considerations can be different. Moreover, as gaseous $\mathrm{O}_{2}$ is produced, the formation size and rate of bubbles, as well as their effective removal from the active site is crucial to their operation, particularly at high current density where bubbles can mask further reaction. Therefore, porous 3D architectures have the potential to more dramatically improve the performance of metal free catalysts for the OER than they do for the ORR - certainly the mass transport characteristics are a vital consideration for synthesis of 3D doped carbon OER catalysts.

Graphene-based catalysts exhibit strong intrinsic $\pi-\pi$ interactions and van der Waals forces, which make them likely to aggregate, leading to a decrease in surface area, OER activity and stability. ${ }^{[281,282]}$ It is usually prepared in the form of powder, which then requires the use of binders in order to form a working electrode structure, which then decreases the conductivity and can block diffusion and active sites. Therefore, the development of highly active sites with an optimized structural design is crucial to improve the catalytic performance of graphene catalysts for OER. Chen et al. fabricated a N,O-dual doped graphene-CNT (or NG-CNT) hydrogel film electrocatalyst via layer-by-layer assembly of chemically converted graphene and CNTs followed by ammonia treatment, with high OER activity in both acidic and alkaline media, outperforming even $\mathrm{IrO}_{2} \cdot{ }^{[271]}$ The activity of the material was attributed to the dual active sites mechanism from the synergy of chemically converted graphene and CNTs. Additionally, the interconnected porosity of the NG-CNT allows for the effective use of the active centers created by the dopants, and the larger pores in the hydrogel also lead to a fast release of the oxygen evolved (Figure 10a-e). A phytic acid - doped hydrogel on carbon cloth (PA-PP/CC) containing phosphorous was successfully prepared using a dip-coating dry method (Figure 10fh). ${ }^{[276]}$ This material exhibited high inherent activity with lower onset potential (1.51 V vs RHE) and high current density across the whole potential window. Notably, the PA-PPy/CC displayed 


\section{WILEY-VCH}

a small overpotential of $340 \mathrm{mV}$ to achieve a current density of $10 \mathrm{~mA} \mathrm{~cm}$, a Tafel slope of $54.9 \mathrm{mV} \mathrm{dec}{ }^{-1}$, and long-term stability. The high OER activity was attributed both to the $\mathrm{P}$ active sites on the PA and the porous conductive networks on the hydrogel, which allowed fast charge and mass transport during the OER.

The pyridinic and quaternary $\mathrm{N}$ atoms have been claimed to be responsible for the increase in the OER activity, in a similar manner to the ORR. ${ }^{[283]} \mathrm{g}-\mathrm{C}_{3} \mathrm{~N}_{4}$ is a great choice for introducing $\mathrm{N}$ into carbon materials. However, its low conductivity and the difficulties in mixing with carbon are the main drawbacks. Ma et al. developed an innovative strategy for the self-assembly of $\mathrm{g}_{-} \mathrm{C}_{3} \mathrm{~N}_{4}$ nanosheets (NSs) and carbon nanotubes (CNTs). ${ }^{[272]}$ The $3 \mathrm{D} g-\mathrm{C}_{3} \mathrm{~N}_{4}$ NS-CNT composite structure was created through the $\pi-\pi$ stacking and electrostatic interactions between the carbon nitride nanosheets and the carbon nanotubes (Figure 11a-b). Strong coupling between the $\mathrm{g}-\mathrm{C}_{3} \mathrm{~N}_{4} \mathrm{NSs}$ and CNTs in the assembled 3D structure was confirmed by XRD and XPS. The catalyst exhibited higher OER activity and durability than Ir-based noble metal catalysts, with a sharp onset potential at $\sim 1.53 \mathrm{~V}$ and operating potential (vs RHE) to deliver a $10 \mathrm{~mA} \mathrm{~cm}^{-2}$ current density of $1.60 \mathrm{~V}$ (Figure 11c), comparable to state-of-the-art noble metal catalysts. ${ }^{[22]}$ This was attributed to the high nitrogen content, unique porous architecture (efficient mass transport) and charge transfer in the three-dimensional nanostructure. ${ }^{[272]}$ To illustrate the importance of the 3D architecture, the authors also prepared an analogous material but using bulk g- $\mathrm{C}_{3} \mathrm{~N}_{4}$ instead of $\mathrm{g}-\mathrm{C}_{3} \mathrm{~N}_{4} \mathrm{NSs}$, which resulted in very low OER activity and unfavourable kinetics. ${ }^{[272]}$ But of course, without the CNT network, the electrical conductivity of the $\mathrm{g}-\mathrm{C}_{3} \mathrm{~N}_{4}$ is substantially lower and thus the effect of the mass transport through the 3D structure cannot be fully decoupled from this. Remarkable performance was also observed for graphene / $\mathrm{gC}_{3} \mathrm{~N}_{4}$ nanosheets supported onto cellulose paper, which was attributed to the presence of $\mathrm{N}$ active sites, rich porosity, and 3D conductive networks (Figure 11d-e). ${ }^{[275]}$ Analysis of the OER measurements revealed high activity and kinetics comparable to those of $\mathrm{IrO}_{2}$, as well as excellent durability during long-term cycling.

Chemical modification of carbons via doping with heteroatoms (N, P, S, and B) can potentially improve the adsorption of intermediates and subsequent electron transfer by modifying their electronic structures. ${ }^{\text {[284-289] }}$ Therefore, most high performing OER electrocatalysts based on carbon have heteroatoms in their structure. $\mathrm{P}$, for example, can induce a local charge density because of its lone pair of electrons in the $3 p$ orbital, and accommodate the lone pairs of electrons from $\mathrm{O}^{*}$ to initiate the OER process. ${ }^{[290]}$ Thus, it is no big surprise for the edgeselectively P-doped few-layer graphene to be reported as an efficient metal-free electrocatalyst 


\section{WILEY-VCH}

for OER, with onset potential $1.48 \mathrm{~V} v s$ RHE, much lower than pristine graphene (onset potential $1.54 \mathrm{~V} v s \mathrm{RHE}) .{ }^{[291]}$

Particularly, co-doping can result in synergistic effects and improve the OER activity to a larger extent. ${ }^{[292]}$ Following this strategy, 3D carbon nanofibers co-doped with $\mathrm{N}$ and $\mathrm{P}$ were prepared through pyrolysis of polyaniline obtained via induced polymerization in the presence of phosphonic acid (Figure 12a-b). ${ }^{[133]}$ They showed excellent stability and high OER performance (onset of $1.51 \mathrm{~V} v s \mathrm{RHE}$ ) at a relatively low overpotential $\left(0.31 \mathrm{~V}\right.$ at $\left.10 \mathrm{~mA} \mathrm{~cm}^{-2}\right)$, close to that of iridium oxide (Figure 12c). The doping increased the surface area and improved mass / charge transfer as well as provided active sites for the OER.${ }^{[133]}$ Experimental results and DFT calculations seemed to confirm that the co-doping of $\mathrm{N}$ and $\mathrm{P}$ into the carbon structure was key for an improved OER performance. Experimental investigation has revealed that codoping carbon with $\mathrm{P}$ and $\mathrm{N}$ led to an increase in active surface area and the density of active sites in comparison to the single doped or pristine carbon-based counterparts. ${ }^{[133]}$ DFT calculations indicate that $\mathrm{N}$ and $\mathrm{P}$ dopants synergistically coactivate the adjacent $\mathrm{C}$ atoms inducing enhanced activity towards OER. This implies that $\mathrm{N}, \mathrm{P}$ codoping can sufficiently decrease the total free energy for the carbon framework. The electrocatalytic OER overpotential was considerably reduced through heteroatom codoping. Therefore, N, S and N, P-codoped 3D carbon-based electrodes are most efficient for OER electrocatalysis.

Also exploring the co-doping synergistic effect, Zhao and coworkers prepared a nitrogen and sulfur co-doped graphene/carbon nanotube (NS-GR/CNT) with 3D architecture through a hydrothermal approach. ${ }^{[274]}$ The material showed high OER performance, with an onset potential of $804 \mathrm{mV}$ (vs RHE), more negative than other samples only doped with $\mathrm{N}$ or undoped. Although, the $\mathrm{N}$ doping enhances the OER catalytic activity as previously reported, ${ }^{[22,293]} \mathrm{S}$ proved to significantly enhance this effect through the formation of C-S-C structures. ${ }^{[274]}$ This correlates with what has been found in other works that claim that $\mathrm{S}$ doping leads to charge and spin densities changes ${ }^{[16,294]}$ which, in turn, will have a crucial effect in the electrocatalytic OER activity of the carbon materials. DFT studies also showed that C-S-C drastically reduces the adsorption energy of $\mathrm{OH}^{-}$, improving OER performance. ${ }^{[274]}$

In fact, the heteroatoms co-doping into carbon materials have produced a significant number of OER electrocatalysts that also have multifunctional activities. ${ }^{\left[237,{ }^{295-302]}\right.}$ Also, N,S-co-doped carbon was prepared by X. Yu et al., in the form of N,S-co-doped graphite foam (NSGF). ${ }^{[275]}$ The NSGF was prepared from commercial graphite foil and applied without using current 


\section{WILEY-VCH}

collectors (Figure 12d-f). N, S co-doped NSGF electrode was found to have much higher activity for the OER than N-doped graphite foam, confirming what had been found by other studies. ${ }^{[274]}$

Although pristine CNT and graphene are conductive they are not very active for OER, attributable to the less number of hierarchical pores and active sites. 3D structures were therefore, constructed from graphite, $\mathrm{CNT}, \mathrm{gC}_{3} \mathrm{~N}_{4}$ and graphene through the layer-by-layer assembling, electrostatic and $\pi-\pi$ stacking interactions, creating interconnected 3D pores and porous conductive networks, improving charge and mass transport for OER, with performance, better or closer to that of $\mathrm{IrO}_{2 .}{ }^{[133]}$ The OER performance of N-doped carbon films and N-O doped hydrogels are found to be much higher than that of $3 \mathrm{D}$ N-carbon film, $\mathrm{C}_{3} \mathrm{~N}_{4} / \mathrm{CNT}$, and S,N doped carbon foam (Figure 9a and Table S2). The conductivity of 3D structures comes from that of CNT, graphene or carbon fibers, which enabled to have kinetics comparable to $\mathrm{IrO}_{2} \cdot{ }^{[275]}$ Doping heteroatoms to the carbon atoms in such structures introduces more active sites and increases the electron transfer as well as the adsorption of intermediates, leading to improved OER performance. $\mathrm{N}$ and $\mathrm{P}$ combination seems to work well for OER, attributable to the synergistic effect, active surface area and the density of active sites. P-N site shows better stability than either $\mathrm{N}$ and $\mathrm{S}$, or $\mathrm{N}$ and $\mathrm{O}$ co-ordinated sites. 3D carbons have overall been reported to be stable in alkaline, attributable to stable coupling between the $1 \mathrm{D}$ and $2 \mathrm{D}$ structures. The stability of such structures in alkaline should not be over rated as they were mostly obtained from the half cell tests, though the carbon oxidation reactions leading to the protonation of oxygen functionalities in acid creates the stability issues. We therefore recommend the use of microscopy and chromatography techniques for the identification and analysis of the oxidation products, surface defects and surface oxygen contents, followed by the estimation of the fraction of charge attributable to the carbon oxidation reactions through electrochemical methods. ${ }^{[34,149,155,303]}$ Perhaps, it will tell us the steps that need to be taken for improving stability. We suggest that the stability of 3D structures can be improved through surface engineering methods. ${ }^{[34,303]}$ For example, thin coating of conductive and acid resistance materials to the catalyst surface can protect the active sites and the defects from the corrosion reactions in acid. The stable defects (pentagonal effects, armchair edges, zig-zag edges) can be introduced to the 3D carbon surface to improve the acid tolerance limit. The assembly of surface engineered 1D and 2D structures through covalent cross-linking can improve the mechanical strengths of the resulting 3D structures and the freestanding 3D electrodes. ${ }^{[274]}$ The printing and patterning of $1 \mathrm{D}$ and $2 \mathrm{D}$ carbon structures on the conductive substrates, followed by coating 


\section{WILEY-VCH}

their surface with thin layers of acid-resistant conducting inks with suitable porogens, can also improve the porosity and the stability of the active layers in the resulting $3 \mathrm{D}$ structures. ${ }^{[121]}$ The surface treatment of such conductive layers with plasma or high energy $\mathrm{CO}_{2}$ lasers could also form controlled oxidative defects (zig-zag edges) and hierarchical pores (holes) with stable active sites, which could lead to better performance in OER. ${ }^{[304]}$

\section{3D carbons for the hydrogen evolution reaction (HER)}

Hydrogen is considered the perfect energy carrier due to high energy density and non-polluting emissions, and so is seen as a future substitute for fossil fuels in the automotive and stationary power sectors. ${ }^{[305-307]}$ Among all the available ways of generating hydrogen (water, biomass, coal), only water splitting can truly provide clean, sustainable hydrogen when coupled with green electricity. Water electrolysis via the HER can generate clean a pure hydrogen that can then be employed in polymer electrolyte membrane fuel cells. ${ }^{[308]}$ Due to the relatively simple mechanism, hydrogen electrocatalysis kinetics are generally more facile than for oxygen electrocatalysis, ${ }^{[309]}$ making it possible to achieve very high exchange current density at negligible voltage loss even with minimal catalyst loading. ${ }^{[310]}$ However, Pt-based electrocatalysts are still the most active compounds for HER catalysis. ${ }^{[90,311]}$ Some of the reasons for this are that Pt can produce hydrogen from water without the need of high potential (onset potential $\sim 0 \mathrm{mV}$ vs RHE), ${ }^{[312]}$ it possesses a high exchange current density, and particularly low free energy of hydrogen binding. ${ }^{[313,314]}$ However, the use of Pt has hindered the deployment of large-scale devices for hydrogen generation, and such systems are still considered prohibitively expensive compared to generation of hydrogen via refining of fossil fuels. ${ }^{[314]}$ Because of this, multiple non-noble metal-based HER electrocatalysts have been extensively researched for replacing Pt-based materials at the cathode of electrolysers, including $3 d$ transition metal ( $\mathrm{Fe}, \mathrm{Co}, \mathrm{Ni}, \mathrm{Mo}, \mathrm{W})$ compounds such sulfides, phosphides, nitrides and carbides. ${ }^{[315-320]}{ }^{[321-325]}$ However, most of these catalysts are based on the essential metal-H bond interaction for the HER, prone to corrosion and passivation in acidic medium, ${ }^{[326]}$ the catalytic activities are inferior to $\mathrm{Pt} / \mathrm{C}$ with large overpotentials, and the catalysts exhibit agglomeration and dissolution accompanied by important structural changes during prolonged operation. $^{[9]}$

Carbon-based materials have attracted great attention as promising metal free catalysts for HER due to their abundance, tuneable hierarchical structures towards versatile applications, large surface area and excellent conductivity, ${ }^{[90,327-329]}$ and many metal free carbon materials have 


\section{WILEY-VCH}

been reported in the recent years with excellent performance for the HER. ${ }^{[18,330-344]}$ Figure 9b summarizes metal free 3D carbons for the HER (Table S3). Wang et al. ${ }^{[336]}$ recently explored for the first time the engineering of the morphology of graphene as a way to modulate the electronic structure of the carbon skeleton with the aim of enhancing its ability to reduce $\mathrm{H}^{+}$to $\mathrm{H}_{2}$. They synthesized a 3D graphene network with high density of sharp edge sites using atmospheric pressure chemical vapour deposition (APCVD), with an extremely low onset potential of $\sim 18 \mathrm{mV}$ in acidic medium. ${ }^{[336]}$ This performance was comparable to those of transition metal-hybrids or heteroatom-doped carbons. XPS and DFT calculations confirmed the excellent HER activity was due to the sharp edge sites of the pure carbon skeleton, which exhibited higher charge density than internal carbon, hence promoting the proton adsorption and reduction.

Doping or co-doping of carbon structures with heteroatoms has developed as a viable way to enhance the electrocatalytic HER activity of carbon materials, ${ }^{[9,326,345,346]}$ although the actual role of dopants in the catalytic mechanism, or even the hydrogen evolution mechanism itself in metal free systems, is still in debate and controversial in the literature. ${ }^{[347]}$ Therefore strategies to build a HER catalyst based on metal free materials are largely based on improving the active reaction centers via doping and forming 3D architectures. ${ }^{[9,348,349]}$ Among the multiple HER electrocatalysts proposed, $\mathrm{g}_{-} \mathrm{C}_{3} \mathrm{~N}_{4}$ 3D structures combined with graphene have shown promising results. ${ }^{[289,350]}$ Gangadharan et al. ${ }^{[338]}$ synthesized a 3D structure based on N-doped $\mathrm{GO}$ and carbon nitride tetrapods $\left(\mathrm{CN}_{\mathrm{x}} @ \mathrm{~N}-\mathrm{RGO}\right)$. The material was prepared through the decomposition of melamine foam in the presence of argon, leading to a reduction of GO to RGO and doping with the $\mathrm{N}$ coming from the melamine. The spatial configuration of this catalyst provided a high density of in-plane $\mathrm{N}$ coordinated active centers while the $3 \mathrm{D}$ macroporous structure led to an efficient distribution of reactants and products.

CNx@N-RGO achieved a small overpotential of only $193 \mathrm{mV}$ to reach a current density of 10 $\mathrm{mA} \mathrm{cm}{ }^{-2}$, higher than previously reported Pt-free systems. Similarly, Zhao et al. ${ }^{[342]}$ assembled a 3D structure of $1 \mathrm{D} \mathrm{g}-\mathrm{C}_{3} \mathrm{~N}_{4}$ nanoribbons with $2 \mathrm{D}$ graphene sheets via hydrothermal synthesis, creating a multi pathway network of charge and mass transport that exhibited high electrocatalytic activity for the HER (Figure 13a-c). The g- $\mathrm{C}_{3} \mathrm{~N}_{4}$ nanoribbons-G showed a low onset overpotential of $80 \mathrm{mV}$ and overpotential of $207 \mathrm{mV}$ to approach a current of $10 \mathrm{~mA} \mathrm{~cm} \mathrm{~cm}^{-2}$, showing the potential of designing and developing highly efficient metal free catalyst for the HER. The high HER activity and stability was attributed to (i) the unique 1D structure of the g- $\mathrm{C}_{3} \mathrm{~N}_{4}$, which provides active $\mathrm{H}$ binding sites ${ }^{[21]}$ and facilities inter-electron transport along 


\section{WILEY-VCH}

its surface; (ii) enhanced electron transfer from graphene to the $g-\mathrm{C}_{3} \mathrm{~N}_{4}$ from the in situ deposition of the nanoribbon onto the 3D graphene structure; (iii) grid-like structure that enables the electrolyte to fully infiltrate through the catalyst. A freestanding porous carbon nitride@N-Graphene film (PCN@N-Graphene) was produced via a simple vacuum filtration method (Figure 13d-f). ${ }^{[18,21]}$ The material presented a structure similar to van der Waals heterostructures, but with a 3D architecture, leading to a remarkable performance with an overpotential of just $80 \mathrm{mV}$. Interestingly, the HER activity of the film varied with the $\%$ of PCN nanolayers, being the hybrid film with $9.1 \%$ of PCN nanolayers the one exhibiting the best HER activity. An abundance of exposed active sites, synergistic effect between PCN layers and graphene, $\mathrm{N}$ introduction into graphene, and hierarchical porous structure all contributed to an excellent performance of the material for HER.

As previously mentioned, heteroatom doping into carbon structures could significantly enhance the electrocatalytic activity of carbon materials. Among the multiple strategies, co-doping of graphene has proven very successful strategy for improving HER activity. ${ }^{[21,346,350]}$ Yan et al. ${ }^{[343]}$ produced for the first time a N,P-codoped carbon network from electrochemical polymerized supermolecules via polymerization of aniline ( $\mathrm{N}$ and $\mathrm{C}$ precursor) in the presence of phytic acid (PA) (P and $\mathrm{C}$ precursor) (Figure 14a-b). The interaction between PA and aniline formed a unique 3D structure, beneficial for electron and mass transport through the catalyst. Moreover, the polymerization of aniline in the presence of PA produced a uniform N- and Pdoping. The resulting material treated at $900{ }^{\circ} \mathrm{C}$ (PANI-PA-900) exhibited high HER performance and durability, with only $151 \mathrm{mV}$ (vs RHE) overpotential to achieve a current density of $10 \mathrm{~mA} \mathrm{~cm}{ }^{-2}$. Another successful co-doping of a carbon material for HER was conducted by Chen et al., ${ }^{[334]}$ who successfully created a highly conductive 3D hierarchical nanoporous graphene doped with $\mathrm{N}$ and $\mathrm{S}$ (Figure 14c-d) via a two-step CVD method. The material showed one of the best HER activities for a metal free electrocatalyst, with an onset potential of $-0.12 \mathrm{~V}$.

Although, good examples of metal free 3D carbons with innovative structural and functional features have been proposed and have been shown to decrease the overpotential for HER compared with more simplistic carbon-based metal free catalysts, significant breakthroughs in this track are yet to be achieved. The performance plot of some 3D porous catalysts for HER constructed as a function of onset potential and overpotential is given in Figure $\mathbf{9 b}$. Among these, the $\mathrm{N}$ doped 3D graphene shows the best performance in HER. The defects (zig-zag edges and pentagonal defects) could be introduced to the framework of 3D graphene to increase the 


\section{WILEY-VCH}

number of active sites and stability. Further support and stability to the framework and active sites could be given through covalent cross-linking of 0D or 1D structures with 3D graphene.

\section{3D carbons for bifunctional oxygen electrocatalysis (OER and ORR)}

Among the multiple sustainable energy conversion and storage devices, metal-air batteries stand as one of the most promising energy technologies due to their high energy density compared to other energy storage systems, such as Li ion batteries. The ability to employ a metallic negative electrode, as opposed to the layered intercalated graphite used in Li ion, accounts for this order of magnitude increase in theoretical energy density. This makes them ideal candidates for multiple energy applications, from electric vehicles to flexible electronic devices, especially where weight is a critical factor. ${ }^{[351,352]}$ While the battery is in operation, the reactions taking place at the positive electrode of the metal-air batteries, ORR during discharge and OER during charge, are key to the operation of these devices, as well as in the case of regenerative fuel cells. ${ }^{[353]}$ However, the performance of these devices is limited by the sluggish kinetics of the oxygen electrochemistry. ${ }^{[16,29,307,354,355]}$ Noble metals (Pt, Ir, Ru) and transition metal ( $\mathrm{Ni}, \mathrm{Fe}, \mathrm{Mn}$, $\mathrm{Co}$ ) compounds have commonly been employed for oxygen electrocatalysts. ${ }^{[9,356-368]}$ but, the high cost, scarce resource, and poor durability of these metalbased catalysts have been disadvantageous for their widespread and large-scale applications in renewable energy technologies. ${ }^{[369-371]}$

Additionally, flexible energy devices are attracting increasing attention because of their unique properties, including lightweight and malleable shape, which enable their use in bendable portable devices - of particular interest for the burgeoning wearables market. ${ }^{[372]}$ Unfortunately, current oxygen electrodes are rigid and heavy, and the design of flexible electrodes requires materials with three-dimensional architectures featuring outstanding oxygen electrocatalytic activity and excellent mechanical properties. In this regard, metal free carbons present a great alternative to transition metal and noble metal materials as bifunctional oxygen electrocatalysts for application in flexible devices, particularly where flexible free standing electrodes can be utilized. Some of the most promising examples are summarized in Figure 9c (Table S4).

As previously mentioned, the insertion of heteroatoms in carbon frameworks has shown the potential to enable the asymmetrical delocalization of charge, creating efficient active sites, which could favour the adsorption of oxygen species, hence enhancing the oxygen reduction and evolution processes. ${ }^{[29,31,237,296-300,302,373-380]}$ As such, a 3D N,P co-doped mesoporous nanocarbon (NPMC) foam prepared using a template-free method exhibited promising 


\section{WILEY-VCH}

bifunctional catalytic activity towards ORR and OER, and good performance and long-term stability when tested in a full Zn-air rechargeable cell. ${ }^{[16]}$ The battery exhibited an open-circuit voltage of $\sim 1.48 \mathrm{~V}$, energy density of $\sim 835 \mathrm{Wh} \mathrm{kg}_{\mathrm{zn}}{ }^{-1}$ and peak power density of $\sim 55 \mathrm{~mW} \mathrm{~cm}^{-2}$. First-principles studies revealed that the $\mathrm{N}$ and $\mathrm{P}$ co-doping and the highly $3 \mathrm{D}$ porous network $\left(\sim 1660 \mathrm{~m}^{2} \mathrm{~g}^{-1}\right)$ were crucial to produce competitive oxygen bifunctional activity.

Heteroatom-doped $\mathrm{C}_{3} \mathrm{~N}_{4}$ can exhibit outstanding catalytic oxygen bifunctional electrocatalytic activity, mostly in alkaline media. A 3D carbon nanoparticle sandwiched between $\mathrm{P}$ and $\mathrm{S}$ codoped carbon nitride sponge (P,S-CNS), prepared simply by polymerization and pyrolysis of aminoguanidine, demonstrated high specific surface area $\left(1474 \mathrm{~m}^{2} \mathrm{~g}^{-1}\right)$ and higher ORR and OER bifunctional catalytic activities than that of Pt/C for ORR (limiting current density $=7.14$ $\mathrm{mA} \mathrm{cm}{ }^{-2}$ at $10 \mathrm{~mA} \mathrm{~cm}{ }^{-2}$, onset potential $=0.97 \mathrm{~V}$ vs $\mathrm{RHE}$ ) and $\mathrm{RuO}_{2}$ for OER (onset potential $1.26 \mathrm{~V} v s$ RHE, potential $=1.56 \mathrm{~V}$ at $10 \mathrm{~mA} \mathrm{~cm}{ }^{-2}$ ), respectively $\left(\right.$ Figure 15a) ${ }^{[373]}$ The resultant electrode exhibited an outstanding durability and suitability as an oxygen positive electrode in rechargeable primary Zn-air batteries. DFT investigations revealed the bifunctional activity originates from dual doping and efficient mass/charge transfer. Also using heteroatom-doped $\mathrm{C}_{3} \mathrm{~N}_{4}$, P-doped $\mathrm{C}_{3} \mathrm{~N}_{4}$ nanoflowers deposited onto a carbon fiber paper (CFP) showed onset potential of $-0.94 \mathrm{~V} v s$ RHE for ORR and $1.53 \mathrm{~V}$ vs RHE for OER (Figure 15b-c). ${ }^{[381]}$ Apart from the $\mathrm{N}$-induced positively charged $\mathrm{C}$ atoms, commonly considered as the active center for both ORR and OER, P species are also key in promoting the electrocatalytic activity. When $\mathrm{C}_{3} \mathrm{~N}_{4}$ is doped with $\mathrm{P}$, three out its five valence electrons form covalent bonds with neighbours $\mathrm{N}$ to adopt a forced planar structure and the remaining lone pair can delocalize to the $\pi$ conjugated heptazine ring, leaving positively charged P centers. ${ }^{[148,381,382]}$

N-doped mesoporous carbon nanosheet - MWCNT hybrid composites prepared by pyrolyzing glucose, urea and CNTs has shown to produce an efficient metal free bifunctional oxygen electrocatalyst. ${ }^{[300]}$ The resulting catalyst presented an excellent OER activity, with onset potential of only $0.32 \mathrm{~V} v s \mathrm{RHE}$ at $10 \mathrm{~mA} \mathrm{~cm}^{-2}$, as well as for ORR, with onset potential of $0.95 \mathrm{~V} v s$ RHE in $0.1 \mathrm{M} \mathrm{KOH}$. The remarkable bifunctional activity was attributed to the 3D mesoporous structure that enhanced mass and electron transfer and the high $\mathrm{N}$ content (up to 10.7 at\%). ${ }^{[300]}$

COFs, constructed through molecular building blocks with light elements $(\mathrm{C}, \mathrm{N}, \mathrm{O}, \mathrm{H}, \mathrm{P}, \mathrm{B}$, and $\mathrm{S}$ ), have attracted enormous attention as metal free carbon catalysts. ${ }^{[383]}$ Among them, carbon- and nitrogen-based COFs (holey $\mathrm{C}_{2} \mathrm{~N}$ ) have received significant attention because of 


\section{WILEY-VCH}

their versatile and tunable electronic/chemical functionalities, persistent pore structures with ultrahigh surface areas, strong covalent linkages derived from their building blocks, and high cross-linking densities, that greatly improve structural stability and flexibility. ${ }^{[377,384]}$ Moreover, the homogeneous distribution of heteroatoms in COFs significantly enhance their electrocatalytic activity. Shinde et al. ${ }^{[377]}$ reported the fabrication of a 3D sulfur-modulated holey $\mathrm{C}_{2} \mathrm{~N}$ aerogel with continual porous structures using COF building blocks (Figure 16). This material presented a high surface area of $1943 \mathrm{~m}^{2} \mathrm{~g}^{-1}$, exhibited remarkable structural stability and improved oxygen release and mass transport properties, facilitating enhanced penetration of the aqueous electrolyte. The resulting $S-\mathrm{C}_{2} \mathrm{~N}$ aerogel exhibited outstanding bifunctional performance $(\Delta \mathrm{E}=0.65 \mathrm{~V})$ and improved stability towards the ORR and OER, surpassing those of noble metal benchmarks. A rechargeable zinc-air battery assembled with the $\mathrm{S}-\mathrm{C}_{2} \mathrm{~N}$ aerogel demonstrated high electrochemical performance and long-term durability, outperforming noble metal catalysts. Computational studies revealed that the excellent bifunctional electrocatalytic performance was a consequence of the heteroatom-induced charge density polarization effect. ${ }^{[377]}$

In an effort to develop a more energy efficient way to create hierarchically 3D porous carbon structures, a metal free mesoporous N-doped carbon electrode was prepared, taking advantage of the mechanical strength of wood and the natural microchannels present in its structure. This is the first example of direct transformation of biomass into self-supporting porous cathodes for devices based on oxygen-involving reactions. ${ }^{[378]}$ The material exhibited a high surface area of $1039 \mathrm{~m}^{2} \mathrm{~g}^{-1}$, and proved to be highly active for both ORR and OER in alkaline electrolyte, making it a great low cost oxygen bifunctional cathode in rechargeable $\mathrm{Zn}$-air batteries.

\section{3D carbons for overall water splitting (OER and HER)}

The development of multifunctional carbon catalysts is still in the early stages. ${ }^{[9,63]}$ Among these, of particular interest although very challenging, is the design of bifunctional electrocatalysts for OER - HER or ORR - HER that can show high activity for both reactions. The main challenge here lies in achieving highly active and stable electrocatalysts with the lowest overpotential for both reactions under the same $\mathrm{pH}$. To date, most of research for overall water splitting has been based on transition metal catalyst pairs, due to their high active sites. ${ }^{[295,}$ ${ }^{385-395]}$ However, the majority are not stable under acidic medium. There have been some good examples of 3D carbon electrocatalysts for ORR-HER and OER-HER in the literature, with promising activities, due the great number of active sites and good mass and electron transport 


\section{WILEY-VCH}

(Figure 9d and Table S5). ${ }^{[345,346,396-398]}$ Particularly interesting are the materials that can produce overall electrochemical water splitting into $\mathrm{O}_{2}$ and $\mathrm{H}_{2}$. The free energy change for the conversion of one molecule of $\mathrm{H}_{2} \mathrm{O}$ into $\mathrm{H}_{2}$ and $1 / 2 \mathrm{O}_{2}$ under standard conditions is $237.2 \mathrm{~kJ}$ $\mathrm{mol}^{-1}$, which corresponds to a reversible electrolysis cell voltage of $1.23 \mathrm{~V}$ per electron transferred, although in practice the thermoneutral voltage of electrolysis is $1.48 \mathrm{~V}$ and an overpotential is required for useful current densities, driving the cell voltage to higher values. ${ }^{[399]}$

Among the 3D carbon catalysts for OER and HER, a self-supported carbon nitride/carbon nanotube/carbon fiber $\left(\mathrm{C}_{3} \mathrm{~N}_{4}-\mathrm{CNT}-\mathrm{CF}\right)$ and sulfur-doped $\mathrm{C}_{3} \mathrm{~N}_{4}$-CNT-CF showed excellent activity for the OER and the HER, respectively. ${ }^{[397]} \mathrm{A} \mathrm{C}_{3} \mathrm{~N}_{4}-\mathrm{CNT}-\mathrm{CF} \| \mathrm{S}-\mathrm{C}_{3} \mathrm{~N}_{4}-\mathrm{CNT}-\mathrm{CF}$ system performed as a water splitting system, with low onset potential and high stability in acidic and alkaline media (Figure 17a-e). The 3D interconnected carbon fibers (CF) were annealed from cotton and used as supporting substrates for the CNTs. This provided a unique porous structure as well as mechanical stability before the $\mathrm{C}_{3} \mathrm{~N}_{4}$ was grown in situ. The onset potential of the $\mathrm{C}_{3} \mathrm{~N}_{4}$-CNT-CF electrode was $1.52 \mathrm{~V}$ vs RHE, and at 1.6V (vs RHE), the OER specific current was $10 \mathrm{~mA} \mathrm{~cm}$, values close to those of metal-based catalysts. ${ }^{[400,401]}$ The addition of $\mathrm{S}$ significantly increased the performance for the HER, exhibiting a cathodic current density of $10 \mathrm{~mA} \mathrm{~cm}^{-2}$ at $236 \mathrm{mV}$ (vs RHE) versus $348 \mathrm{mV}$ (vs RHE) for the same material without $\mathrm{S}$. Both showed good stability and performance in both acid and alkaline media, when assembled in a water splitting electrolyzer. The success of this material was attributed to a well-thought design of a hierarchical 3D conductive network that enhanced the electrolyte penetration and electron transport, with $\mathrm{C}_{3} \mathrm{~N}_{4}$ and $\mathrm{S}$ doping ensuring an excellent OER and HER electrocatalytic activity, respectively.

Co-doping combined with a 3D structure is also a promising strategy for the design of HER OER efficient metal free electrocatalysts. Lai et al. developed a 3D N-P-O-tridoped porous graphite nanocarbon catalyst directly grown on oxidized carbon cloth (ONPPGC/OCC) performing in acid and alkaline media for both HER and OER (Figure 17f-g) ${ }^{[398]}$ Full water splitting could be achieved at all $\mathrm{pH}$ values. Aniline and phytic acid were the sources of $\mathrm{N}$ and $\mathrm{P}$, respectively, where $\mathrm{O}$ was introduced via a mild oxidation process. The final structure was a highly interconnected porous network, with uniform distribution of all elements and high degree of graphitization. An efficient water electrolyzer could achieve $10 \mathrm{~mA} \mathrm{~cm}{ }^{-2}$ at a cell voltage of $1.66 \mathrm{~V}$ with great stability by using ONPPGC/OCC as both anode and cathode. 


\section{WILEY-VCH}

Apart from HER-OER overall water electrolysis catalysts, HER-ORR bifunctional electrocatalysts are of interest in regenerative fuel cells. ${ }^{[402]}$ Dai et al. developed a metal free HER-ORR catalyst based on 3D porous graphitic carbon co-doped with $\mathrm{N}$ and $\mathrm{P}$ prepared by self-assembling melamine and phytic acid into a melamine-phytic acid supermolecular aggregate (MPSA) in the presence of GO (MPSA/GO), followed by pyrolysis ${ }^{[398 .]}$ Heteroatom doping here induced charge redistribution and led to an enhancement of the ORR activity. The resultant metal free carbon catalysts exhibited remarkably high bifunctional electrocatalytic activities with an excellent durability for both hydrogen evolution and oxygen reduction reactions.

Zhang et al. ${ }^{[403]}$ produced a 3D N-doped carbon through the calcination of discarded cigarette butts as a carbon source and dicyandiamide as a $\mathrm{N}$ source. The resultant electrocatalyst possessed 20\% $\mathrm{N}$ and required $143 \mathrm{mV}$ (vs RHE) to achieve $10 \mathrm{~mA} \mathrm{~cm}^{-2}$ in HER, performance comparable to that of $\mathrm{Pt} / \mathrm{C}$. The high ORR activity through an ideal $4-\mathrm{e}^{-}$pathway was attributed to the high amounts of pyridinic active sites $(10 \mathrm{at} \% \mathrm{~N})$.

A N,S-doped carbon nanofiber network coated with N,P-doped carbon nanoparticles was designed as a HER-ORR bifunctional electrocatalyst by Mulyadi et al. ${ }^{[404]}$ The 3D architecture was prepared from naturally abundant cellulose nanofibrils. The materials showed good bifunctionality toward ORR and HER with the HER performance exhibiting an onset potential of $233 \mathrm{mV}$ ( $v s . \mathrm{RHE}$ ), and a current density of $10 \mathrm{~mA} \mathrm{~cm}^{-2}$ at $331 \mathrm{mV}$ (vs. RHE). The same material was also used for ORR, which could deliver an onset potential $10 \mathrm{mV}$ more negative than commercial Pt/C and a cathodic peak of $0.84 \mathrm{~V}$ (vs. RHE). These values are better than most reported metal free electrocatalysts. The superior performance of carbon hybrid was attributed to the combination of a more exposed highly active N,P-doped carbon, a good integration of N,P-doped carbon with N,S-doped carbon nanofibers, and an accelerated electron transport through N,S-doped carbon nanofibers as good conductivity channels.

\section{3D carbons for trifunctional electrocatalysis (ORR, OER and HER)}

While many metal free carbon materials have been reported to exhibit remarkable electrocatalytic activity either for ORR, or OER, or HER, or as bifunctional electrocatalysts, they do not perform well simultaneously towards the OER, HER and ORR. This is due to their instability in acidic media. The number of metal free 3D trifunctional carbons that can catalyse HER, ORR and OER is scarce, with some examples with 2D structure. ${ }^{[151,154,405]}$ Recently, a N,S-co-doped 3D graphitic framework (N,S 3DPG) was used to create a cost-effective, highly 


\section{WILEY-VCH}

efficient trifunctional electrocatalyst for HER, OER and ORR in alkaline media, based on a cross-linked 3D structure. ${ }^{[276]}$ Based on the newly developed HER/OER/ORR trifunctional electrocatalyst, they designed an integrated energy system, in which a perovskite solar cell was used to split water electrochemically, producing hydrogen and oxygen which was used to produce sustainable electricity using a fuel cell, providing a new approach to cost-effective generation of energy from water and sunlight. The high performance of N,S-3DPG was attributed to the doping with $\mathrm{N}$ and $\mathrm{S}$, along with the unique $3 \mathrm{D}$ porous architecture.

Huang et al. also synthesized a trifunctional 3D N,S-codoped carbon electrocatalysts (Figure 18). They created a guanine-derived N,S-codoped CNT-graphene hybrid with a hierarchically porous structure and CNT-graphene 3D framework, as a trifunctional HER, OER and ORR electrocatalyst. ${ }^{[406]}$ This new catalyst was prepared using a template-free approach. The formed graphene perfectly distributed uniformly within the OCNTs and the heteroatoms were homogeneously scattered in the entire hybrid. The hierarchical structure provided numerous accessible active sites, improved porosity (surface area of $462 \mathrm{~m}^{2} \mathrm{~g}^{-1}$ for the NSG@CNT-2 sample) and conductivity to facilitate adsorption of intermediates and electron and mass transfer.

A strong ORR activity was evident with a peak at $\sim 0.83 \mathrm{~V}$ (vs RHE) in $0.1 \mathrm{M} \mathrm{KOH}$ in the CV test, and onset potential of $1.03 \mathrm{~V}$ ( $v s \mathrm{RHE}$ ), and diffusion-limited current of $6.9 \mathrm{~mA} \mathrm{~cm}^{-2}$, values even higher than those of $20 \% \mathrm{Pt} / \mathrm{C}$ (onset $1.03 \mathrm{~V}$ vs RHE, diffusion-limited current of $5.9 \mathrm{~mA}$ $\mathrm{cm}^{-2}$ ). In the case of the OER, the onset potential of NSG@CNT-2 was 1.3V. N,S co-doping resulted particularly critical for the OER activity. The HER tests also confirmed NSG@CNT2 as the best catalyst with onset potential of $190 \mathrm{mV}$ and only $350 \mathrm{mV}$ overpotential to achieve $10 \mathrm{~mA} \mathrm{~cm}{ }^{-2}$, much lower than most metal free carbons. Results revealed that both an interconnected porosity and doping are key for high electrocatalytic performance. A favourable pore size distribution of meso- and macropores contributed greatly to a high diffusion-limited current value while the amount of pyridinic and graphitic $\mathrm{N}$ seemed to have a more positive effect on the ORR activity than the total amount of $\mathrm{N}$.

\section{Summary and Perspectives}

In this review paper we have summarised recent state of the art in $3 \mathrm{D}$ carbons synthesis, functionalisation and applications in electrocatalysis. Emphasis was put on the importance of hierarchy and 3D structure but also on the dopants and defects and their role in electrocatalysis. 


\section{WILEY-VCH}

3D structures can significantly enhance the mass transport and provide high surface area for the creation of active sites and a different location of active sites, with the edge sites being the most powerful. Additionally, the presence of hierarchical porosity facilitates the mass transport, i.e. the transport of reactants and products to/from the active sites throughout the structural network, as well as the electron transfer, and improves the mechanical properties too. These aspects contribute to accelerating the reaction kinetics and increased efficiency. Unfortunately, more studies exploring the compromises between the number of active sites, dopants and electronic conductivity, and detailed computational models that can lead to a deeper understanding of the structure-performance relationships are needed.

The processing of self-supporting 3D porous electrodes, especially those that do not need the introduction of binders or additional components, is particularly attractive in electrocatalysis.

Looking forward, advanced manufacturing techniques including graded void structure achievable with robotic spraying and/or templating could lead to significant performance gains in real working electrodes along with continuous efforts in additive manufacturing and 3D printing.

In addition to structural design and control, chemical doping has proven to be instrumental in the improvement of the electrocatalytic performance of metal free carbon materials. In the case of the ORR, it was found that $\mathrm{N}$ doping induced charge redistribution in the carbon structure. This facilitated the chemisorption of $\mathrm{O}_{2}$ and hence the electron transfer for the ORR. The advantage of pyridinic $\mathrm{N}$ sites over other $\mathrm{N}$ environments, particularly graphitic $\mathrm{N}$, has been widely discussed in the literature. After the latest studies that combine theoretical and experimental approaches (particularly where innovative experimental procedures were able to control the exact $\mathrm{N}$ environment in model catalysts), there seems to be a consensus in that graphitic $\mathrm{N}$, as well as hierarchical porosity improve the mass transport characteristics of ORR catalysts is clear, with the best performing materials showing high meso and macroporosity. However, the exact mechanism by which heteroatom doping increases the activity is still under debate in the literature, and some studies have even suggested that the defects generated as a consequence of heteroatom doping are the ones responsible for the enhancement in the electrocatalytic activity of these carbon materials. However, the research of defect - induced electrocatalytic activity still needs further development, and the authors anticipate that this avenue will lead to a better understanding of the mechanisms behind the catalytic activity of carbon materials and will be a key focus of future research in this field. 


\section{WILEY-VCH}

Co-doping with different heteroatoms is an efficient strategy to further enhance the electrocatalytic activity of the 3D porous carbons for the ORR. Co-doping with $\mathrm{S}$ and $\mathrm{N}$ can be an effective route to exceptional ORR performance, particularly in acidic media, provided that the specific active sites can be preferentially formed. DFT calculations revealed that co-doping with $\mathrm{B}$ and $\mathrm{N}$ leads to a modification in the energy bandgap, charge density, and spin density. This promotes the ORR through synergistic electron transfer interactions between the $\mathrm{B}$ and $\mathrm{N}$ dopants and the surrounding carbon atoms. Thus, the effect of the heteroatom doping in 3D carbon electrocatalysts varies depending on the dopant locations within the carbon structure, even if the dopant amounts and dopant elements are the same. Ternary doping is also emerging as a viable route to highly active metal free catalysts, however, much more work is needed to understand the underlying cause of this activity and to gain mechanistic insight to the active sites. Some recent evidence also suggests that five membered carbon ring defects in the graphene structure could be active sites in themselves, opening up the potential for entirely carbon-based electrocatalysts for the ORR.

A very important factor to be considered is the best practice for electrocatalysts testing and reported in Section 5, making sure no trace metals contaminate the electrocatalysts and the Pt counter electrodes are avoided in particular in OER and HER. More attention should be given to the study of the stability of such carbon. Catalysts especially in the case of bifunctionality and several cycles should be performed and the electrochemical testing coupled with in situ detection analytics to monitor gas evolution and make clear structure-function correlations. Care must also be taken in order to perform electrochemical testing correctly, and a standardised protocol would be tremendously useful for the field, though this is difficult given the vast array of different carbon structures in the literature. Of particular importance, however, is the need to use a thin enough layer of catalyst in $\mathrm{R}(\mathrm{R}) \mathrm{DE}$ experiments so as to avoid masking the intermediate peroxide via recombination in the catalyst layer and giving a falsely high value of electron transfer number - something that has been highlighted long ago and is not always adhered to.

In addition, different testing configurations to RDE/RRDE such as gas diffusion layer electrodes/floating electrodes should be explored for conditions closer to a real device and more realistic performance determination.

The progress being made in metal free catalysts for the ORR will lead to the accelerated commercialisation of fuel cells and metal-air batteries via cost reduction and potentially 


\section{WILEY-VCH}

greener-synthetic routes to material synthesis. The outlook is positive for this field, although a standardisation in electrochemical practices would be a key development for researchers at this pivotal time for ORR electrocatalysis research.

As in the case of the ORR, mono - and multi-doping have also proven successful in the design of HER and OER 3D porous carbon electrocatalysts. Here, again, the enhancement in performance has been proposed to be due to a charge induction effect around the heteroatom doped carbon lattice. OER activities surpassing those of traditional metal based electrocatalysis have been demonstrated for $\mathrm{N}$ - doped 3D carbons, although only in alkaline electrolyte. $\mathrm{N}, \mathrm{S}$ and N, P co-doped carbon materials showed enhanced catalytic activities for both OER and HER. Additionally, hybridisation of carbon catalysts with other materials, such as graphitic $\mathrm{C}_{3} \mathrm{~N}_{4}$, has also given excellent electrocatalytic results. It is worth mentioning that in the case of the oxygen and hydrogen evolution processes, the need for a 3D structure is even more stringent, since $\mathrm{O}_{2}$ and $\mathrm{H}_{2}$ bubbles formed during the electrocatalytic process tend to deposit onto the surface of the catalyst, blocking the active sites and preventing further reaction, which in turn increases the mass transfer resistance of the system. A 3D porous structure facilitates the management and removal of the formed bubbles. Oxygen bifunctional electrocatalysts (OER and ORR), overall water splitting electrocatalysts (OER and HER) and multifunctional electrocatalysts (OER, ORR and HER) have attracted increasing interest in the recent years, as they offer the possibility of being applied as metal - air battery electrodes and regenerative fuel cells. However, there are also associated challenges to achieve high electrocatalytic activity for all the processes catalysed in the same electrolyte media.

Doping, and especially multiple heteroatom doping of carbon materials for electrocatalysis applications, is a powerful strategy for the design of carbon -based electrocatalysts with high performance for a variety of reactions, including OER, ORR and HER. Undoubtedly, there have been exciting developments in new innovative synthesis techniques that have led to the creation of multiple 3D porous structures that incorporate multiple heteroatoms. However, we must bear in mind the fact that adding heteroatoms to the carbon structure will usually bring additional synthesis steps that add complexity to the process, and introduce potential for poorly controlled material properties with added complexity. This can make the scaling up of multi - heteroatom - doped systems difficult, even more when a specific engineering of the doping sites and their locations is needed, for example in ensuring that there is a minimum distance between two different heteroatoms in a co-doped structure. Moreover, there is still a lack of clear understanding of the mechanistic processes in these systems, and more work in this area will 


\section{WILEY-VCH}

be most welcome in the near future. A combination of experimental and theoretical studies will be key to unravel the catalytic active centers in these materials, the effect of the $3 \mathrm{D}$ porous network in the overall electrocatalytic activity, and the role of the heteroatoms. The results derived from these combined studies can then be used to guide the rational design of the new 3D porous structures with the desired properties for their application in energy conversion and storage technologies. We need to develop new synthesis and doping strategies to precisely control the atomic location, content and distribution of the catalytic active centers within the carbon structure, and identify the chemical nature of the active centers to gain insightful mechanistic understanding. Additionally, the design of mechanically robust 3D porous structures is also needed for optimised electrocatalytic performance. The combination of experimental and theoretical tools will be key to understand the mechanism and kinetics of the active sites, and will be decisive in the design of the desired carbon electrocatalyst. Machine learning and artificial intelligence could play and increasing role in the guided design of ideal catalytic structures, though a synthetic challenge then remains to be met.

One of the key challenges that carbon electrocatalysts need to overcome in order to be able to compete with their metal - based counterparts has to do with their stability in acidic electrolyte. Most metal -free carbon electrocatalysts suffer significant degradation in acidic media, and show lower catalytic performance than $\mathrm{Pt} / \mathrm{C}$ (ORR) and $\mathrm{IrO}_{2}$ (OER). Some of the 3D carbon materials developed until now and mentioned in this review already exhibit high activity in alkaline conditions, even higher than the noble metal catalysts. However, currently commercial fuel cells and water electrolysers work with a proton conducting polymer electrolyte membrane, Nafion ${ }^{\circledR}$, which is highly acidic. Until research in anionic membranes has been further developed and performances in alkaline media can compare to those of acidic systems, metal free carbons will not be able to be used as electrodes in these systems. It is also crucial that the development of innovative in situ coupled characterisation techniques to understand the electrocatalytic process, and the role and nature of the active sites, defects, dopants and 3D architecture, follows the pace of developments in the materials synthesis.

There is no doubt that research in this field will continue in the next coming years, as there is real potential for carbons to become the catalyst of choice in energy conversion and storage devices. Carbon is a low cost widely available material, easy to tune according to the needs of the application, showing remarkable catalytic performance, in some cases, even as multifunctional electrocatalyst. However, efforts should focus on four main aspects: (1) developing easy to scale synthesis strategies to develop 3D porous carbon structures, which can 


\section{WILEY-VCH}

also provide an easy control over the atomic positions of the active sites and defects; (2) improving carbon stability under acidic conditions; (3) standardising electrochemical testing protocols and accelerated stress tests so that fair comparison of catalysts can be made; (4) designing new in situ characterisation techniques that can lead to a better understanding of the electrocatalytic process and the role of the multiple factors in the activity of the carbon electrocatalysts, all of this combined with powerful computational studies.

\section{Acknowledgements}

A.B.J thanks the EPSRC for the funding of her EPSRC First Grant (EP/P031323/1) MT thanks EPSRC (EP/R021554/2 and EP/S018204/2) for financial support. J.F. thanks the China Scholarship Council (CSC) for partially support this project.

Received: ((will be filled in by the editorial staff))

Revised: ((will be filled in by the editorial staff))

Published online: ((will be filled in by the editorial staff)) 


\section{WILEY-VCH}

Copyright WILEY-VCH Verlag GmbH \& Co. KGaA, 69469 Weinheim, Germany, 2018.

[1] M. S. Burke, L. J. Enman, A. S. Batchellor, S. H. Zou and S. W. Boettcher, Chem. Mater., 2015, 27, 7549.

[2] F. Safizadeh, E. Ghali and G. Houlachi, Int. J. Hydrogen Energy, 2015, 40, 256.

[3] B. Bayatsarmadi, Y. Zheng, A. Vasileff and S. Z. Qiao, Small, 2017, 13, 1700191.

[4] J. J. Duan, S. Chen, M. Jaroniec and S. Z. Qiao, ACS Catal., 2015, 5, 5207.

[5] S. Han, D. Wu, S. Li, F. Zhang and X. Feng, Adv. Mater., 2014, 26, 849.

[6] J. Tang, J. Liu, N. L. Torad, T. Kimura and Y. Yamauchi, Nano Today, 2014, 9, 305.

[7] Z. Yang, J. Ren, Z. Zhang, X. Chen, G. Guan, L. Qiu, Y. Zhang and H. Peng, Chem. Rev., 2015, 115, 5159.

[8] D. He, H. Tang, Z. Kou, M. Pan, X. Sun, J. Zhang and S. Mu, Adv. Mater., 2017, 29, 1601741.

[9] C. Hu and L. Dai, Angew. Chem. Int. Ed., 2016, 55, 11736.

[10] M. Zhou, H. L. Wang and S. Guo, Chem. Soc. Rev., 2016, 45, 1273.

[11] W. Zhang, S. Y. Zhu, R. Luque, S. Han, L. Z. Hu and G. B. Xu, Chem. Soc. Rev., 2016, 45,715 .

[12] Y. Xu, M. Kraft and R. Xu, Chem. Soc. Rev., 2016, 45, 3039.

[13] V. Chabot, D. Higgins, A. P. Yu, X. C. Xiao, Z. W. Chen and J. J. Zhang, Energy Environ. Sci., 2014, 7, 1564.

[14] R. Paul, F. Du, L. Dai, Y. Ding, Z. L. Wang, F. Wei and A. Roy, Adv. Mater., 2019, 31, 1805598.

[15] A. Vasileff, Y. Zheng and S. Z. Qiao, Adv. Energy Mater., 2017, 7, 1700759.

[16] J. Zhang, Z. Zhao, Z. Xia and L. Dai, Nat. Nanotechnol., 2015, 10, 444.

[17] S. Y. Gao, L. Y. Li, K. R. Geng, X. J. Wei and S. X. Zhang, Nano Energy, 2015, 16, 408.

[18] J. Duan, S. Chen, M. Jaroniec and S. Z. Qiao, ACS Nano, 2015, 9, 931.

[19] J. P. Lai, A. Nsabimana, R. Luque and G. B. Xu, Joule, 2018, 2, 76.

[20] H. Nishihara, T. Simura, S. Kobayashi, K. Nomura, R. Berenguer, M. Ito, M. Uchimura, H. Iden, K. Arihara, A. Ohma, Y. Hayasaka and T. Kyotani, Adv. Funct. Mater., 2016, 26, 6418. [21] Y. Zheng, Y. Jiao, Y. Zhu, L. H. Li, Y. Han, Y. Chen, A. Du, M. Jaroniec and S. Z. Qiao, Nat. Commun., 2014, 5, 3783.

[22] Y. Zhao, R. Nakamura, K. Kamiya, S. Nakanishi and K. Hashimoto, Nat. Commun., 2013, 4, 2390.

[23] B. Kumar, M. Asadi, D. Pisasale, S. Sinha-Ray, B. A. Rosen, R. Haasch, J. Abiade, A. L. Yarin and A. Salehi-Khojin, Nat. Commun., 2013, 4, 2819.

[24] T. P. Fellinger, F. Hasche, P. Strasser and M. Antonietti, J. Am. Chem. Soc., 2012, 134, 4072.

[25] J. Shui, M. Wang, F. Du and L. Dai, Sci. Adv., 2015, 1, e1400129.

[26] Y. Xue, J. Liu, H. Chen, R. Wang, D. Li, J. Qu and L. Dai, Angew. Chem. Int. Ed., 2012, $51,12124$.

[27] Y. F. Jiang, L. J. Yang, T. Sun, J. Zhao, Z. Y. Lyu, O. Zhuo, X. Z. Wang, Q. Wu, J. Ma and Z. Hu, ACS Catal., 2015, 5, 6707.

[28] D. H. Guo, R. Shibuya, C. Akiba, S. Saji, T. Kondo and J. Nakamura, Science, 2016, 351, 361.

[29] K. Gong, F. Du, Z. Xia, M. Durstock and L. Dai, Science, 2009, 323, 760.

[30] S. Wang, E. Iyyamperumal, A. Roy, Y. Xue, D. Yu and L. Dai, Angew. Chem. Int. Ed., 2011, 50, 11756.

[31] L. Qu, Y. Liu, J. B. Baek and L. Dai, ACS Nano, 2010, 4, 1321.

[32] L. M. Dai, Current Opinion in Electrochemistry, 2017, 4, 18. 


\section{WILEY-VCH}

[33] Y. Jia, J. Chen and X. D. Yao, Mater. Chem. Front., 2018, 2, 1250.

[34] Y. Jia, L. Z. Zhang, L. Z. Zhuang, H. L. Liu, X. C. Yan, X. Wangl, J. D. Liu, J. C. Wang, Y. R. Zheng, Z. H. Xiao, E. Taran, J. Chen, D. J. Yang, Z. H. Zhu, S. Y. Wang, L. M. Dai and X. D. Yao, Nat. Catal., 2019, 2, 688.

[35] Z. J. Fan, Y. Liu, J. Yan, G. Q. Ning, Q. Wang, T. Wei, L. J. Zhi and F. Wei, Adv. Energy Mater., 2012, 2, 419.

[36] K. Fu, Y. Yao, J. Dai and L. Hu, Adv. Mater., 2017, 29, 1603486.

[37] Y. Ito, Y. Tanabe, H. J. Qiu, K. Sugawara, S. Heguri, N. H. Tu, K. K. Huynh, T. Fujita, T.

Takahashi, K. Tanigaki and M. Chen, Angew. Chem. Int. Ed., 2014, 53, 4822.

[38] Y. Q. Wang, L. Tao, Z. H. Xiao, R. Chen, Z. Q. Jiang and S. Y. Wang, Adv. Funct. Mater., 2018, 28, 1705356.

[39] W. Stöber, A. Fink and E. Bohn, J. Colloid Interf. Sci, 1968, 26, 62.

[40] C. T. Kresge, M. E. Leonowicz, W. J. Roth, J. C. Vartuli and J. S. Beck, Nature, 1992, $359,710$.

[41] D. Guo, H. Wei, X. Chen, M. Liu, F. Ding, Z. Yang, Y. Yang, S. Wang, K. Yang and S. Huang, J. Mater. Chem. A, 2017, 5, 18193.

[42] G. A. Ferrero, K. Preuss, A. Marinovic, A. B. Jorge, N. Mansor, D. J. Brett, A. B. Fuertes, M. Sevilla and M. M. Titirici, ACS Nano, 2016, 10, 5922.

[43] H. Chen, J. Wydra, X. Zhang, P. S. Lee, Z. Wang, W. Fan and M. Tsapatsis, J. Am. Chem. Soc., 2011, 133, 12390.

[44] F. Liu, T. Willhammar, L. Wang, L. Zhu, Q. Sun, X. Meng, W. Carrillo-Cabrera, X. Zou and F. S. Xiao, J. Am. Chem. Soc., 2012, 134, 4557.

[45] W. Yang, T. P. Fellinger and M. Antonietti, J. Am. Chem. Soc., 2011, 133, 206.

[46] H. W. Liang, X. Zhuang, S. Bruller, X. Feng and K. Mullen, Nat. Commun., 2014, 5, 4973.

[47] S. Lee, M. Choun, Y. Ye, J. Lee, Y. Mun, E. Kang, J. Hwang, Y. H. Lee, C. H. Shin, S. H.

Moon, S. K. Kim, E. Lee and J. Lee, Angew. Chem. Int. Ed., 2015, 54, 9230.

[48] P. Nugent, Y. Belmabkhout, S. D. Burd, A. J. Cairns, R. Luebke, K. Forrest, T. Pham, S. Ma, B. Space, L. Wojtas, M. Eddaoudi and M. J. Zaworotko, Nature, 2013, 495, 80.

[49] J. T. Zhang, H. L. Li, P. Z. Guo, H. Y. Ma and X. S. Zhao, J. Mater. Chem. A, 2016, 4, 8497.

[50] S. Yang, X. Feng, X. Wang and K. Mullen, Angew. Chem. Int. Ed., 2011, 50, 5339.

[51] D. Yu, Q. Zhang and L. Dai, J. Am. Chem. Soc., 2010, 132, 15127.

[52] Y. Jiao, Y. Zheng, M. Jaroniec and S. Z. Qiao, J. Am. Chem. Soc., 2014, 136, 4394.

[53] Y. Xue, Y. Ding, J. Niu, Z. Xia, A. Roy, H. Chen, J. Qu, Z. L. Wang and L. Dai, Sci. Adv., 2015, 1 , e1400198.

[54] H. Wang, J. Jia, P. Song, Q. Wang, D. Li, S. Min, C. Qian, L. Wang, Y. F. Li, C. Ma, T. Wu, J. Yuan, M. Antonietti and G. A. Ozin, Angew. Chem. Int. Ed., 2017, 56, 7847.

[55] S. H. Lee, H. W. Kim, J. O. Hwang, W. J. Lee, J. Kwon, C. W. Bielawski, R. S. Ruoff and S. O. Kim, Angew. Chem. Int. Ed., 2010, 49, 10084.

[56] C. S. Cundy and P. A. Cox, Chem. Rev., 2003, 103, 663.

[57] K. Kim, T. Lee, Y. Kwon, Y. Seo, J. Song, J. K. Park, H. Lee, J. Y. Park, H. Ihee, S. J. Cho and R. Ryoo, Nature, 2016, 535, 131.

[58] E. Braun, Y. Lee, S. M. Moosavi, S. Barthel, R. Mercado, I. A. Baburin, D. M. Proserpio and B. Smit, Proc. Natl. Acad. Sci. U. S. A., 2018, 115, E8116.

[59] C. P. Han, L. Xu, H. F. Li, R. Y. Shi, T. F. Zhang, J. Q. Li, C. P. Wong, F. Y. Kang, Z. Q. Lin and B. H. Li, Carbon, 2018, 140, 296.

[60] Z. Chen, C. Xu, C. Ma, W. Ren and H. M. Cheng, Adv. Mater., 2013, 25, 1296.

[61] X. Dong, J. Chen, Y. Ma, J. Wang, M. B. Chan-Park, X. Liu, L. Wang, W. Huang and P. Chen, Chem. Commun., 2012, 48, 10660.

[62] J. Bong, T. Lim, K. Seo, C. A. Kwon, J. H. Park, S. K. Kwak and S. Ju, Sci. Rep., 2015, 5, 14321. 


\section{WILEY-VCH}

[63] C. G. Hu and L. M. Dai, Adv. Mater., 2017, 29, 1604942.

[64] S. Zhu, K. Xu, S. M. Sui, J. J. Li, L. Y. Ma, C. N. He, E. Z. Liu, F. He, C. S. Shi, L. Miao, J. J. Jiang and N. Q. Zhao, J. Mater. Chem. A, 2017, 5, 19175.

[65] T. Tang, T. Zhang, W. Li, X. Huang, X. Wang, H. Qiu and Y. Hou, Nanoscale, 2019, 11, 7440.

[66] J. Yu and J. So, Chem. Phys. Lett., 2019, 716, 237.

[67] G. X. Xin, M. M. Wang, W. H. Zhang, J. L. Song and B. W. Zhang, Electrochim. Acta, 2018, 291, 168.

[68] S. Zhu, J. Li, L. Ma, L. Guo, Q. Li, C. He, E. Liu, F. He, C. Shi and N. Zhao, ACS Appl. Mater. Interfaces, 2016, 8, 11720.

[69] L. Pan, Y. X. Wang, H. Hu, X. X. Li, J. L. Liu, L. Guan, W. Tian, X. B. Wang, Y. P. Li and M. B. Wu, Carbon, 2018, 134, 345.

[70] Y. Mun, M. J. Kim, S.-A. Park, E. Lee, Y. Ye, S. Lee, Y.-T. Kim, S. Kim, O.-H. Kim and Y.-H. Cho, Appl. Catal. B Environ., 2018, 222, 191.

[71] L. Borchardt, Q. L. Zhu, M. E. Casco, R. Berger, X. D. Zhuang, S. Kaskel, X. L. Feng and Q. Xu, Mater. Today, 2017, 20, 592.

[72] S. Q. Ma, G. A. Goenaga, A. V. Call and D. J. Liu, Chem. Eur. J., 2011, 17, 2063.

[73] A. J. Amali, J.-K. Sun and Q. Xu, Chem. Commun., 2014, 50, 1519.

[74] W. Kukulka, K. Cendrowski and E. Mijowska, Electrochim. Acta, 2019, 307, 582.

[75] L. L. Chai, L. J. Zhang, X. Wang, L. Q. Xu, C. Han, T. T. Li, Y. Hu, J. J. Qian and S. M. Huang, Carbon, 2019, 146, 248.

[76] H. Jin, H. Zhou, D. He, Z. Wang, Q. Wu, Q. Liang, S. Liu and S. Mu, Appl. Catal. B Environ., 2019, 250, 143.

[77] Q. Li, P. Xu, W. Gao, S. Ma, G. Zhang, R. Cao, J. Cho, H. L. Wang and G. Wu, Adv. Mater., 2014, 26, 1378.

[78] R. Wang, X. Y. Dong, J. Du, J. Y. Zhao and S. Q. Zang, Adv. Mater., 2018, 30, 1703711.

[79] J. W. Colson and W. R. Dichtel, Nat. Chem., 2013, 5, 453.

[80] X. Feng, X. Ding and D. Jiang, Chem. Soc. Rev., 2012, 41, 6010.

[81] D. Chen, H. Zhou, H. Li, J. Chen, S. Li and F. Zheng, Sci. Rep., 2017, 7, 14985.

[82] D. I. Abouelamaiem, G. J. He, I. Parkin, T. P. Neville, A. B. Jorge, S. Ji, R. F. Wang, M. M. Titirici, P. R. Shearing and D. J. L. Brett, Sustainable Energy \& Fuels, 2018, 2, 772.

[83] S. F. Zhou, L. H. Zhou, Y. P. Zhang, J. Sun, J. L. Wen and Y. Yuan, J. Mater. Chem. A, 2019, 7, 4217.

[84] Z. Y. Wu, C. Li, H. W. Liang, J. F. Chen and S. H. Yu, Angew. Chem. Int. Ed., 2013, 52, 2925.

[85] S. Herou, P. Schlee, A. B. Jorge and M. Titirici, Current Opinion in Green and Sustainable Chemistry, 2018, 9, 18.

[86] K. Xiao, L. X. Ding, G. X. Liu, H. B. Chen, S. Q. Wang and H. H. Wang, Adv. Mater., 2016, 28, 5997.

[87] J. Luo, H. D. Jang, T. Sun, L. Xiao, Z. He, A. P. Katsoulidis, M. G. Kanatzidis, J. M. Gibson and J. Huang, ACS Nano, 2011, 5, 8943.

[88] S. Kavadiya, R. Raliya, M. Schrock and P. Biswas, J. Nanopart. Res., 2017, 19, 43.

[89] Y. S. Zhang and A. Khademhosseini, Science, 2017, 356, eaaf3627.

[90] X. Liu and L. M. Dai, Nat. Rev. Mater., 2016, 1, 16064.

[91] D. C. Marcano, D. V. Kosynkin, J. M. Berlin, A. Sinitskii, Z. Sun, A. Slesarev, L. B. Alemany, W. Lu and J. M. Tour, ACS Nano, 2010, 4, 4806.

[92] M. K. Shin, B. Lee, S. H. Kim, J. A. Lee, G. M. Spinks, S. Gambhir, G. G. Wallace, M. E. Kozlov, R. H. Baughman and S. J. Kim, Nat. Commun., 2012, 3, 650.

[93] J. Wang, J. Tang, B. Ding, V. Malgras, Z. Chang, X. Hao, Y. Wang, H. Dou, X. Zhang and Y. Yamauchi, Nat. Commun., 2017, 8, 15717. 


\section{WILEY-VCH}

[94] D. A. Dikin, S. Stankovich, E. J. Zimney, R. D. Piner, G. H. Dommett, G. Evmenenko, S. T. Nguyen and R. S. Ruoff, Nature, 2007, 448, 457.

[95] X. Chen, M. Qiu, H. Ding, K. Fu and Y. Fan, Nanoscale, 2016, 8, 5696.

[96] J. Q. Huang, Z. L. Xu, S. Abouali, M. A. Garakani and J. K. Kim, Carbon, 2016, 99, 624.

[97] J. H. Li, S. F. Zhao, G. P. Zhang, Y. J. Gao, L. B. Deng, R. Sun and C. P. Wong, J. Mater. Chem. A, 2015, 3, 15482 .

[98] J. Anjali, V. K. Jose and J. M. Lee, J. Mater. Chem. A, 2019, 7, 15491.

[99] Z. Shen, H. Ye, C. Zhou, M. Kroger and Y. Li, Nanotechnology, 2018, 29, 104001.

[100] Q. Q. Zhang, Y. Wang, B. Q. Zhang, K. R. Zhao, P. G. He and B. Y. Huang, Carbon, 2018, 127, 449.

[101] M. Qiao, C. Tang, G. He, K. Qiu, R. Binions, I. P. Parkin, Q. Zhang, Z. Guo and M. M. Titirici, J. Mater. Chem. A, 2016, 4, 12658.

[102] M. Qiao, S. S. Meysami, G. A. Ferrero, F. Xie, H. Meng, N. Grobert and M. M. Titirici, Adv. Funct. Mater., 2018, 28, 1707284.

[103] K. Preuss, L. C. Tanase, C. M. Teodorescu, I. Abrahams and M. M. Titirici, J. Mater. Chem. A, 2017, 5, 16336.

[104] M. S. Ahmed and Y. B. Kim, Sci. Rep., 2017, 7, 43279.

[105] Z. H. Li, Q. H. Yang, K. Fan, W. F. Xie, W. Qiao, M. F. Shao and M. Wei, J. Mater. Chem. A, 2018, 6, 21287.

[106] A. A. Koos, F. Dillon, E. A. Obraztsova, A. Crossley and N. Grobert, Carbon, 2010, 48, 3033.

[107] A. Hussain, Y. Liao, Q. Zhang, E. X. Ding, P. Laiho, S. Ahmad, N. Wei, Y. Tian, H. Jiang and E. I. Kauppinen, Nanoscale, 2018, 10, 9752.

[108] Z. Y. Yang, Y. H. Wang, Z. Dai, Z. W. Lu, X. Y. Gu, H. Zhao, G. Z. Sun, W. Lan, Z. X. Zhang, X. J. Pan, J. Y. Zhou and E. Q. Xie, Carbon, 2019, 146, 610.

[109] D. Yu, K. Goh, H. Wang, L. Wei, W. Jiang, Q. Zhang, L. Dai and Y. Chen, Nat. Nanotechnol., 2014, 9, 555.

[110] F. Du, D. S. Yu, L. M. Dai, S. Ganguli, V. Varshney and A. K. Roy, Chem. Mater., 2011, $23,4810$.

[111] G. K. Dimitrakakis, E. Tylianakis and G. E. Froudakis, Nano Lett., 2008, 8, 3166.

[112] C. Tang, Q. Zhang, M.-Q. Zhao, G.-L. Tian and F. Wei, Nano Energy, 2014, 7, 161.

[113] S. Chen, T. Huang, H. Zuo, S. H. Qian, Y. F. Guo, L. J. Sun, D. Lei, Q. L. Wu, B. Zhu, C. L. He, X. M. Mo, E. Jeffries, H. Yu and Z. W. You, Adv. Funct. Mater., 2018, 28, 1805108. [114] S. Chandrasekaran, B. Yao, T. Y. Liu, W. Xiao, Y. Song, F. Qian, C. Zhu, E. B. Duoss, C. M. Spadaccini, Y. Li and M. A. Worsley, Mater. Horizons, 2018, 5, 1166.

[115] W. Zhu, H. Fu, Z. F. Xu, R. Z. Liu, P. Jiang, X. Y. Shao, Y. S. Shi and C. Z. Yan, J. Eur. Ceram. Soc., 2018, 38, 4604.

[116] K. Fu, Y. Wang, C. Yan, Y. Yao, Y. Chen, J. Dai, S. Lacey, Y. Wang, J. Wan, T. Li, Z. Wang, Y. Xu and L. Hu, Adv. Mater., 2016, 28, 2587.

[117] Z. Lyu, G. J. Lim, R. Guo, Z. Kou, T. Wang, C. Guan, J. Ding, W. Chen and J. Wang, Adv. Funct. Mater., 2019, 29, 1806658.

[118] Y. Xue, J. Liu, H. Chen, R. Wang, D. Li, J. Qu and L. Dai, Angew. Chem. Int. Ed., 2012, $51,12124$.

[119] A. J. Capel, R. P. Rimington, M. P. Lewis and S. D. R. Christie, Nat. Rev. Chem., 2018, $2,422$.

[120] B. E. Kelly, I. Bhattacharya, H. Heidari, M. Shusteff, C. M. Spadaccini and H. K. Taylor, Science, 2019, 363, 1075.

[121] C. Zhu, T. Y. Han, E. B. Duoss, A. M. Golobic, J. D. Kuntz, C. M. Spadaccini and M. A. Worsley, Nat. Commun., 2015, 6, 6962.

[122] D. X. Luong, A. K. Subramanian, G. A. L. Silva, J. Yoon, S. Cofer, K. Yang, P. S. Owuor, T. Wang, Z. Wang, J. Lou, P. M. Ajayan and J. M. Tour, Adv. Mater., 2018, 30, e1707416. 


\section{WILEY-VCH}

[123] Q. Zhang, F. Zhang, S. P. Medarametla, H. Li, C. Zhou and D. Lin, Small, 2016, 12, 1702. [124] Y. X. Chen, Z. A. Zhang, Y. Q. Lai, X. D. Shi, J. M. Li, X. B. Chen, K. Zhang and J. Li, J. Power Sources, 2017, 359, 529.

[125] P. Parandoush, C. Zhou and D. Lin, Adv. Eng. Mater., 2019, 21, 1800622.

[126] S. Lawes, A. Riese, Q. Sun, N. C. Cheng and X. L. Sun, Carbon, 2015, 92, 150.

[127] M. Wei, F. Zhang, W. Wang, P. Alexandridis, C. Zhou and G. Wu, J. Power Sources, 2017, 354, 134.

[128] Y. Yang, X. Li, X. Zheng, Z. Chen, Q. Zhou and Y. Chen, Adv. Mater., 2018, 30, 1704912. [129] S. D. Lacey, D. J. Kirsch, Y. Li, J. T. Morgenstern, B. C. Zarket, Y. Yao, J. Dai, L. Q. Garcia, B. Liu, T. Gao, S. Xu, S. R. Raghavan, J. W. Connell, Y. Lin and L. Hu, Adv. Mater., 2018, 30, e1705651.

[130] C. Yang, Q. Cao, P. Puthongkham, S. T. Lee, M. Ganesana, N. V. Lavrik and B. J. Venton, Angew. Chem. Int. Ed., 2018, 57, 14255.

[131] Y. Liu, J. Ma, T. Lu and L. Pan, Sci. Rep., 2016, 6, 32784.

[132] P. Schlee, S. Herou, R. Jervis, P. R. Shearing, D. J. L. Brett, D. Baker, O. Hosseinaei, P. Tomani, M. M. Murshed, Y. Li, M. J. Mostazo-Lopez, D. Cazorla-Amoros, A. B. Jorge Sobrido and M. M. Titirici, Chem. Sci., 2019, 10, 2980.

[133] Y. P. Zhu, Y. Jing, A. Vasileff, T. Heine and S. Z. Qiao, Adv. Energy Mater., 2017, 7, 1602928.

[134] P. Yan, J. Liu, S. D. Yuan, Y. J. Liu, W. L. Cen and Y. Q. Chen, Appl. Surf. Sci., 2018, 445, 398.

[135] X. K. Kong, C. L. Chen and Q. W. Chen, Chem. Soc. Rev., 2014, 43, 2841.

[136] J. Mahmood, E. K. Lee, M. Jung, D. Shin, I. Y. Jeon, S. M. Jung, H. J. Choi, J. M. Seo, S. Y. Bae, S. D. Sohn, N. Park, J. H. Oh, H. J. Shin and J. B. Baek, Nat. Commun., 2015, 6, 6486.

[137] Z. H. Zhao, M. T. Li, L. P. Zhang, L. M. Dai and Z. H. Xia, Adv. Mater., 2015, 27, 6834.

[138] S. Kundu, T. C. Nagaiah, W. Xia, Y. M. Wang, S. Van Dommele, J. H. Bitter, M. Santa,

G. Grundmeier, M. Bron, W. Schuhmann and M. Muhler, J. Phys. Chem. C, 2009, 113, 14302.

[139] J. Ortiz-Medina, Z. Wang, R. Cruz-Silva, A. Morelos-Gomez, F. Wang, X. Yao, M.

Terrones and M. Endo, Adv. Mater., 2019, 31, e1805717.

[140] R. Liu, D. Wu, X. Feng and K. Mullen, Angew. Chem. Int. Ed., 2010, 49, 2565.

[141] Z. Y. Lin, G. H. Waller, Y. Liu, M. L. Liu and C. P. Wong, Nano Energy, 2013, 2, 241.

[142] L. Panchakarla, K. Subrahmanyam, S. Saha, A. Govindaraj, H. Krishnamurthy, U. Waghmare and C. Rao, Adv. Mater., 2009, 21, 4726.

[143] P. A. Denis, R. Faccio and A. W. Mombru, ChemPhysChem, 2009, 10, 715.

[144] X. Zou, L. Wang and B. I. Yakobson, Nanoscale, 2018, 10, 1129.

[145] E. Gracia-Espino, J. Phys. Chem. C, 2016, 120, 27849.

[146] I. Y. Jeon, S. Zhang, L. Zhang, H. J. Choi, J. M. Seo, Z. Xia, L. Dai and J. B. Baek, Adv. Mater., 2013, 25, 6138.

[147] D. Deng, L. Yu, X. Pan, S. Wang, X. Chen, P. Hu, L. Sun and X. Bao, Chem. Commun., 2011, 47, 10016.

[148] W. Wang, L. Shang, G. Chang, C. Yan, R. Shi, Y. Zhao, G. I. N. Waterhouse, D. Yang and T. Zhang, Adv. Mater., 2019, 31, e1808276.

[149] J. L. Tang, Y. S. Liu, G. Q. Lv, C. T. Yang and G. C. Yang, Carbon, 2019, 145, 411.

[150] X. Yan, Y. Jia and X. Yao, Chem. Soc. Rev., 2018, 47, 7628.

[151] Y. Jia, L. Z. Zhang, A. J. Du, G. P. Gao, J. Chen, X. C. Yan, C. L. Brown and X. D. Yao, Adv. Mater., 2016, 28, 9532.

[152] L. Zhang, Q. Xu, J. Niu and Z. Xia, Phys. Chem. Chem. Phys., 2015, 17, 16733.

[153] K. Mamtani and U. S. Ozkan, Catal. Lett., 2015, 145, 436.

[154] H. Jiang, J. X. Gu, X. S. Zheng, M. Liu, X. Q. Qiu, L. B. Wang, W. Z. Li, Z. F. Chen, X. B. Ji and J. Li, Energy Environ. Sci., 2019, 12, 322. 


\section{WILEY-VCH}

[155] R. G. Ma, G. X. Lin, Y. Zhou, Q. Liu, T. Zhang, G. C. Shan, M. H. Yang and J. C. Wang, Npj Comput. Mater., 2019, 5, 78.

[156] T. Li, D. L. Chen, L. L. Gu, S. L. Chen, C. Li, J. X. Liao, Y. M. Zhou, Y. J. Xu, C. H. Sun, Z. Y. Yang and H. M. Yang, Ceram. Int., 2019, 45, 8354.

[157] S. S. Kocha, K. Shinozaki, J. W. Zack, D. J. Myers, N. N. Kariuki, T. Nowicki, V. Stamenkovic, Y. J. Kang, D. G. Li and D. Papageorgopoulos, Electrocatalysis, 2017, 8, 366.

[158] C. Campos-Roldán, R. González-Huerta and N. Alonso-Vante, J. Electrochem. Soc., 2018, 165, J3001.

[159] R. Jervis, N. Mansor, A. J. Sobrido, S. Jones, C. Gibbs, T. P. Neville, J. Millichamp, P. R. Shearing and D. J. L. Brett, J. Electrochem. Soc., 2017, 164, F1551.

[160] A. R. Zeradjanin, ChemSusChem, 2018, 11, 1278.

[161] U. I. Kramm, R. Marschall and M. Rose, ChemCatChem, 2019, 11, 2563.

[162] D. Li, H. Lv, Y. Kang, N. M. Markovic and V. R. Stamenkovic, Annu Rev Chem Biomol Eng, 2016, 7, 509.

[163] Y. Li and J. Lu, ACS Energy Lett., 2017, 2, 1370.

[164] A. Bonakdarpour, M. Lefevre, R. Yang, F. Jaouen, T. Dahn, J.-P. Dodelet and J. Dahn, Electrochem. Solid-State Lett., 2008, 11, B105.

[165] J. Wu, R. Z. Yang and W. N. Yan, Int. J. Hydrogen Energy, 2019, 44, 12941.

[166] W. Wang, J. Luo and S. L. Chen, Chem. Commun., 2017, 53, 11556.

[167] S. Klaus, Y. Cai, M. W. Louie, L. Trotochaud and A. T. Bell, J. Phys. Chem. C, 2015, $119,7243$.

[168] R. Ye, J. Dong, L. Wang, R. Mendoza-Cruz, Y. Li, P. F. An, M. J. Yacaman, B. I. Yakobson, D. Chen and J. M. Tour, Carbon N Y, 2018, 132, 623.

[169] I. Spanos, M. F. Tesch, M. Q. Yu, H. Tuysuz, J. Zhang, X. L. Feng, K. Mullen, R. Schlogl and A. K. Mechler, ACS Catal., 2019, 9, 8165.

[170] L. Zhao, X. L. Sui, J. Z. Li, J. J. Zhang, L. M. Zhang, G. S. Huang and Z. B. Wang, Appl. Catal. B Environ., 2018, 231, 224.

[171] I. M. Patil, V. Reddy, M. Lokanathan and B. Kakade, Appl. Surf. Sci., 2018, 449, 697.

[172] J. Ma, Y. Yu, C. L. Chen, D. J. Xiao, K. Li, J. Ma, Y. Liao and X. Zuo, Chemistryselect, 2018, 3, 9013.

[173] Y. Wang, X. Jin, Y. Pan, J. M. Li, N. N. Guo and R. W. Wang, Chemnanomat, 2018, 4, 954.

[174] J. H. Tong, W. Y. Li, J. P. Ma, W. H. Wang, L. L. Bo, Z. Q. Lei and A. Mahboob, ACS Appl. Energy Mater., 2018, 1, 5746.

[175] Y. J. Zhou, Y. Sun, H. B. Wang, C. Zhu, J. Gao, D. Wu, H. Huang, Y. Liu and Z. H. Kang, Inorg. Chem. Front., 2018, 5, 2985.

[176] Y. F. Li, Y. Z. Liu, S. Chen, P. F. Wang, S. X. Yuan, X. M. Li, H. Song and C. M. Chen, Mater. Today Energy, 2018, 10, 388.

[177] T. L. Gong, R. Y. Qi, X. D. Liu, H. Li and Y. M. Zhang, Nano-Micro Letters, 2019, 11, 9 .

[178] M. Florent, R. Wallace and T. J. Bandosz, ChemCatChem, 2019, 11, 851.

[179] Y. Li, H. J. Wen, J. Yang, Y. Z. Zhou and X. N. Cheng, Carbon, 2019, 142, 1.

[180] Y. L. Lv, L. Yang and D. P. Cao, ChemElectroChem, 2019, 6, 741.

[181] M. L. Zhang, H. C. Tao, Y. C. Liu, C. Yan, S. Hong, J. Masa, A. W. Robertson, S. Z. Liu, J. S. Qiu and Z. Y. Sun, ACS Sustainable Chem. Eng., 2019, 7, 3434.

[182] H. Han, Y. Noh, Y. Kim, W. S. Jung, S. Park and W. B. Kim, Nanoscale, 2019, 11, 2423.

[183] X. Ao, X. Y. Xue, Z. X. Yang, Y. Yang and C. D. Wang, Mater. Today Energy, 2019, 12,62 .

[184] J. H. Tang, Y. J. Wang, W. Q. Zhao, R. J. X. Zeng, T. Liu and S. G. Zhou, J. Electroanal. Chem., 2019, 847, 113230.

[185] A. Kongkanand and M. F. Mathias, J. Phys. Chem. Lett., 2016, 7, 1127. 


\section{WILEY-VCH}

[186] S. Yi, H. Jiang, X. Bao, S. Zou, J. Liao and Z. Zhang, J. Electroanal. Chem., 2019, 848, 113279.

[187] R. Borup, J. Meyers, B. Pivovar, Y. S. Kim, R. Mukundan, N. Garland, D. Myers, M. Wilson, F. Garzon, D. Wood, P. Zelenay, K. More, K. Stroh, T. Zawodzinski, J. Boncella, J. E. McGrath, M. Inaba, K. Miyatake, M. Hori, K. Ota, Z. Ogumi, S. Miyata, A. Nishikata, Z. Siroma, Y. Uchimoto, K. Yasuda, K. Kimijima and N. Iwashita, Chem. Rev., 2007, 107, 3904. [188] W. L. Gu, L. Y. Hu, J. Li and E. K. Wang, Electroanal., 2018, 30, 1217.

[189] Y. Shao, J. P. Dodelet, G. Wu and P. Zelenay, Adv. Mater., 2019, 31, e1807615.

[190] D. B. Xiong, X. F. Li, L. L. Fan and Z. M. Bai, Catalysts, 2018, 8, 301.

[191] Y. Shao, Z. Jiang, Q. Zhang and J. Guan, ChemSusChem, 2019, 12, 2133.

[192] N. Ramaswamy and S. Mukerjee, Advances in Physical Chemistry, 2012, 2012, 2012.

[193] B. Blizanac, P. Ross and N. Markovic, Electrochim. Acta, 2007, 52, 2264.

[194] Y. Wu, S. Nagata and Y. Nabae, Electrochim. Acta, 2019, 319, 382.

[195] Z. Shi, J. J. Zhang, Z. S. Liu, H. J. Wang and D. P. Wilkinson, Electrochim. Acta, 2006, $51,1905$.

[196] S. Wang, D. Yu and L. Dai, J. Am. Chem. Soc., 2011, 133, 5182.

[197] S. K. Singh, K. Takeyasu and J. Nakamura, Adv. Mater., 2019, 31, e1804297.

[198] H. B. Yang, J. Miao, S. F. Hung, J. Chen, H. B. Tao, X. Wang, L. Zhang, R. Chen, J. Gao, H. M. Chen, L. Dai and B. Liu, Sci. Adv., 2016, 2, e1501122.

[199] H. Niwa, K. Horiba, Y. Harada, M. Oshima, T. Ikeda, K. Terakura, J. Ozaki and S. Miyata, J. Power Sources, 2009, 187, 93.

[200] J. J. Wu, L. L. Ma, R. M. Yadav, Y. C. Yang, X. Zhang, R. Vajtai, J. Lou and P. M. Ajayan, ACS Appl. Mater. Interfaces, 2015, 7, 14763.

[201] K. R. Lee, K. U. Lee, J. W. Lee, B. T. Ahn and S. I. Woo, Electrochem. Commun., 2010, $12,1052$.

[202] H. Miao, S. H. Li, Z. H. Wang, S. S. Sun, M. Kuang, Z. P. Liu and J. L. Yuan, Int. J. Hydrogen Energy, 2017, 42, 28298.

[203] Z. Q. Luo, S. H. Lim, Z. Q. Tian, J. Z. Shang, L. F. Lai, B. MacDonald, C. Fu, Z. X. Shen, T. Yu and J. Y. Lin, J. Mater. Chem., 2011, 21, 8038.

[204] J. Sun, L. Wang, R. Song and S. Yanga, Nanotechnology, 2016, 27, 055404.

[205] T. Xing, Y. Zheng, L. H. Li, B. C. Cowie, D. Gunzelmann, S. Z. Qiao, S. Huang and Y. Chen, ACS Nano, 2014, 8, 6856.

[206] T. Wang, Z. X. Chen, Y. G. Chen, L. J. Yang, X. D. Yang, J. Y. Ye, H. P. Xia, Z. Y. Zhou and S. G. Sun, ACS Energy Lett., 2018, 3, 986.

[207] T. Kondo, S. Casolo, T. Suzuki, T. Shikano, M. Sakurai, Y. Harada, M. Saito, M. Oshima, M. I. Trioni, G. F. Tantardini and J. Nakamura, Phys. Rev. B, 2012, 86, 035436.

[208] R. Shibuya, T. Kondo and J. Nakamura, ChemCatChem, 2018, 10, 2019.

[209] L. P. Zhang and Z. H. Xia, J. Phys. Chem. C, 2011, 115, 11170.

[210] X. M. Zhang, Z. X. Xia, H. Q. Li, S. S. Yu, S. L. Wang and G. Q. Sun, RSC Adv., 2019, 9, 7086.

[211] Y. Zhang, Y. Zhou, Z. H. Wang, S. L. Zhao, C. H. Tan and J. S. Chen, Int. J. Electrochem. Sci., 2019, 14, 3024.

[212] P. P. Chen, J. B. Zang, S. Y. Zhou, S. P. Jia, P. F. Tian, H. X. Cai, H. W. Gao and Y. H. Wang, Carbon, 2019, 146, 70.

[213] A. Chakraborty, B. Bera, D. Priyadarshani, P. Leuaa, D. Choudhury and M. Neergat, RSC Adv., 2019, 9, 466.

[214] B. H. Zhang, C. P. Wang, D. Liu, Y. J. Liu, X. L. Yu and L. Wang, ACS Sustainable Chem. Eng., 2018, 6, 13807.

[215] L. Mu, R. W. Wang and C. Tang, Biomass Conversion and Biorefinery, 2019, 9, 401.

[216] X. G. Li, Y. L. Zhao, Y. J. Yang and S. Y. Gao, Nano Energy, 2019, 62, 628. 


\section{WILEY-VCH}

[217] X. Y. Tian, M. H. Zhou, C. L. Tan, M. Li, L. Liang, K. R. Li and P. Su, Chem. Eng. J., 2018, 348, 775 .

[218] B. B. Xie, Y. Zhang and R. J. Zhang, Materials Science and Engineering B-Advanced Functional Solid-State Materials, 2019, 242, 1.

[219] M. Eckardt, K. Sakaushi, A. Lyalin, M. Wassner, N. Husing, T. Taketsugu and R. J. Behm, Electrochim. Acta, 2019, 299, 736.

[220] M. Qiao, G. A. Ferrero, L. F. Velasco, W. V. Hor, Y. Yang, H. Luo, P. Lodewyckx, A. B. Fuertes, M. Sevilla and M. M. Titirici, ACS Appl. Mater. Interfaces, 2019, 11, 11298.

[221] M. Hassan, D. D. Wu, X. D. Song, W. W. Qiu, Q. Mao, S. Z. Ren and C. Hao, J. Electroanal. Chem., 2018, 829, 157.

[222] A. Liu, M. Ma, X. Zhang, J. Ming, L. Jiang, Y. Li, Y. Zhang and S. Liu, J. Electroanal. Chem., 2018, 824, 60.

[223] Q. Shi, Y. Ma, L. Qin, B. Tang, W. Y. Yang and Q. Liu, ChemElectroChem, 2019, 6, 2924.

[224] Z. D. Lei, X. Long, M. Yang, D. G. Yang, H. B. Chen and H. M. Li, ChemElectroChem, 2019, 6, 848 .

[225] R. Jinnouchi, T. Hatanaka, Y. Morimoto and M. Osawa, Phys. Chem. Chem. Phys., 2012, $14,3208$.

[226] V. Vijayakumar and S. Y. Nam, J. Ind. Eng. Chem., 2019, 70, 70.

[227] Z. F. Pan, L. An, T. S. Zhao and Z. K. Tang, Prog. Energ. Combust., 2018, 66, 141.

[228] M. Rauf, Y. D. Zhao, Y. C. Wang, Y. P. Zheng, C. Chen, X. D. Yang, Z. Y. Zhou and S. G. Sun, Electrochem. Commun., 2016, 73, 71.

[229] O. Naumov, S. Naumov, B. Abel and A. Varga, Nanoscale, 2018, 10, 6724.

[230] Z. Liu, H. G. Nie, Z. Yang, J. Zhang, Z. P. Jin, Y. Q. Lu, Z. B. Xiao and S. M. Huang, Nanoscale, 2013, 5, 3283.

[231] J. B. Zhu, K. Li, M. L. Xiao, C. P. Liu, Z. J. Wu, J. J. Ge and W. Xing, J. Mater. Chem. $A, \mathbf{2 0 1 6}, 4,7422$.

[232] Z. X. Song, W. W. Liu, N. C. Cheng, M. N. Banis, X. Li, Q. Sun, B. W. Xiao, Y. L. Liu, A. Lushington, R. Y. Li, L. M. Liu and X. L. Sun, Mater. Horizons, 2017, 4, 900.

[233] Z. Zhang, J. Sun, M. Dou, J. Ji and F. Wang, ACS Appl. Mater. Interfaces, 2017, 9, 16236.

[234] D. H. Li, Y. Jia, G. J. Chang, J. Chen, H. W. Liu, J. C. Wang, Y. F. Hu, Y. Z. Xia, D. J. Yang and X. D. Yao, Chem, 2018, 4, 2345.

[235] A. L. Cazetta, L. Spessato, K. C. Bedin, I. P. Souza, R. A. Araújo, A. F. Martins, T. L. Silva, R. Silva and V. C. Almeida, Appl. Surf. Sci., 2019, 467, 75.

[236] J. C. Li, X. P. Qin, P. X. Hou, M. Cheng, C. Shi, C. Liu, H. M. Cheng and M. H. Shao, Carbon, 2019, 147, 303.

[237] X. B. Huang, Q. Wang, D. Jiang and Y. M. Huang, Catal. Comm., 2017, 100, 89.

[238] I. L. Alonso-Lemus, M. Z. Figueroa-Torres, D. Lardizabal-Gutierrez, P. Bartolo-Perez, J. C. Carrillo-Rodriguez and F. J. Rodriguez-Varela, Sustainable Energy \& Fuels, 2019, 3, 1307. [239] Y.-N. Sun, M.-L. Zhang, L. Zhao, Z.-Y. Sui, Z.-Y. Sun and B.-H. Han, Adv. Mater. Interfaces, 2019, 6, 1900592.

[240] Z. Zhou, A. Chen, X. Fan, A. Kong and Y. Shan, Appl. Surf. Sci., 2019, 464, 380.

[241] P. Li, H. S. Jang, J. Zhang, M. C. Tian, S. L. Chen, B. Yuan, Z. X. Wu, X. Liu and J. Cho, ChemElectroChem, 2019, 6, 393.

[242] J. R. Han, Y. L. Zhang, F. S. Niu, T. Chen, J. Q. Liu and Y. H. Xu, Electrocatalysis, 2019, $10,56$.

[243] J. Yu, C. Wang, W. Yuan, Y. Shen and A. Xie, Chemistry, 2019, 25, 2877.

[244] L. Yang, S. Jiang, Y. Zhao, L. Zhu, S. Chen, X. Wang, Q. Wu, J. Ma, Y. Ma and Z. Hu, Angew. Chem. Int. Ed., 2011, 50, 7132.

[245] S. Akula, B. Balasubramaniam, P. Varathan and A. K. Sahu, ACS Appl. Energy Mater., 2019, 2, 3253. 


\section{WILEY-VCH}

[246] W. J. Liu, Y. Q. Wen, J. W. Wang, D. C. Zhong, J. B. Tan and T. B. Lu, J. Mater. Chem. A, 2019, 7, 9587.

[247] L. Wang, K. Liang, L. Deng and Y.-N. Liu, Appl. Catal. B Environ., 2019, 246, 89.

[248] S. Kattel, P. Atanassov and B. Kiefer, J. Mater. Chem. A, 2014, 2, 10273.

[249] S. Y. Wang, L. P. Zhang, Z. H. Xia, A. Roy, D. W. Chang, J. B. Baek and L. M. Dai, Angew. Chem. Int. Ed., 2012, 51, 4209.

[250] Q. L. Wei, M. Cherif, G. X. Zhang, A. Almesrati, J. T. Chen, M. J. Wu, N. Komba, Y. F. $\mathrm{Hu}, \mathrm{T}$. Regier, T. K. Sham, F. Vidal and S. H. Sun, Nano Energy, 2019, 62, 700.

[251] M. S. A. S. Shah, J. Lee, A. Rauf, J. H. Park, B. Lim and P. J. Yoo, Nanoscale, 2018, 10, 19498.

[252] H. Q. Rong, T. R. Zhan, Y. Sun, Y. H. Wen, X. E. Liu and H. N. Teng, Electrochim. Acta, 2019, 318, 783.

[253] N. L. Yang and D. Wang, Chem, 2018, 4, 2262.

[254] M. Inaba, A. W. Jensen, G. W. Sievers, M. Escudero-Escribano, A. Zana and M. Arenz, Energy Environ. Sci., 2018, 11, 988.

[255] M. Markiewicz, C. Zalitis and A. Kucernak, Electrochim. Acta, 2015, 179, 126.

[256] Y. Sun, S. Gao, F. Lei and Y. Xie, Chem. Soc. Rev., 2015, 44, 623.

[257] S. L. Zhao, Y. Wang, J. C. Dong, C. T. He, H. J. Yin, P. F. An, K. Zhao, X. F. Zhang, C. Gao, L. J. Zhang, J. W. Lv, J. X. Wang, J. Q. Zhang, A. M. Khattak, N. A. Khan, Z. X. Wei, J. Zhang, S. Q. Liu, H. J. Zhao and Z. Y. Tang, Nat. Energy, 2016, 1, 1.

[258] M. Li, Z. Zhao, T. Cheng, A. Fortunelli, C. Y. Chen, R. Yu, Q. Zhang, L. Gu, B. V. Merinov, Z. Lin, E. Zhu, T. Yu, Q. Jia, J. Guo, L. Zhang, W. A. Goddard, 3rd, Y. Huang and $\mathrm{X}$. Duan, Science, 2016, 354, 1414.

[259] A. T. Swesi, J. Masud and M. Nath, Energy Environ. Sci., 2016, 9, 1771.

[260] K. N. Ferreira, T. M. Iverson, K. Maghlaoui, J. Barber and S. Iwata, Science, 2004, 303, 1831.

[261] Y. Gorlin and T. F. Jaramillo, J. Am. Chem. Soc., 2010, 132, 13612.

[262] N. T. Suen, S. F. Hung, Q. Quan, N. Zhang, Y. J. Xu and H. M. Chen, Chem. Soc. Rev., 2017, 46, 337.

[263] D. Yan, Y. Li, J. Huo, R. Chen, L. Dai and S. Wang, Adv. Mater. Process., 2017, 29, 1606459.

[264] M. Tahir, L. Pan, F. Idrees, X. W. Zhang, L. Wang, J. J. Zou and Z. L. Wang, Nano Energy, 2017, 37, 136.

[265] Y. F. Li, ChemSusChem, 2019, 12, 1846.

[266] Z. Y. Cai, X. M. Bu, P. Wang, J. C. Ho, J. H. Yang and X. Y. Wang, J. Mater. Chem. A, 2019, 7, 5069.

[267] P. P. Li, R. B. Zhao, H. Y. Chen, H. B. Wang, P. P. Wei, H. Huang, Q. Liu, T. S. Li, X. F. Shi, Y. Y. Zhang, M. L. Liu and X. P. Sun, Small, 2019, 15, 1805103.

[268] R. V. Mom, J. Cheng, M. T. M. Koper and M. Sprik, J. Phys. Chem. C, 2014, 118, 4095.

[269] M. T. Li, L. P. Zhang, Q. Xu, J. B. Niu and Z. H. Xia, J. Catal., 2014, 314, 66.

[270] X. Y. Lu, W. L. Yim, B. H. R. Suryanto and C. Zhao, J. Am. Chem. Soc., 2015, 137, 2901.

[271] S. Chen, J. J. Duan, M. Jaroniec and S. Z. Qiao, Adv. Mater., 2014, 26, 2925.

[272] T. Y. Ma, S. Dai, M. Jaroniec and S. Z. Qiao, Angew. Chem. Int. Ed., 2014, 53, 7281.

[273] S. Chen, J. Duan, J. Ran and S. Z. Qiao, Adv. Sci., 2015, 2, 1400015.

[274] J. Zhao, Y. Liu, X. Quan, S. Chen, H. Zhao and H. Yu, Electrochim. Acta, 2016, 204, 169.

[275] X. W. Yu, M. Zhang, J. Chen, Y. R. Li and G. Q. Shi, Adv. Energy Mater., 2016, 6, 1501492.

[276] Q. Hu, G. M. Li, X. F. Liu, B. Zhu, X. Y. Chai, Q. L. Zhang, J. H. Liu and C. X. He, Angew. Chem. Int. Ed., 2019, 58, 4318. 


\section{WILEY-VCH}

[277] C. G. Hu, X. Y. Chen, Q. B. Dai, M. Wang, L. T. Qu and L. M. Dai, Nano Energy, 2017, $41,367$.

[278] W. F. Zhang, Y. G. Li, Y. Q. Xu, Z. S. Zhang, S. F. Wang and G. S. Fu, ChemCatChem, 2018, 10, 2305.

[279] T. R. Zhang, Y. S. Zhu and J. Y. Lee, J. Mater. Chem. A, 2018, 6, 8147.

[280] T. Y. Ma, J. R. Ran, S. Dai, M. Jaroniec and S. Z. Qiao, Angew. Chem. Int. Ed., 2015, 54, 4646.

[281] Q. Liao, N. Li, S. Jin, G. Yang and C. Wang, ACS Nano, 2015, 9, 5310.

[282] N. Li, H. W. Song, H. Cui and C. X. Wang, Nano Energy, 2014, 3, 102.

[283] J. Liang, Y. Zheng, J. Chen, J. Liu, D. Hulicova-Jurcakova, M. Jaroniec and S. Z. Qiao, Angew. Chem., 2012, 124, 3958.

[284] T. Asefa, Accounts. Chem. Res., 2016, 49, 1873.

[285] H. Yu, L. Shang, T. Bian, R. Shi, G. I. N. Waterhouse, Y. Zhao, C. Zhou, L.-Z. Wu, C.H. Tung and T. Zhang, Adv. Mater., 2016, 28, 5080.

[286] J. Liang, Y. Jiao, M. Jaroniec and S. Z. Qiao, Angew. Chem., 2012, 51, 11496.

[287] Z. Yang, Z. Yao, G. Li, G. Fang, H. Nie, Z. Liu, X. Zhou, X. Chen and S. Huang, ACS Nano, 2012, 6, 205.

[288] L. P. Zhang, J. B. Niu, M. T. Li and Z. H. Xia, The Journal Of Physical Chemistry C, 2014, 118, 3545 .

[289] Y. Ito, W. Cong, T. Fujita, Z. Tang and M. Chen, Angew. Chem., 2015, 54, 2131.

[290] Y. Zheng, Y. Jiao and S. Z. Qiao, Adv. Mater., 2015, 27, 5372.

[291] Z. Xiao, X. Huang, L. Xu, D. Yan, J. Huo and S. Wang, Chem. Commun., 2016, 52, 13008.

[292] M. Shao, Q. Chang, J.-P. Dodelet and R. Chenitz, Chem. Rev., 2016, 116, 3594.

[293] Z. Y. Lin, G. H. Waller, Y. Liu, M. L. Liu and C. P. Wong, Carbon, 2013, 53, 130.

[294] Y. B. Li, H. M. Zhang, Y. Wang, P. R. Liu, H. G. Yang, X. D. Yao, D. Wang, Z. Y. Tang and H. J. Zhao, Energy Environ. Sci., 2014, 7, 3720.

[295] L.-A. Stern, L. Feng, F. Song and X. Hu, Energy Environ. Sci., 2015, 8, 2347.

[296] J. C. Li, P. X. Hou, S. Y. Zhao, C. Liu, D. M. Tang, M. Cheng, F. Zhang and H. M. Cheng, Energy Environ. Sci., 2016, 9, 3079.

[297] K. J. Lee, Y. J. Sa, H. Y. Jeong, C. W. Bielawski, S. H. Joo and H. R. Moon, Chem. Commun., 2015, 51, 6773.

[298] Z. Liu, Z. Zhao, Y. Wang, S. Dou, D. Yan, D. Liu, Z. Xia and S. Wang, Adv. Mater., 2017, 29, 1606207.

[299] H. W. Park, D. U. Lee, Y. L. Liu, J. S. Wu, L. F. Nazar and Z. W. Chen, J. Electrochem. Soc., 2013, 160, A2244.

[300] X. Li, Y. Fang, S. Zhao, J. Wu, F. Li, M. Tian, X. Long, J. Jin and J. Ma, J. Mater. Chem. $A, \mathbf{2 0 1 6}, 4,13133$.

[301] L.-N. Han, X. Wei, B. Zhang, X.-H. Li, Q.-C. Zhu, K.-X. Wang and J.-S. Chen, RSC Adv., 2016, 6, 56765.

[302] S. Patra, R. Choudhary, E. Roy, R. Madhuri and P. K. Sharma, Nano Energy, 2016, 30, 118.

[303] M. Titirici, Nat. Catal., 2019, 2, 642.

[304] X. Han, R. Q. Ye, Y. Chyan, T. Wang, C. H. Zhang, L. L. Shi, T. Zhang, Y. Zhao and J. M. Tour, ACS Applied Nano Materials, 2018, 1, 5053.

[305] S. A. Gold, 2012,

[306] J. A. Turner, Science, 2004, 305, 972.

[307] T. R. Cook, D. K. Dogutan, S. Y. Reece, Y. Surendranath, T. S. Teets and D. G. Nocera, Chem. Rev., 2010, 110, 6474.

[308] Y. F. Wang, D. Y. C. Leung, J. Xuan and H. Z. Wang, Renew. Sust. Energ. Rev, 2016, 65, 961. 


\section{WILEY-VCH}

[309] C. Wei, R. R. Rao, J. Peng, B. Huang, I. E. L. Stephens, M. Risch, Z. J. Xu and Y. ShaoHorn, Adv. Mater., 2019, 31, e1806296.

[310] K. C. Neyerlin, W. B. Gu, J. Jorne and H. A. Gasteiger, J. Electrochem. Soc., 2007, 154, B631.

[311] J. Zheng, W. Sheng, Z. Zhuang, B. Xu and Y. Yan, Sci. Adv., 2016, 2, e1501602.

[312] N. Furuya and S. Motoo, J. Electroanal. Chem. Interf. Electrochem., 1978, 88, 151.

[313] J. Greeley, T. F. Jaramillo, J. Bonde, I. Chorkendorff and J. K. Nørskov, Nat. Mater., 2006, 5, 909.

[314] P. P. Edwards, V. L. Kuznetsov, W. I. F. David and N. P. Brandon, Energ. Policy, 2008, $36,4356$.

[315] M. Gong, D. Y. Wang, C. C. Chen, B. J. Hwang and H. J. Dai, Nano Res., 2016, 9, 28.

[316] Y. Shi and B. Zhang, Chem. Soc. Rev., 2016, 45, 1529.

[317] M. Zeng and Y. G. Li, J. Mater. Chem. A, 2015, 3, 14942.

[318] F. Qi, P. J. Li, Y. F. Chen, B. J. Zheng, J. B. Liu, J. H. Zhou, J. R. He, X. Hao and W. L. Zhang, Int. J. Hydrogen Energy, 2017, 42, 7811.

[319] H. Vrubel and X. L. Hu, Angew. Chem. Int. Ed., 2012, 51, 12703.

[320] H. Wang, Z. Lu, D. Kong, J. Sun, T. M. Hymel and Y. Cui, ACS Nano, 2014, 8, 4940.

[321] D. Voiry, H. Yamaguchi, J. Li, R. Silva, D. C. Alves, T. Fujita, M. Chen, T. Asefa, V. B.

Shenoy, G. Eda and M. Chhowalla, Nat. Mater., 2013, 12, 850.

[322] P. Chen, K. Xu, Z. Fang, Y. Tong, J. Wu, X. Lu, X. Peng, H. Ding, C. Wu and Y. Xie, Angew. Chem., 2015, 127, 14923.

[323] J. F. Xie, S. Li, X. D. Zhang, J. J. Zhang, R. X. Wang, H. Zhang, B. C. Pan and Y. Xie, Chem. Sci., 2014, 5, 4615.

[324] G. W. Li, C. G. Fu, J. Q. Wu, J. C. Rao, S. C. Liou, X. J. Xu, B. Q. Shao, K. Liu, E. K. Liu, N. Kumar, X. J. Liu, M. Fahlman, J. Gooth, G. Auffermann, Y. Sun, C. Felser and B. M. Zhang, Appl. Catal. B Environ., 2019, 254, 1.

[325] Z. J. Chen, X. G. Duan, W. Wei, S. B. Wang and B. J. Ni, J. Mater. Chem. A, 2019, 7, 14971.

[326] E. J. Popczun, J. R. McKone, C. G. Read, A. J. Biacchi, A. M. Wiltrout, N. S. Lewis and R. E. Schaak, J. Am. Chem. Soc., 2013, 135, 9267.

[327] A. Narita, X. Y. Wang, X. Feng and K. Mullen, Chem. Soc. Rev., 2015, 44, 6616.

[328] H. Zhang, ACS Nano, 2015, 9, 9451.

[329] A. Ambrosi, C. K. Chua, N. M. Latiff, A. H. Loo, C. H. A. Wong, A. Y. S. Eng, A. Bonanni and M. Pumera, Chem. Soc. Rev., 2016, 45, 2458.

[330] D. Y. Wang, M. Gong, H. L. Chou, C. J. Pan, H. A. Chen, Y. Wu, M. C. Lin, M. Guan, J. Yang, C. W. Chen, Y. L. Wang, B. J. Hwang, C. C. Chen and H. Dai, J. Am. Chem. Soc., 2015, 137, 1587.

[331] X. Fan, H. Zhou and X. Guo, ACS Nano, 2015, 9, 5125.

[332] D. H. Youn, S. Han, J. Y. Kim, J. Y. Kim, H. Park, S. H. Choi and J. S. Lee, ACS Nano, 2014, 8, 5164.

[333] C. N. R. Rao and M. Chhetri, Adv. Mater., 2019, 31, 1803668.

[334] L. Chen, J. Han, Y. Ito, T. Fujita, G. Huang, K. Hu, A. Hirata, K. Watanabe and M. Chen, Angew. Chem. Int. Ed., 2018, 57, 13302.

[335] J. H. Zhou, F. Qi, Y. F. Chen, Z. G. Wang, B. J. Zheng and X. Q. Wang, J. Mater. Sci., 2018, 53, 7767.

[336] H. Wang, X. B. Li, L. Gao, H. L. Wu, J. Yang, L. Cai, T. B. Ma, C. H. Tung, L. Z. Wu and G. Yu, Angew. Chem. Int. Ed., 2018, 57, 192.

[337] C. Tang, M. M. Titirici and Q. Zhang, J. Energy Chem., 2017, 26, 1077.

[338] P. K. Gangadharan, S. M. Unni, N. Kumar, P. Ghosh and S. Kurungot, ChemElectroChem, 2017, 4, 2643. 


\section{WILEY-VCH}

[339] S. N. Talapaneni, J. Kim, S. H. Je, O. Buyukcakir, J. Oh and A. Coskun, J. Mater. Chem. A, 2017, 5, 12080 .

[340] Y. Tian, Y. F. Ye, X. J. Wang, S. Peng, Z. Wei, X. Zhang and W. M. Liu, Appl. Catal., A., 2017, 529, 127.

[341] K. Xie, H. P. Wu, Y. N. Meng, K. Lu, Z. X. Wei and Z. Zhang, J. Mater. Chem. A, 2015, 3,78 .

[342] Y. Zhao, F. Zhao, X. Wang, C. Xu, Z. Zhang, G. Shi and L. Qu, Angew. Chem. Int. Ed., 2014, 53, 13934.

[343] D. F. Yan, S. Dou, L. Tao, Z. J. Liu, Z. G. Liu, J. Huo and S. Y. Wang, J. Mater. Chem. A, 2016, 4, 13726.

[344] S. S. Shinde, A. Sami and J. H. Lee, ChemCatChem, 2015, 7, 3873.

[345] J. T. Zhang and L. M. Dai, Angew. Chem. Int. Ed., 2016, 55, 13296.

[346] J. T. Zhang, L. T. Qu, G. Q. Shi, J. Y. Liu, J. F. Chen and L. M. Dai, Angew. Chem. Int. Ed., 2016, 55, 2230.

[347] Y. Ito, Y. H. Shen, D. Hojo, Y. Itagaki, T. Fujita, L. H. Chen, T. Aida, Z. Tang, T. Adschiri and M. W. Chen, Adv. Mater., 2016, 28, 10644.

[348] W. H. He, Y. Wang, C. H. Jiang and L. H. Lu, Chem. Soc. Rev., 2016, 45, 2396.

[349] W. He, C. Jiang, J. Wang and L. Lu, Angew. Chem. Int. Ed., 2014, 53, 9503.

[350] Y. Zheng, Y. Jiao, L. H. Li, T. Xing, Y. Chen, M. Jaroniec and S. Z. Qiao, ACS Nano, 2014, 8, 5290 .

[351] P. G. Bruce, S. A. Freunberger, L. J. Hardwick and J.-M. Tarascon, Nat. Mater., 2012, $11,19$.

[352] M. Armand and J. M. Tarascon, Nature, 2008, 451, 652.

[353] T. W. Kim and K. S. Choi, Science, 2014, 343, 990.

[354] M. K. Debe, Nature, 2012, 486, 43.

[355] A. Kulkarni, S. Siahrostami, A. Patel and J. K. Norskov, Chem. Rev., 2018, 118, 2302.

[356] H. Over, Chem. Rev., 2012, 112, 3356.

[357] J. I. Jung, H. Y. Jeong, J. S. Lee, M. G. Kim and J. Cho, Angew. Chem. Int. Ed., 2014, 53,4582 .

[358] F. Y. Cheng, J. A. Shen, B. Peng, Y. D. Pan, Z. L. Tao and J. Chen, Nat. Chem., 2011, 3, 79.

[359] V. R. Stamenkovic, B. Fowler, B. S. Mun, G. Wang, P. N. Ross, C. A. Lucas and N. M. Markovic, Science, 2007, 315, 493.

[360] C. Chen, Y. Kang, Z. Huo, Z. Zhu, W. Huang, H. L. Xin, J. D. Snyder, D. Li, J. A. Herron, M. Mavrikakis, M. Chi, K. L. More, Y. Li, N. M. Markovic, G. A. Somorjai, P. Yang and V. R. Stamenkovic, Science, 2014, 343, 1339.

[361] F. Meng, H. Zhong, D. Bao, J. Yan and X. Zhang, J. Am. Chem. Soc., 2016, 138, 10226. [362] J. R. Petrie, V. R. Cooper, J. W. Freeland, T. L. Meyer, Z. Zhang, D. A. Lutterman and H. N. Lee, J. Am. Chem. Soc., 2016, 138, 2488.

[363] F. L. Meng, K. H. Liu, Y. Zhang, M. M. Shi, X. B. Zhang, J. M. Yan and Q. Jiang, Small, 2018, 14, e1703843.

[364] X. Mao, L. Zhang, G. Kour, S. Zhou, S. F. Wang, C. Yan, Z. H. Zhu and A. J. Du, ACS Appl. Mater. Interfaces, 2019, 11, 17410.

[365] Y. J. Wang, H. B. Fan, A. Ignaszak, L. Zhang, S. Q. Shao, D. P. Wilkinson and J. J. Zhang, Chem. Eng. J., 2018, 348, 416.

[366] G. L. Chai, K. P. Qiu, M. Qiao, M. M. Titirici, C. X. Shang and Z. X. Guo, Energy Environ. Sci., 2017, 10, 1186.

[367] C. Hu, Y. Lin, J. W. Connell, H. M. Cheng, Y. Gogotsi, M. M. Titirici and L. Dai, Adv. Mater., 2019, 31, e1806128.

[368] M. J. Kim, J. E. Park, S. Kim, M. S. Linn, A. Jin, O. H. Kim, M. J. Kim, K. S. Lee, J. Kim, S. S. Kim, Y. H. Cho and Y. E. Sung, ACS Catal., 2019, 9, 3389. 


\section{WILEY-VCH}

[369] Y. Jiao, Y. Zheng, M. Jaroniec and S. Z. Qiao, Chem. Soc. Rev., 2015, 44, 2060.

[370] G. T. Fu, Z. M. Cui, Y. F. Chen, Y. T. Li, Y. W. Tang and J. B. Goodenough, Adv. Energy Mater., 2017, 7, 1601172.

[371] C. Hang, J. Zhang, J. Zhu, W. Li, Z. Kou and Y. Huang, Adv. Energy Mater., 2018, 8, 1703539.

[372] X. Wang, X. Lu, B. Liu, D. Chen, Y. Tong and G. Shen, Adv. Mater., 2014, 26, 4763.

[373] S. S. Shinde, C.-H. Lee, A. Sami, D.-H. Kim, S.-U. Lee and J.-H. Lee, ACS Nano, 2017, $11,347$.

[374] Z. X. Pei, H. F. Li, Y. Huang, Q. Xue, Y. Huang, M. S. Zhu, Z. F. Wang and C. Y. Zhi, Energy Environ. Sci., 2017, 10, 742.

[375] K. Kordek, L. X. Jiang, K. C. Fan, Z. J. Zhu, L. Xu, M. Al-Mamun, Y. H. Dou, S. Chen, P. R. Liu, H. J. Yin, P. Rutkowski and H. J. Zhao, Adv. Energy Mater., 2019, 9, 1802936.

[376] J. Guo, M. Gao, J. Nie, F. Yin and G. Ma, J Colloid Interface Sci, 2019, 544, 112.

[377] S. S. Shinde, C. H. Lee, J.-Y. Yu, D.-H. Kim, S. U. Lee and J.-H. Lee, ACS Nano, 2017, $12,596$.

[378] X. W. Peng, L. Zhang, Z. X. Chen, L. X. Zhong, D. K. Zhao, X. Chi, X. X. Zhao, L. G. Li, X. H. Lu, K. Leng, C. B. Liu, W. Liu, W. Tang and K. P. Loh, Adv. Mater., 2019, 31, 1900341.

[379] W. Chen, L. Xu, Y. H. Tian, H. A. Li and K. Wang, Carbon, 2018, 137, 458.

[380] X. Y. Wu, S. M. Li, B. Wang, J. H. Liu and M. Yu, Micropor. Mesopor. Mat, 2017, 240, 216.

[381] T. Y. Ma, J. Ran, S. Dai, M. Jaroniec and S. Z. Qiao, Angew. Chem., 2015, 54, 4646.

[382] Y. Zhang, T. Mori, J. Ye and M. Antonietti, J. Am. Chem. Soc., 2010, 132, 6294.

[383] K. Sakaushi and M. Antonietti, Accounts. Chem. Res., 2015, 48, 1591.

[384] Y. Xu, S. Jin, H. Xu, A. Nagai and D. Jiang, Chem. Soc. Rev., 2013, 42, 8012.

[385] M. I. Jamesh, J. Power Sources, 2016, 333, 213.

[386] M. Tahir, N. Mahmood, X. Zhang, T. Mahmood, F. K. Butt, I. Aslam, M. Tanveer, F. Idrees, S. Khalid and I. Shakir, Nano Res., 2015, 8, 3725.

[387] Y. Hou, M. R. Lohe, J. Zhang, S. H. Liu, X. D. Zhuang and X. L. Feng, Energy Environ. Sci., 2016, 9, 478.

[388] J. Yin, P. Zhou, L. An, L. Huang, C. Shao, J. Wang, H. Liu and P. Xi, Nanoscale, 2016, $8,1390$.

[389] M. Ledendecker, S. K. Calderon, C. Papp, H. P. Steinruck, M. Antonietti and M. Shalom, Angew. Chem. Int. Ed., 2015, 54, 12361.

[390] L. L. Feng, G. T. Yu, Y. Y. Wu, G. D. Li, H. Li, Y. H. Sun, T. Asefa, W. Chen and X. X. Zou, J. Am. Chem. Soc., 2015, 137, 14023.

[391] N. Jiang, B. You, M. L. Sheng and Y. J. Sun, Angew. Chem. Int. Ed., 2015, 54, 6251.

[392] Y. Yang, H. L. Fei, G. D. Ruan and J. M. Tour, Adv. Mater., 2015, 27, 3175.

[393] H. Y. Jin, J. Wang, D. F. Su, Z. Z. Wei, Z. F. Pang and Y. Wang, J. Am. Chem. Soc., 2015, 137, 2688.

[394] H. T. Wang, H. W. Lee, Y. Deng, Z. Y. Lu, P. C. Hsu, Y. Y. Liu, D. C. Lin and Y. Cui, Nat. Commun., 2015, 6, 7261.

[395] J. S. Luo, J. H. Im, M. T. Mayer, M. Schreier, M. K. Nazeeruddin, N. G. Park, S. D. Tilley, H. J. Fan and M. Gratzel, Science, 2014, 345, 1593.

[396] X. Yan, Y. Jia, T. Odedairo, X. Zhao, Z. Jin, Z. Zhu and X. Yao, Chem. Commun., 2016, $52,8156$.

[397] Z. Peng, S. W. Yang, D. S. Jia, P. M. Da, P. He, A. M. Al-Enizi, G. Q. Ding, X. M. Xie and G. F. Zheng, J. Mater. Chem. A, 2016, 4, 12878.

[398] J. P. Lai, S. P. Li, F. X. Wu, M. Saqib, R. Luque and G. B. Xu, Energy Environ. Sci., 2016, 9, 1210. 


\section{WILEY-VCH}

[399] M. G. Walter, E. L. Warren, J. R. McKone, S. W. Boettcher, Q. Mi, E. A. Santori and N. S. Lewis, Chem. Rev., 2010, 110, 6446.

[400] Y. C. Wang, T. Zhou, K. Jiang, P. M. Da, Z. Peng, J. Tang, B. A. Kong, W. B. Cai, Z. Q. Yang and G. F. Zheng, Adv. Energy Mater., 2014, 4, 1400696.

[401] S. W. Li, Y. C. Wang, S. J. Peng, L. J. Zhang, A. M. Al-Enizi, H. Zhang, X. H. Sun and G. F. Zheng, Adv. Energy Mater., 2016, 6, 1501661.

[402] G. Y. Chen, S. R. Bare and T. E. Mallouk, J. Electrochem. Soc., 2002, 149, A1092.

[403] Q. Zhang, F. Luo, Y. Ling, L. Guo, K. G. Qu, H. Hu, Z. H. Yang, W. W. Cai and H. S. Cheng, ChemCatChem, 2018, 10, 5194.

[404] A. Mulyadi, Z. Zhang, M. Dutzer, W. Liu and Y. L. Deng, Nano Energy, 2017, 32, 336. [405] Q. Hu, G. M. Li, G. D. Li, X. F. Liu, B. Zhu, X. Y. Chai, Q. L. Zhang, J. Liu and C. He, Adv. Energy Mater., 2019, 9, 1803867.

[406] B. B. Huang, X. Hu, Y. C. Liu, W. Qi and Z. L. Xie, J. Power Sources, 2019, 413, 408. 


\section{WILEY-VCH}

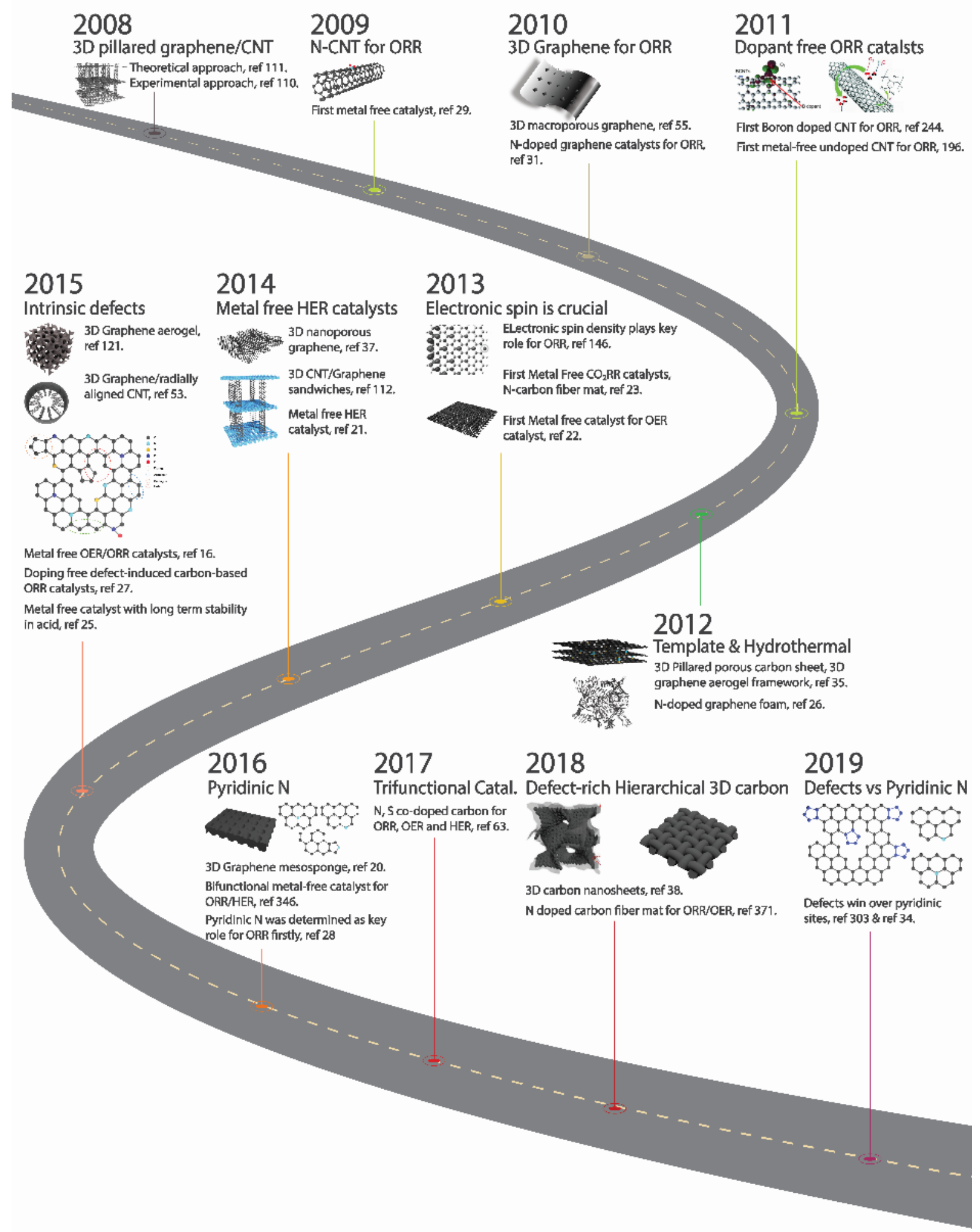

Figure 1. The recent progress of carbon-based metal free catalysts. Timeline showing the important developments of carbon-based metal free catalysts. 


\section{WILEY-VCH}
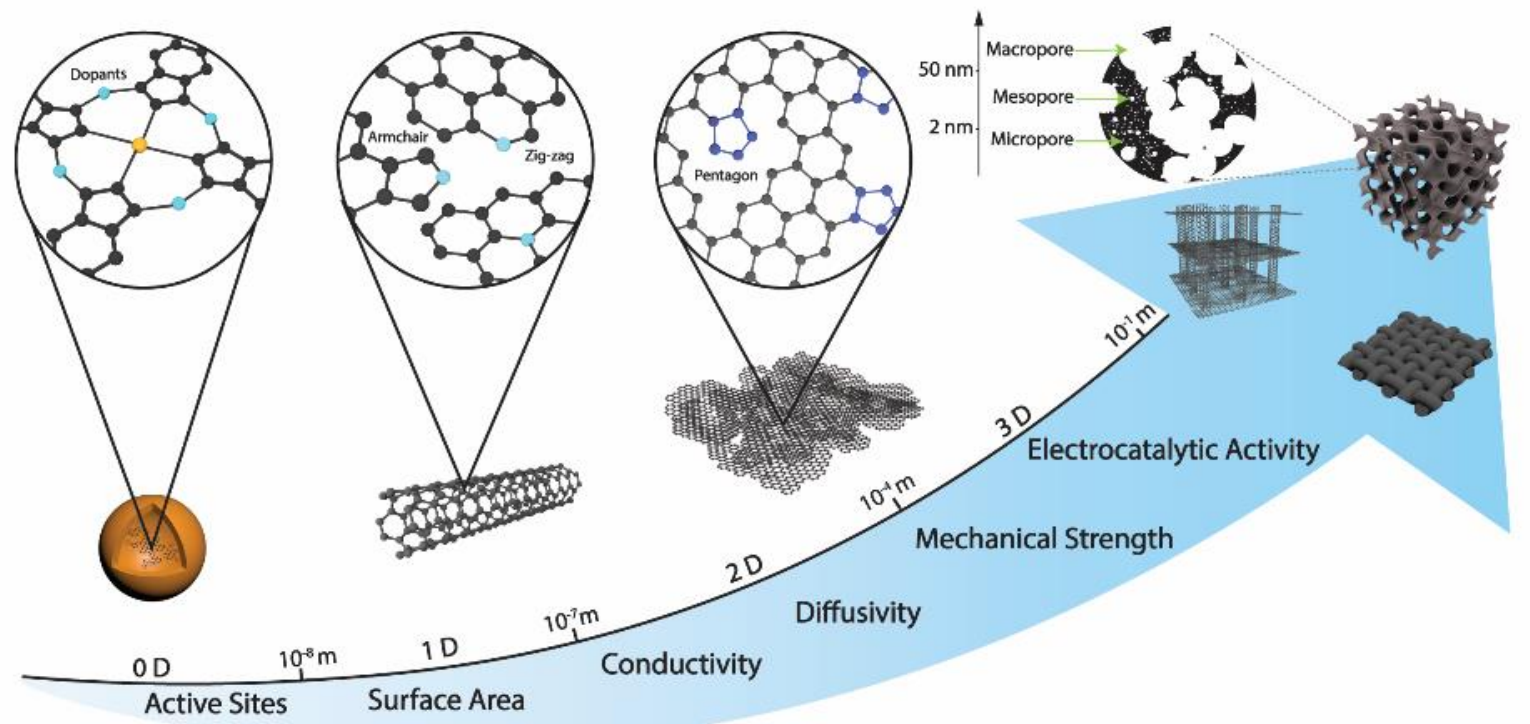

Figure 2. Comparison of the structure-property relationship of carbon structures. Advantages of $3 D$ carbon structures over zero-dimensional $(O D)$ carbon dots, $1 D$ nanotubes and $2 D$ graphene, particularly for catalysis.
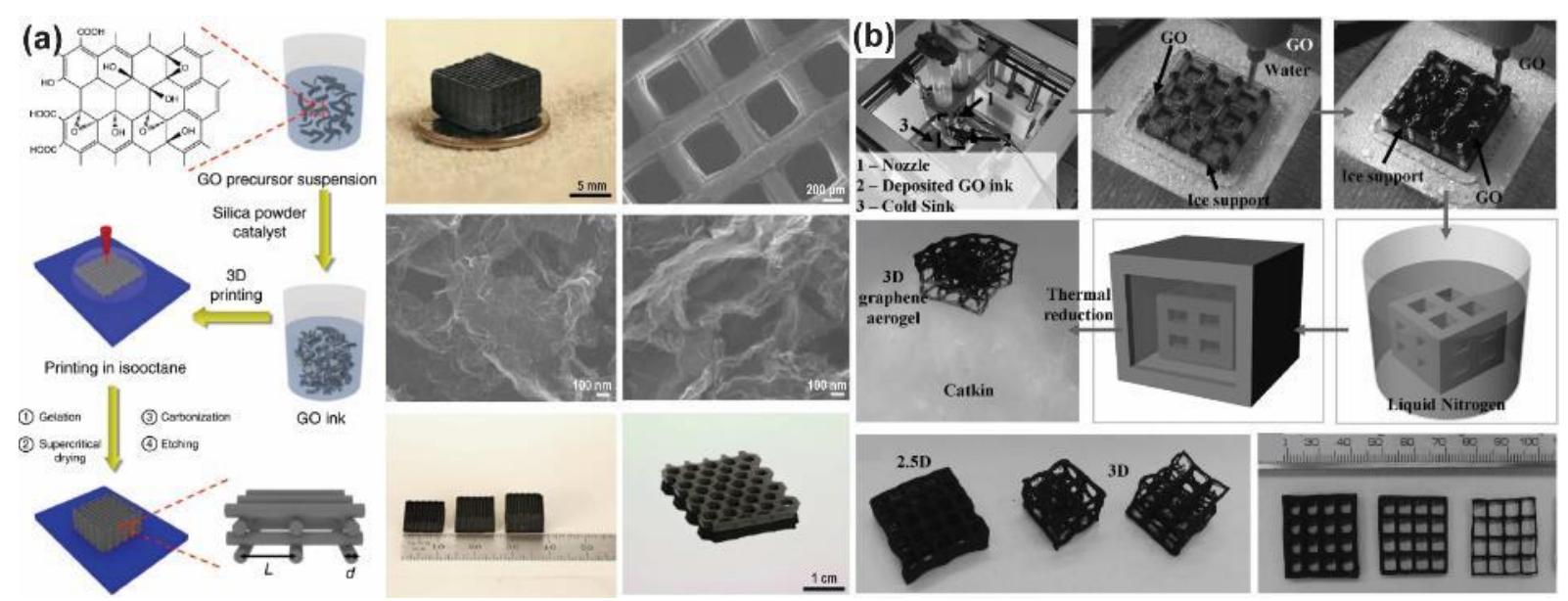

Figure 3. 3D carbon structures prepared via 3D printing and their structural elucidation. Schematic representation of $3 D$ printing approaches to process $3 D$ porous carbons: (a) GO aerogels, ${ }^{[121]}$ (Copyright 2015, Springer Nature) (b) graphene aerogels. ${ }^{[123]}$ (Copyright 2016, Wiley-VCH) 


\section{WILEY-VCH}
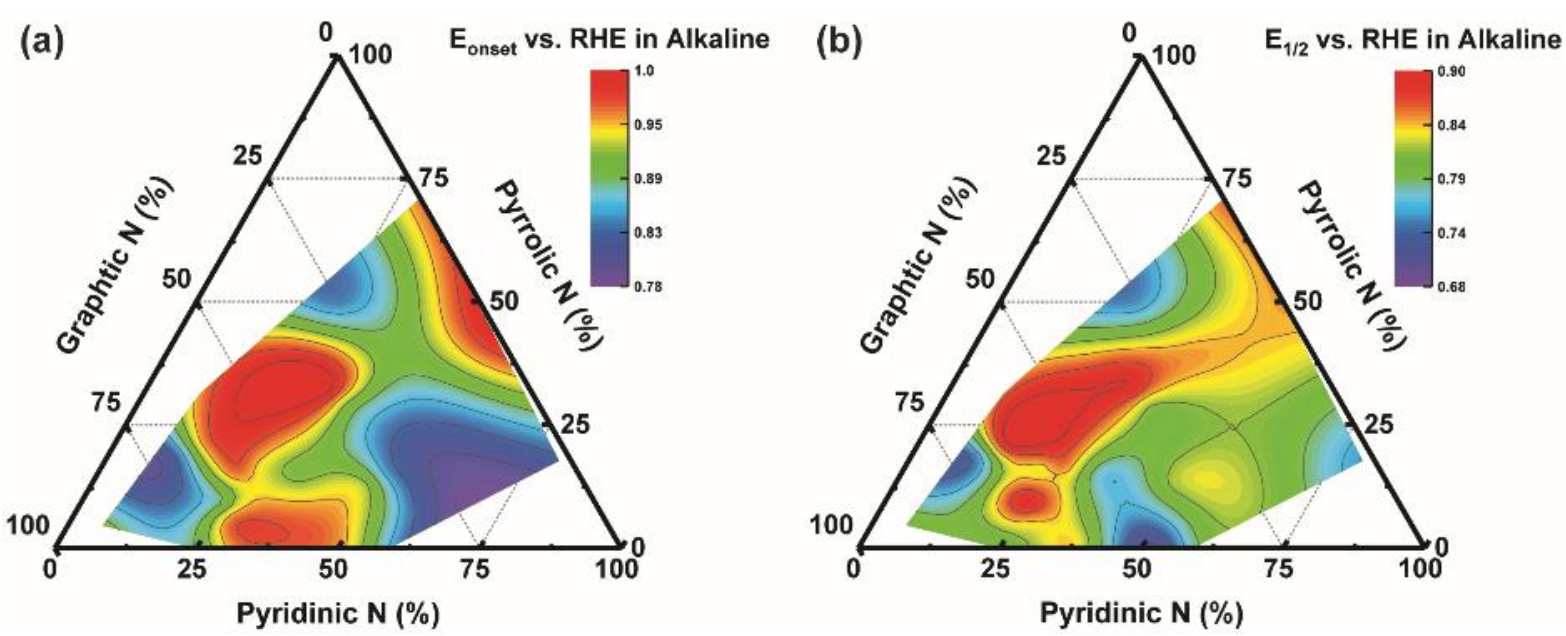

Figure 4. Comparison of the ORR performance of porous metal-free carbons as a function of $N$-type. Ternary plots showing the effect of different $N$-type on ORR performance of metalfree carbons in alkaline. (a) onset potentials, (b) halfwave potentials.
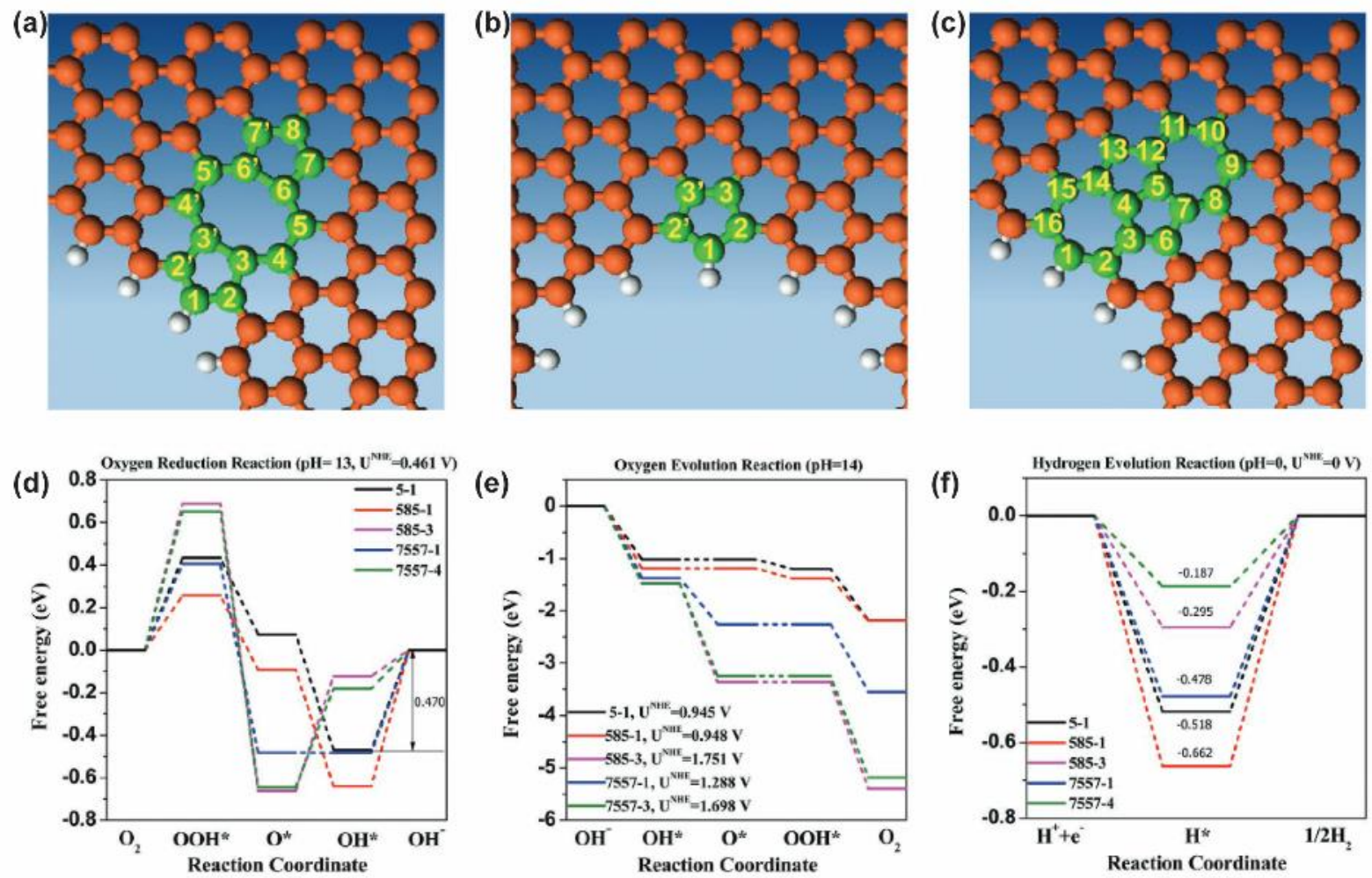

Figure 5. The role of graphene defects in oxygen and hydrogen electrocatalysis. Schematic depicting three types of graphene defects, (a) Edge pentagon. (b) 5-8-5 defect. (c) 7-55-7 defect and their mechanisms for ORR, OER, and HER. $(d)-(f)$ Free energy profiles showing three mechanism pathways for ORR, OER HER on defective graphene in alkaline/acidic media. Note that "OH" "was omitted from the labels for clarity. ${ }^{[151]}$ (Copyright 2016, Wiley-VCH) 

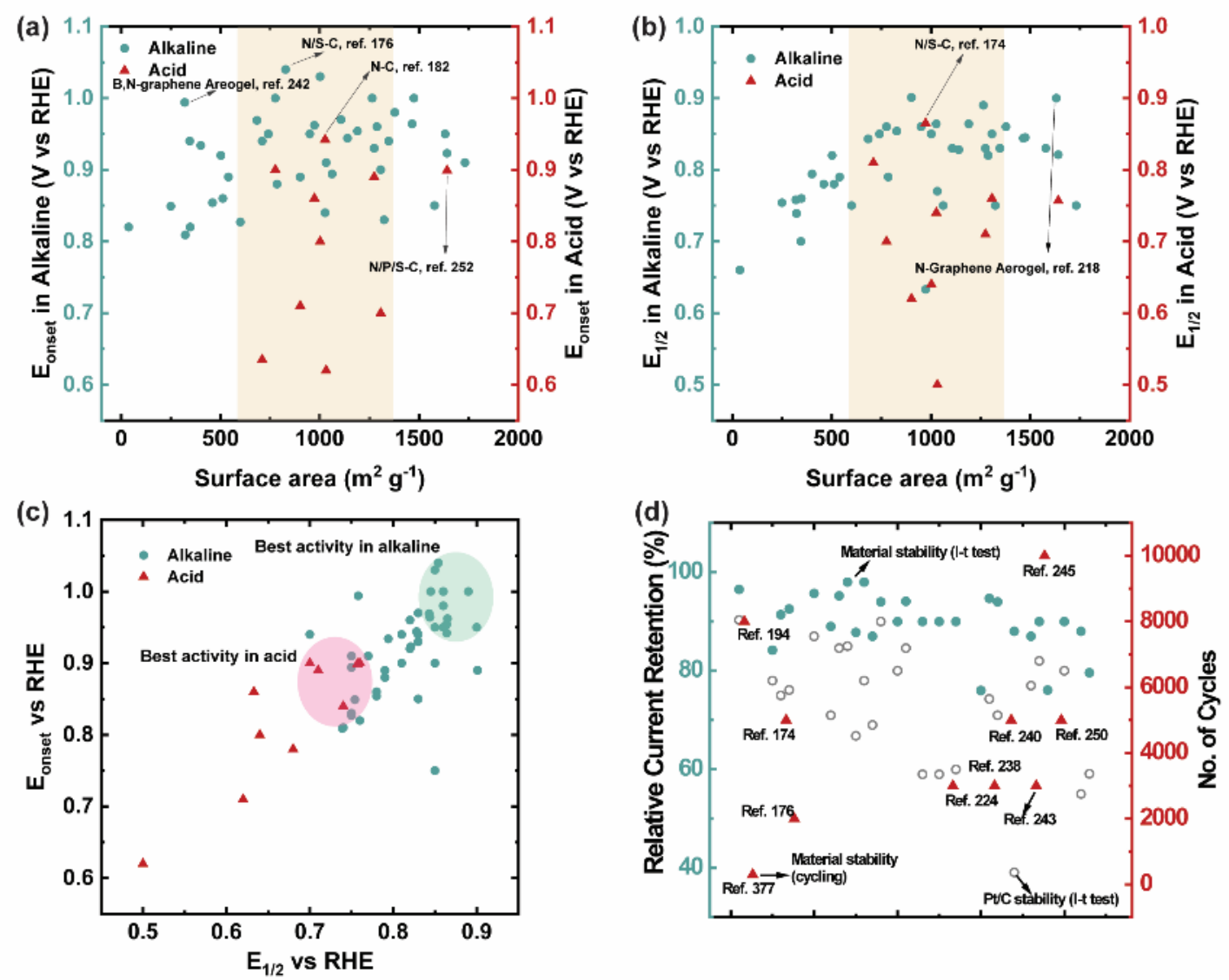

Figure 6. Comparison of ORR performance and stability of metal-free 3D carbon-based catalysts. The ORR performances of metal-free $3 D$ carbons in alkaline and acid: (a) variation in halfwave potential as a function of surface area (b) variation in onset potential as a function of surface area (c) variations in both onset and halfwave potentials in acid (d) stability in alkaline. 


\section{WILEY-VCH}

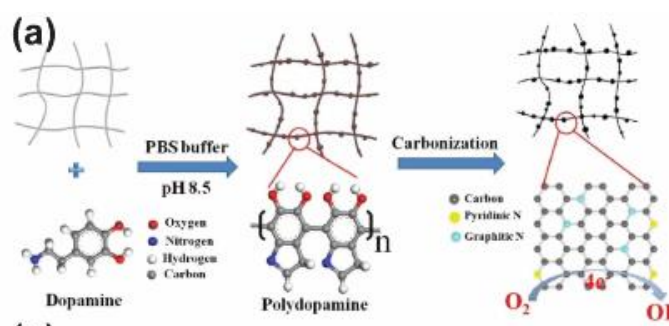

(c)
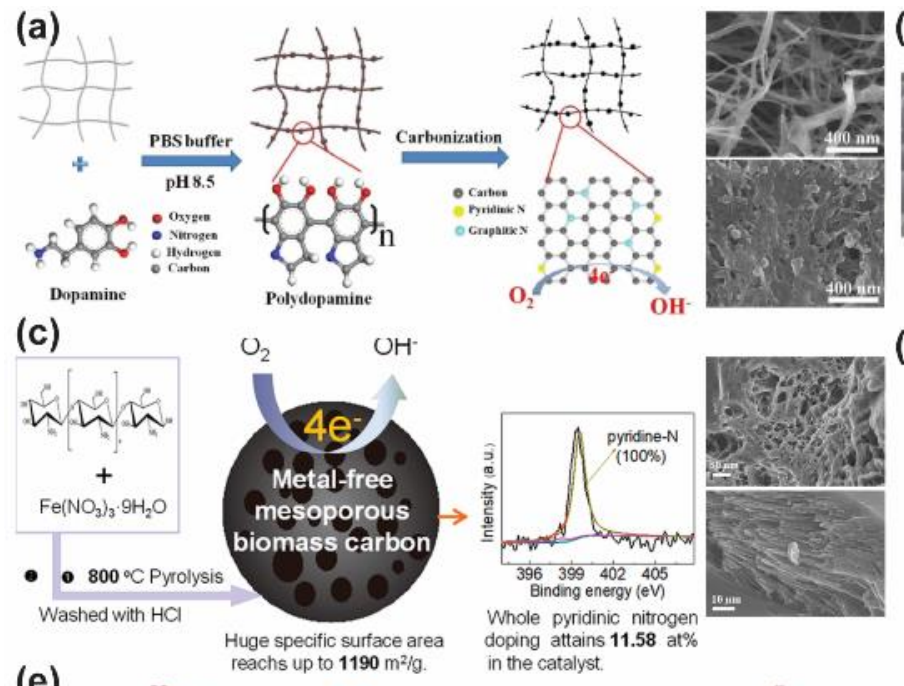

(b)

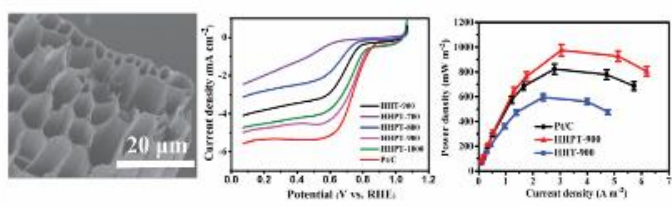

(d)

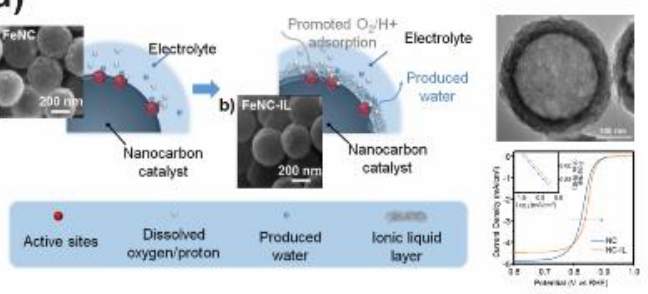

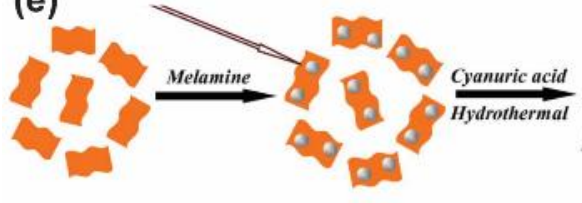

(f) $G O$
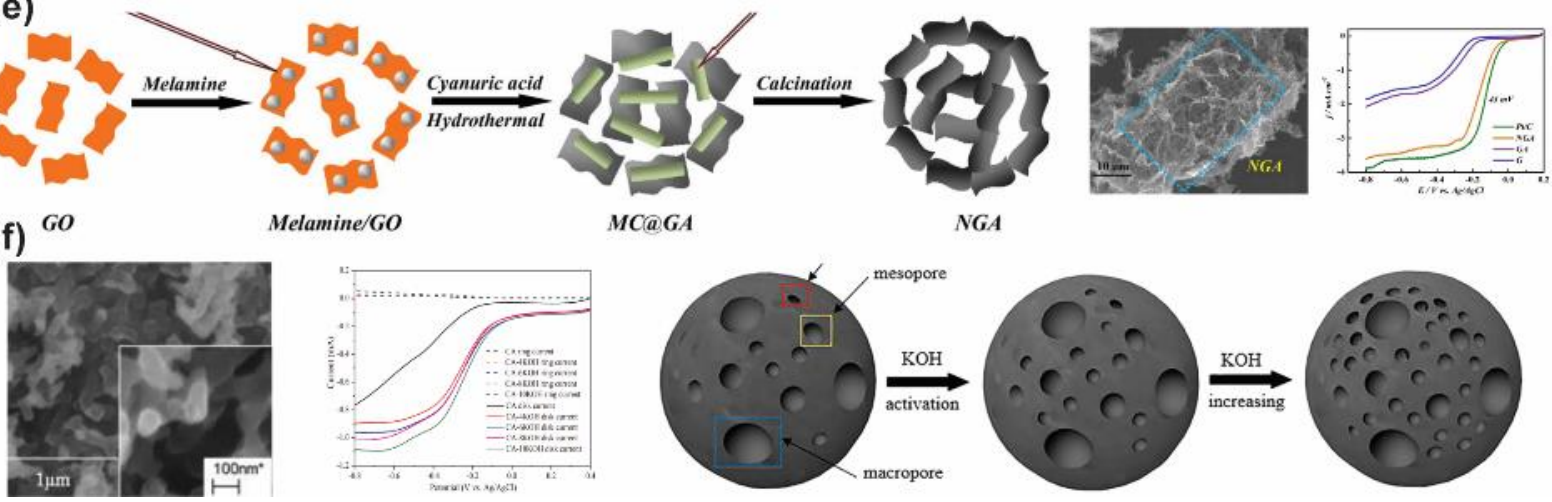

Figure 7. Methods used to prepare $N$-doped porous carbons for ORR. $N$-doped carbons for ORR: (a) $N$-doped carbon nanospheres deposited on carbon fibers from polymerisation of dopamine on cellulose, ${ }^{[223]}$ (Copyright 2019, Wiley-VCH) (b) honeycomb-like structures from dandelion showing good performance in a methanol fuel cell, ${ }^{[184]}$ (Copyright 2019, Elsevier) (c) high surface area mesoporous carbons from chitin show 100\% pyridinic $N,{ }^{[214]}$ (Copyright 2018, ACS) (d) Nanospheres of N-doped carbon catalysts with improved activity by addition of an ionic liquid layer at the surface, ${ }^{[220]}$ (Copyright 2019, ACS) (e) 3d porous $N$-doped graphene framework with melamine and cyanuric acid acting as both the spacers and $N$ source, ${ }^{[170]}$ (Copyright 2018, Elsevier) (f) N-doped carbon aerogels activated with $10 \mathrm{M} \mathrm{KOH}$ increase activity for the ORR and make an effective catalysts for microbial fuel cells. ${ }^{[217]}$ (Copyright 2018, Elsevier) 


\section{WILEY-VCH}

(a)

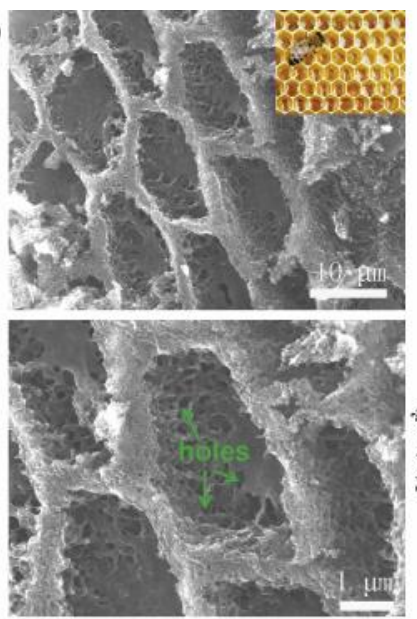

(c)
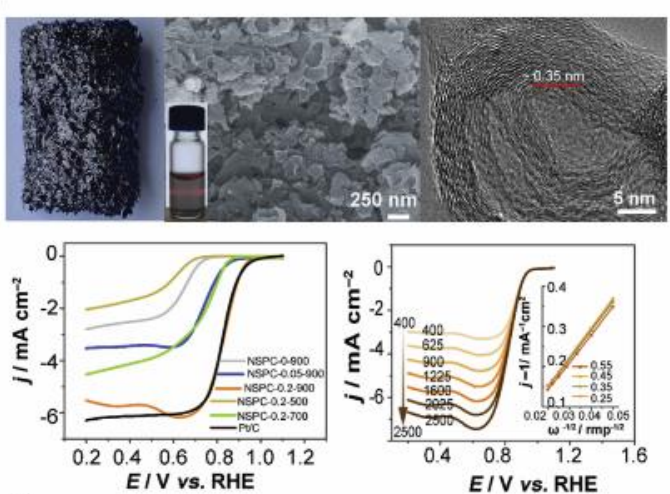
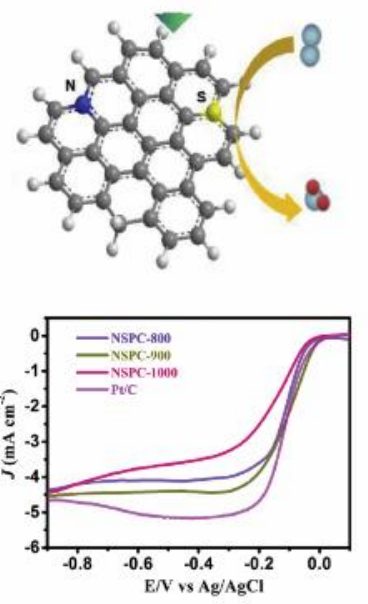

(d) (b)
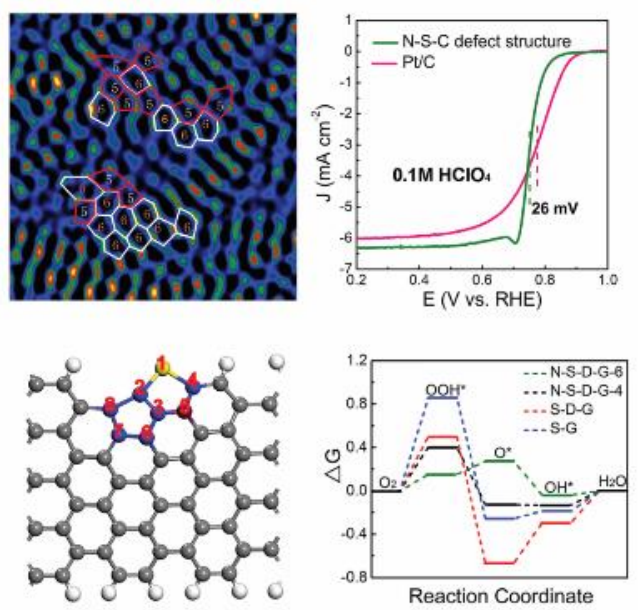

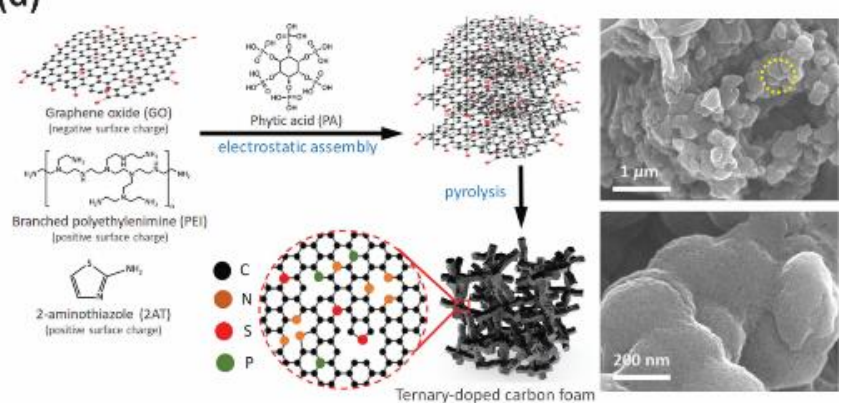

Figure 8. Strategies to introduce hierarchical pores, defects and multiple dopants in carbon structures for active ORR catalysts. Multiple heteroatom doping strategies for active ORR catalysts: (a) Honeycomb N/S doped carbons from crab shells with hierarchical porosity giving good performance, ${ }^{[176]}$ (Copyright 2018, Elsevier) (b) specific pentagon edge doping of S leads to excellent activity for the ORR in alkaline and acid, ${ }^{[234]}$ (Copyright 2018, Elsevier) (c) protein-derived hydrogel $\mathrm{N} / \mathrm{S}$ co-doped catalysts show identical activity to $\mathrm{Pt} / \mathrm{C}$ in alkaline (bottom left) and good performance in acid (bottom right), ${ }^{[247]}$ (Copyright 2019, Elsevier) (d) Synthetic route towards ternary N, S, P doped carbon foams for the ORR. ${ }^{[251]}$ (Copyright 2018, $R S C)$ 
(a)
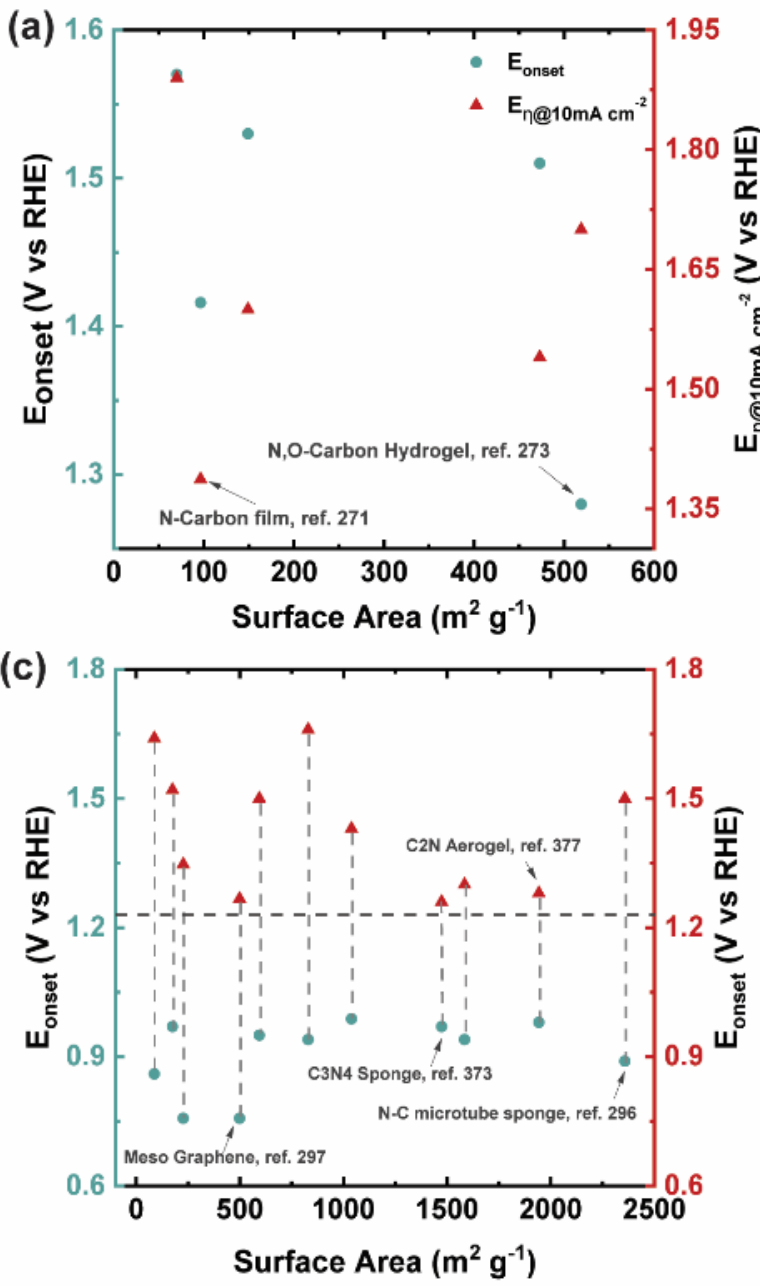

(c) (b)

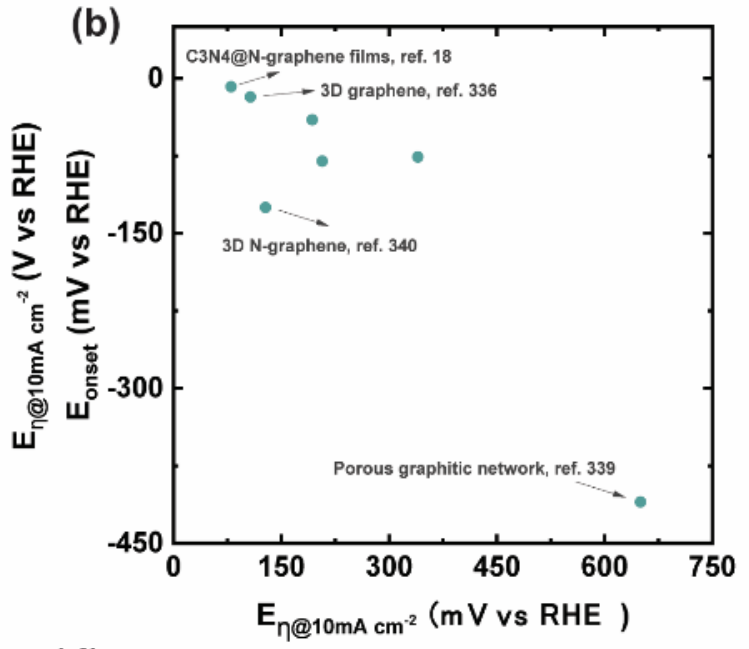

(d)

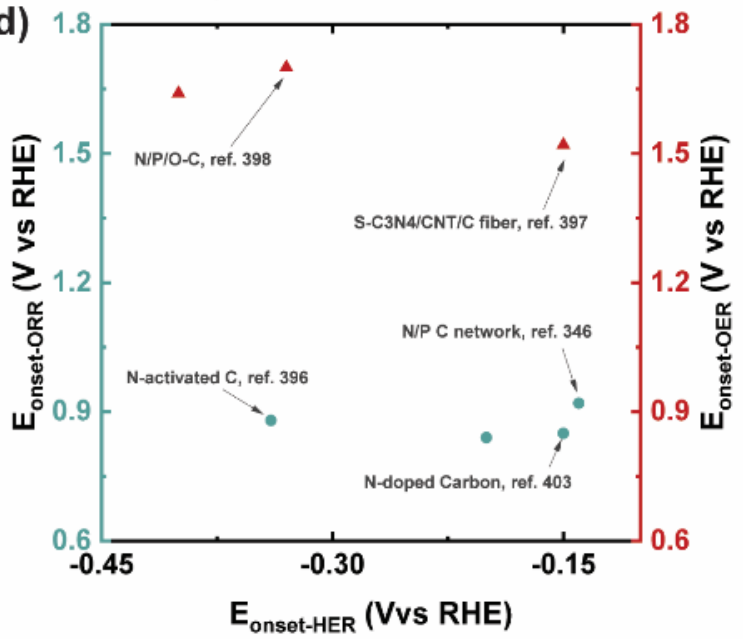

Figure 9. Comparison of the multifunctional catalytic activity of metal-free 3D carbon-based electrocatalysts. The OER performances of metal-free 3D carbons in alkaline and acid: (a) variationin $\eta @ 10 \mathrm{~mA} \mathrm{~cm}^{-2}$ and onset potential as a function of specific surface area, and, $(b)$ variations in both onset and $\eta @ 10 \mathrm{~mA} \mathrm{~cm}^{-2}$ for OER in acid. (c) variation in onset potential of ORR and OER as a function of surface area for the comparison of bifunctional electrocatalytic performance (d) variation in onset potential of ORR, OER and HER for the comparison of the tri-functional electrocatalytic performance. 


\section{WILEY-VCH}

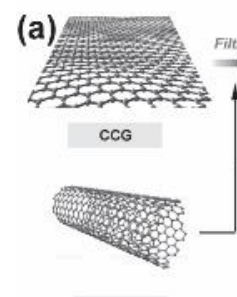

CNTs

(f)

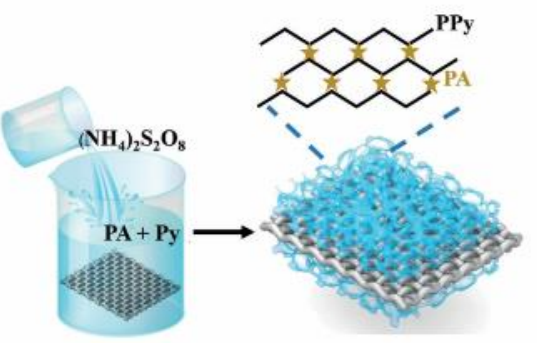

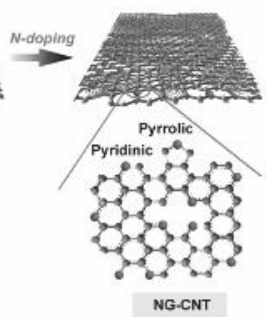

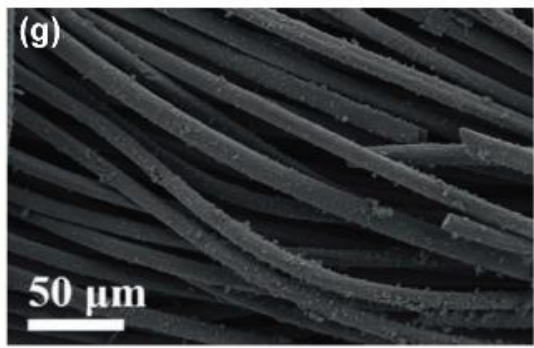

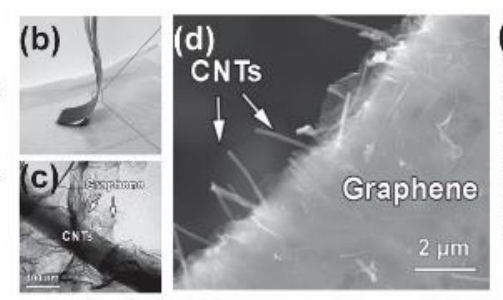
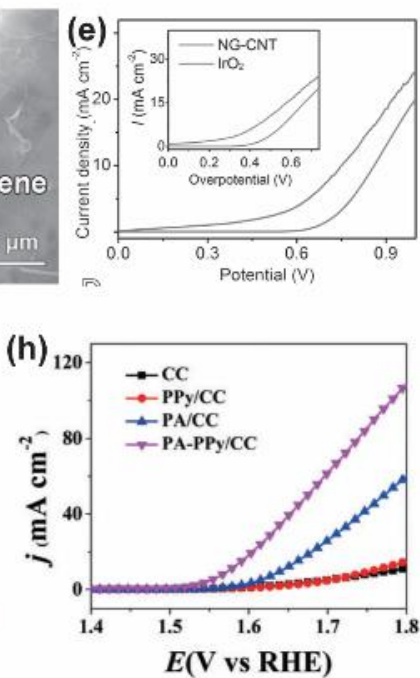

Figure 10. Strategies to prepare hierarchical 3D carbons with $N$ or $P$ doping for the OER. (a) Synthetic process of NG-CNT, (b) Optical image of NG-CNT, (c) SEM image of NG-CNT, (d) TEM image of NG-CNT, (e) LSV plots in comparison to those for G-CNT and IrO $\mathrm{O}_{2}$ collected at $30 \mathrm{mV} \mathrm{s}^{-1}$ in $0.1 \mathrm{M} \mathrm{KOH}$; inset current density vs. overpotential, ${ }^{[271]}$ (Copyright 2014, Wiley$V C H)(f)$ crafting process of phytic acid (PA) doped polypyrrole (PPy) (PA-PPy) hydrogel coated on the carbon cloth (PA-Ppy/CC) via a modified dip-coating dry method, (g) SEM image of PA-PPy/CC, (h) LSV of CC, PPy/CC, PA/CC and PA-PPy/CC electrocatalysts for OER in

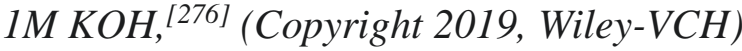

(a)

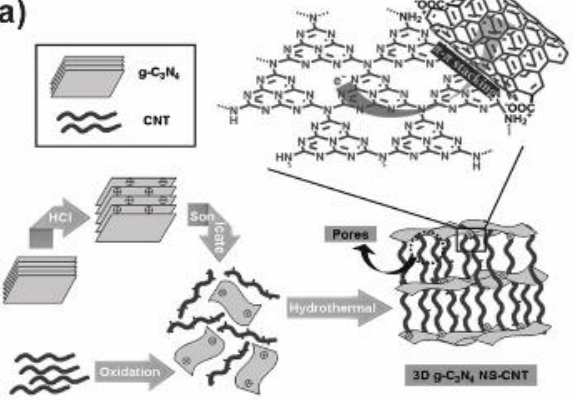

(d)

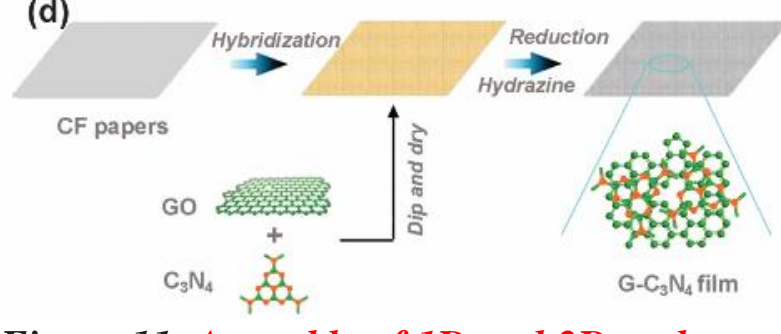

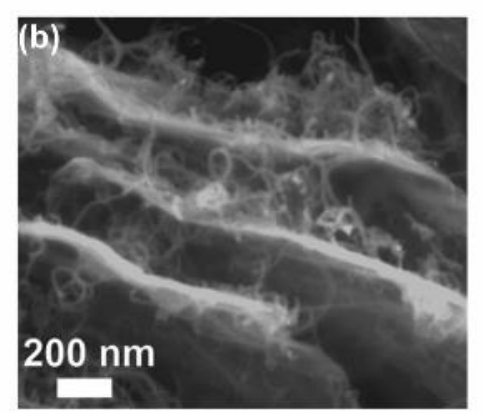

(e)

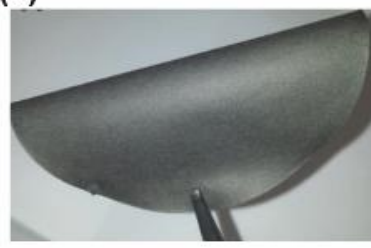

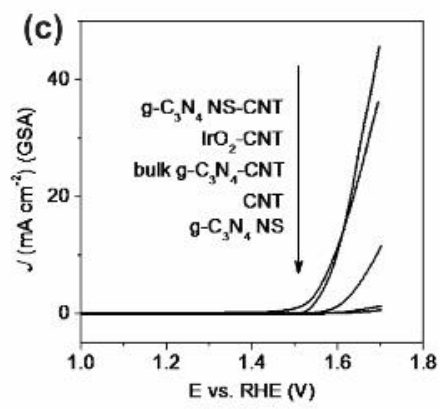

(f)

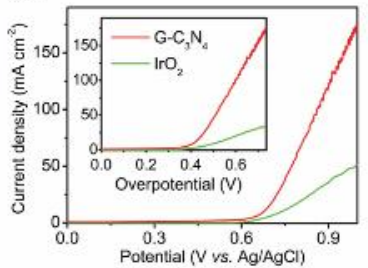

Figure 11. Assembly of $1 D$ and $2 D$ carbons to form $3 D$ carbon structures for the OER. (a) Fabrication of the $3 D \mathrm{~g}-\mathrm{C}_{3} \mathrm{~N}_{4} \mathrm{NS}$-CNT porous composite, (b) SEM image and of $g-C_{3} \mathrm{~N}_{4} \mathrm{NS}$ $C N T$, (c) LSV for g- $C_{3} N_{4} N S-C N T$, IrO ${ }_{2}-C N T$, bulk g-C $C_{3} N_{4}-C N T$, purified oxidized CNTs and $\mathrm{G}-\mathrm{C}_{3} \mathrm{~N}_{4} \mathrm{NSs}$ on a RDE (1500 rpm) in an $\mathrm{O}_{2}$-saturated $0.1 \mathrm{M} \mathrm{KOH}$ solution (scan rate: $5 \mathrm{mVs}$ ${ }^{1}$ ), ${ }^{[272]}$ (Copyright 2014, Wiley-VCH) (d) Optical image of $G-C_{3} N_{4}$, (e) OER electrochemical catalysis on $G-C_{3} N_{4}$, (f) LSV plots comparing $G-C_{3} N_{4}$ and $\mathrm{IrO}_{2}$, Inset: data replotted as the current density versus overpotential. ${ }^{[273]}$ (Copyright 2015, Wiley-VCH) 


\section{WILEY-VCH}

(a)

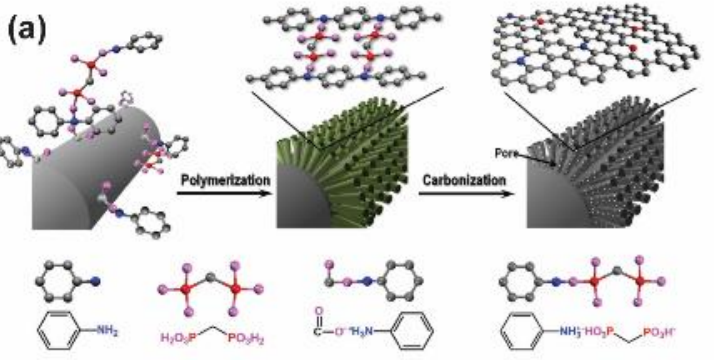

(d)

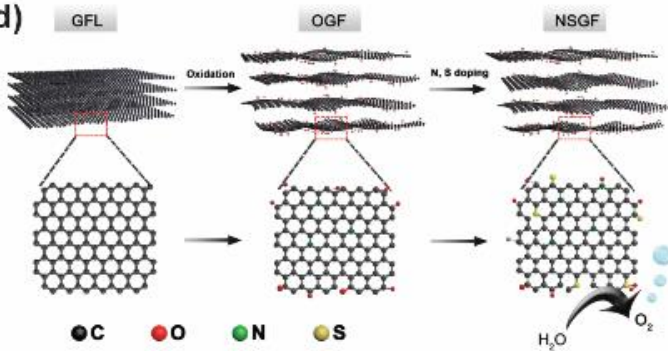

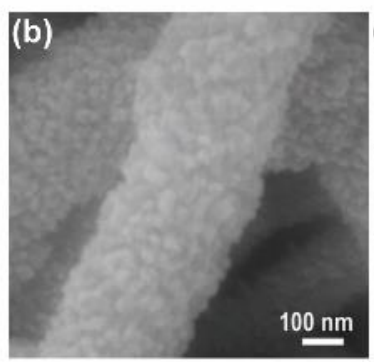
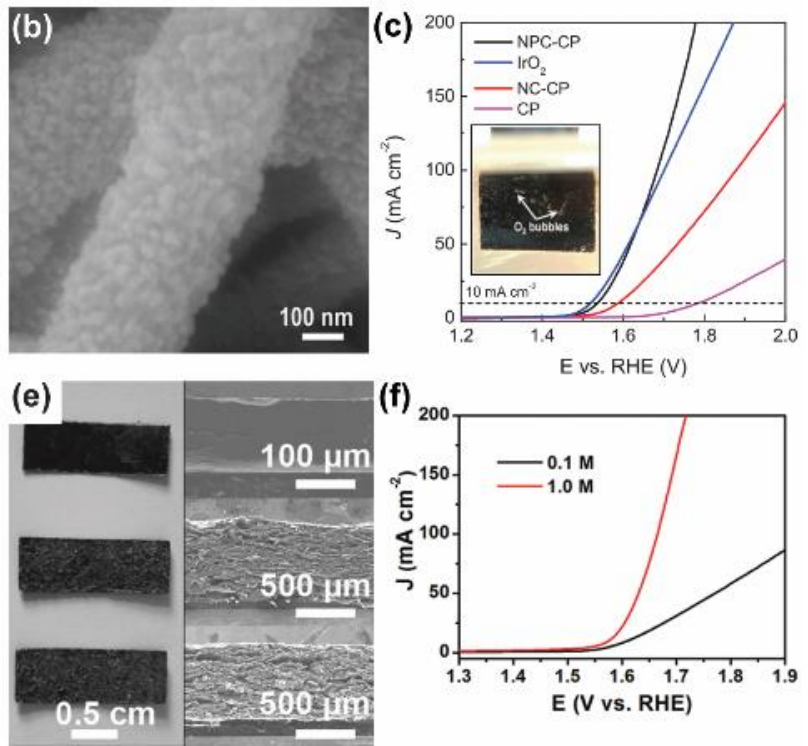

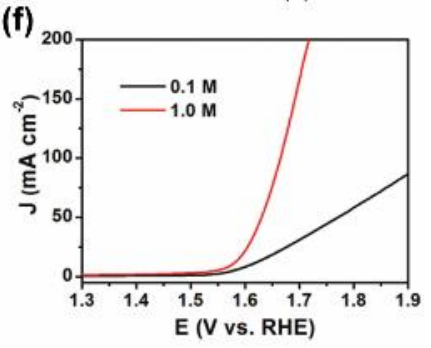

Figure 12. Strategies to introduce co-dopants to 3D carbon nanofibers for stable and active OER catalysts. (a) Schematic illustration of direct growth of $N$ and $P$-doped carbon nanofibers on carbon paper, (b) SEM images of N,P-doped fibers on carbon paper, (c) OER curves of $\mathrm{NPC}-\mathrm{CP}, \mathrm{NC}-\mathrm{CP}, \mathrm{IrO}_{2}$ and pristine $\mathrm{CP}$ in $\mathrm{O}_{2}$-saturated $1 \mathrm{M} \mathrm{KH}\left(\right.$ scan rate: $\left.2 \mathrm{mVs}^{-1}\right),{ }^{[133]}(\mathrm{d}) \mathrm{The}$ procedures for fabricating an NSGF electrode. (e) left: photographs of GFL, OGF, and NSGF from top to down. Right: cross-sectional SEM images corresponding to the left samples, $(f)$ LSV of an NSGF electrode in 0.1 and $1 \mathrm{M} \mathrm{KOH} .^{[275]}$ (Copyright 2015, Wiley-VCH)

(a)

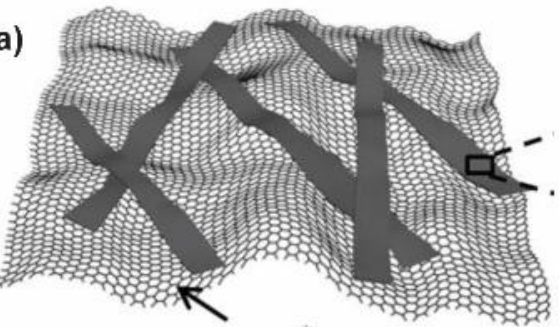

(d)

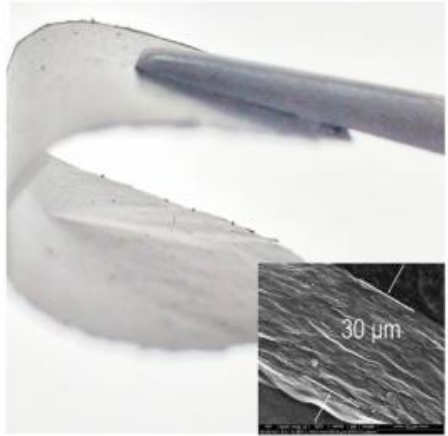

(b)

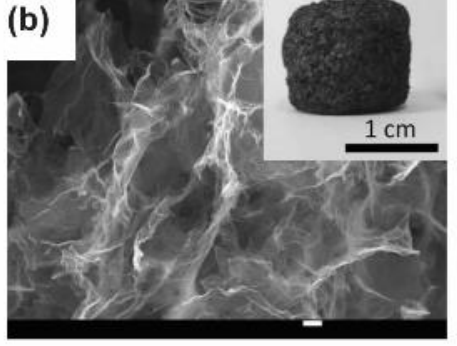

(e)

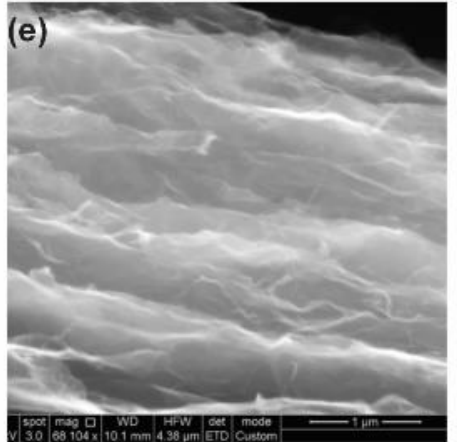

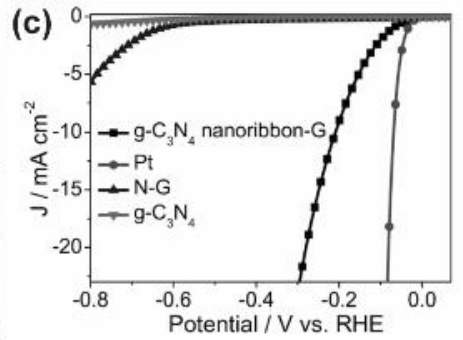

(f)

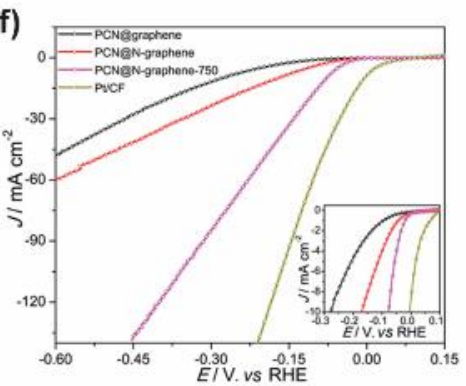

Figure 13. Macroporous 3D carbon structures prepared through the assembly of $2 D$ carbons for OER. (a) Illustration and (b) SEM image of $g-C_{3} N_{4}$ nanoribbons on graphene, (c) HER polarization curves of various catalysts ( $g-C_{3} N_{4}$ nanoribbon- $G$, $P t$ wire, $N-G$ and $\left.g-C_{3} N_{4}\right){ }^{[342]}$ (Copyright 2014, Wiley-VCH) (d) Photograph of PCN@N-graphene film, inset showing the SEM image of the cross-section view, (e) SEM image of the inside structure (f) Polarization curve (inset shows polarization curves with current density below $\left.10 \mathrm{~mA} \mathrm{~cm}{ }^{-2}\right){ }^{[18]}$ (Copyright 2015, ACS) 


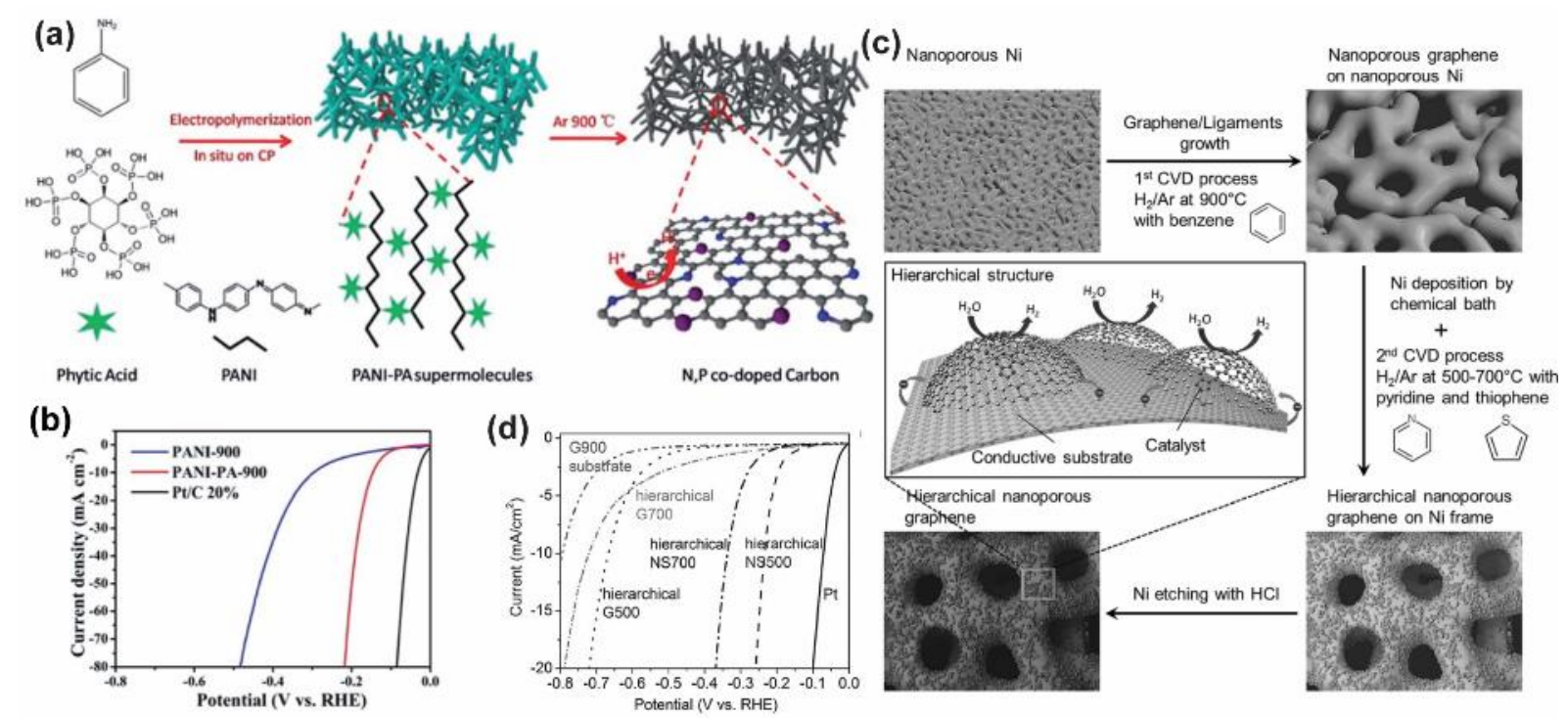

Figure 14. Conductive 3D hierarchical carbons with dual dopants for HER. (a) Illustration of the preparation of PANI-PA-900, (b) LSV curves of various samples for HER in 0.5M $\mathrm{H}_{2} \mathrm{SO}_{4}$, ${ }^{[343]}$ (Copyright 2016, RSC) (c) Fabrication process of hierarchical nanoporous graphene and expected reaction mechanism on hierarchical nanoporous graphene, (d) LSV curves for HER at a scan rate of $10 \mathrm{mV} \mathrm{s}^{-1}$ of the NS-doped samples prepared at different second CVD temperatures. ${ }^{[334]}$ (Copyright 2018, Wiley-VCH) 


\section{WILEY-VCH}
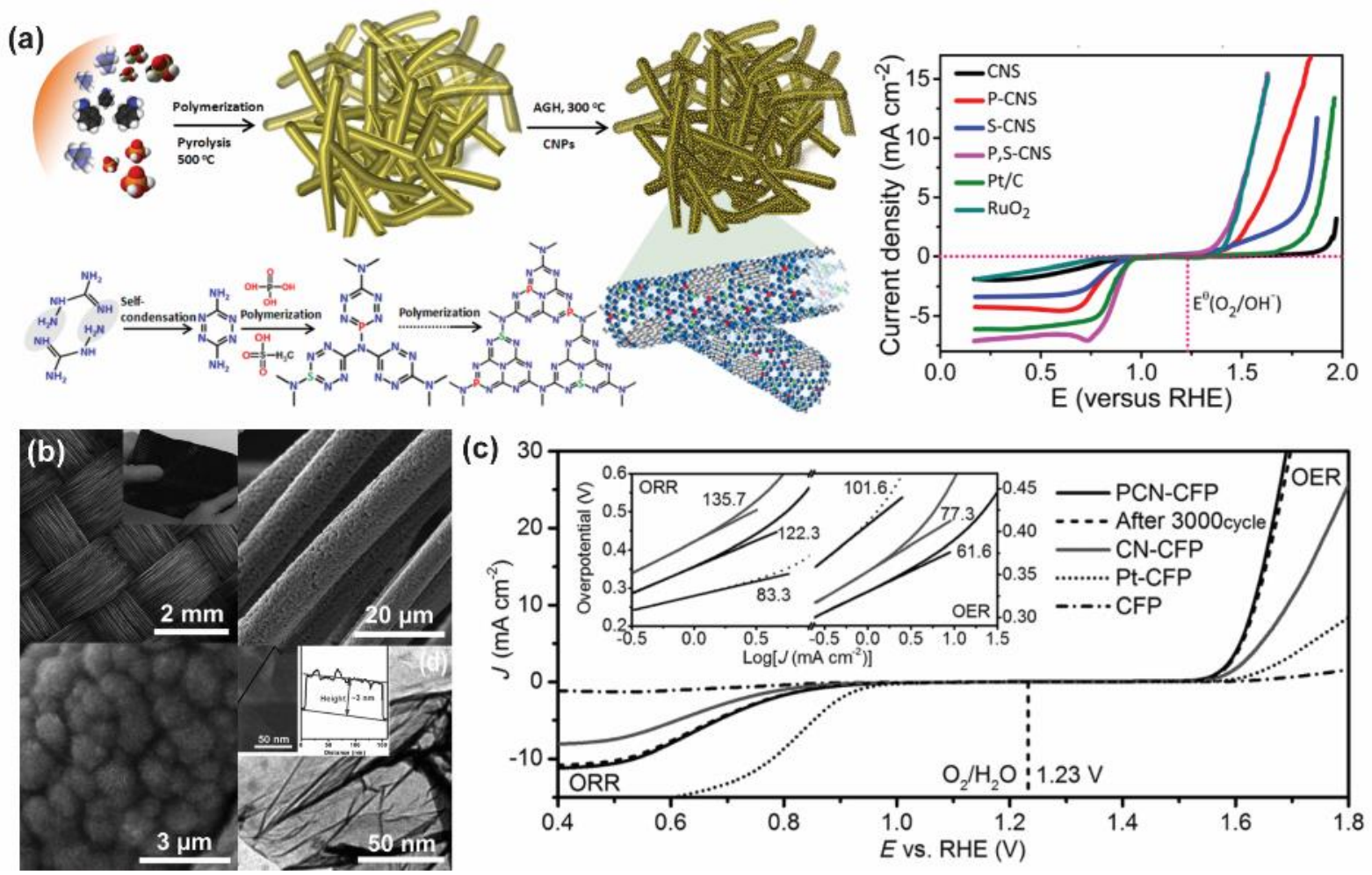

Figure 15. Sandwiched 3D carbon structures with dual dopants for bifunctional catalytic activity. (a) Schematics showing the synthesis of P,S-CNS catalysts, and the reaction mechanism for the formation of the C-N polymeric complex. ${ }^{[373]}$ (Copyright 2017, ACS) (b) SEM images of PCN-CFP and TEM (inset: AFM images with the corresponding height profile) of $P-g-C_{3} N^{4}$ nanosheets, collected from $P-g-C_{3} N_{4}$ nano-flowers in PCN-CNP. (c) LSV of $P C N=C F P, C N-C F P, P t-C F P$, and $C F P$ in $\mathrm{O}_{2}$-saturated $0.1 \mathrm{M} \mathrm{KOH}$ solution, scan rate $0.5 \mathrm{mV}$ $s^{-1}$ (inset: Tafel plots). ${ }^{[381]}$ (Copyright 2015, Wiley-VCH)

(a)

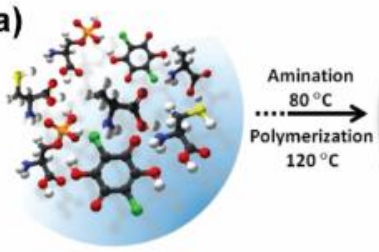

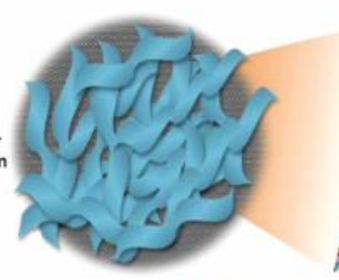
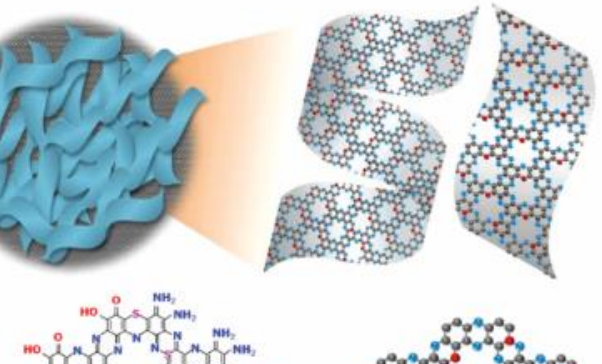

(b)

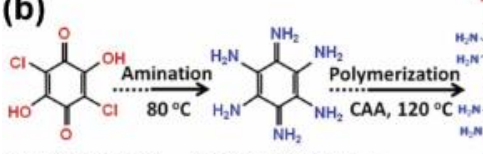

(f)

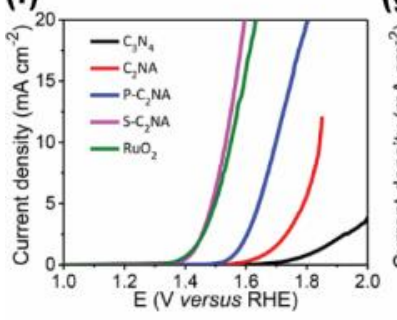

(g)

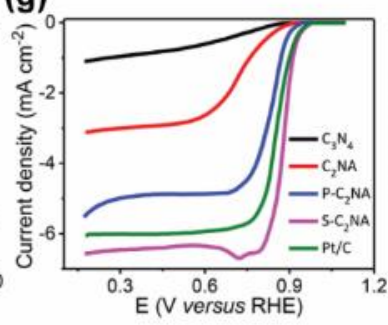

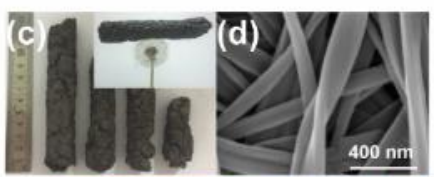

(e) $.001 .07 \%$

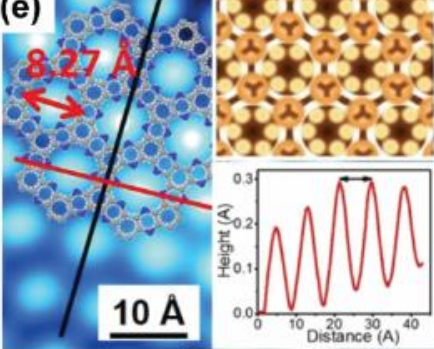

(i)

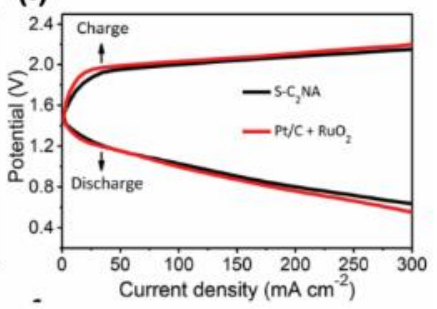

Figure 16. $3 D$ holey $S-C_{2} N$ aerogels prepared from COFs for bifunctional oxygen electrocatalysis. (a) Schematic illustration depicting the development of the $3 D$ holey $S-C_{2} N A$ 


\section{WILEY-VCH}

bifunctional catalysts through animation and polymerization processes and $(b)$ their reaction mechanism, (c) Optical image of the fabricated $3 D$ holey $S-C_{2} N A$ aerogel, (d) SEM images of the $S-C_{2} N A$ catalyst. (e) Atomic-resolution inverted STM image of $S-C_{2} N A$ on $C u(111)$, (f) ORR polarization curves (1600 rpm) for the $\mathrm{C}_{2} \mathrm{~N}$-based and $\mathrm{Pt} / \mathrm{C}$ catalysts in $\mathrm{O}_{2}$-saturated $0.1 \mathrm{M}$ $\mathrm{KOH},(\mathrm{g})$ OER polarization plots (1600 rpm, 0.1M KOH) for different catalysts, (h) Typical specific capacity of the solid-state zinc-air battery using $S-C_{2} N A$ catalyst at 5 and $50 \mathrm{~mA} \mathrm{~cm}$, (i) Discharge and charge polarization profiles of solid state zinc-air battery with $S-C_{2} N A$ and $\mathrm{Pt} / \mathrm{C}+\mathrm{RuO}_{2}$ as cathodes. ${ }^{[377]}$ (Copyright 2018, ACS)

(a)
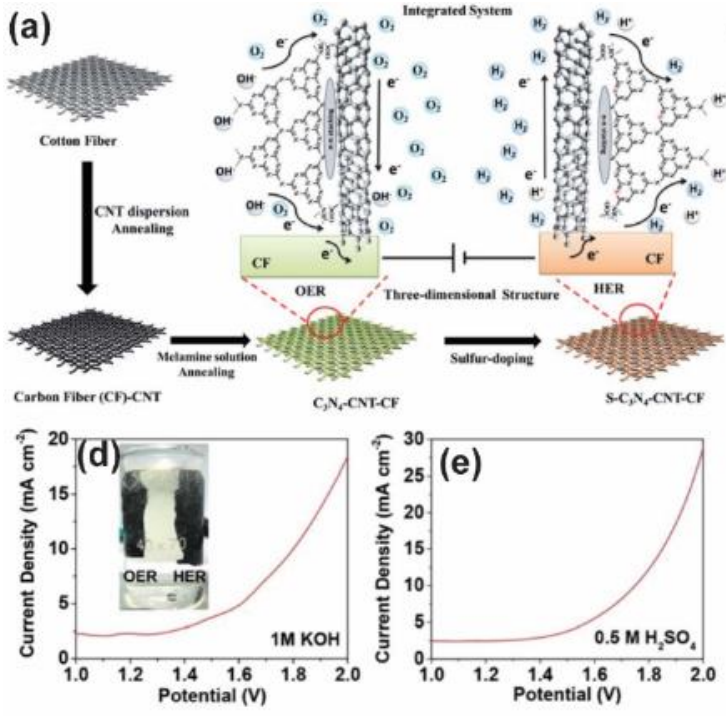

(b)

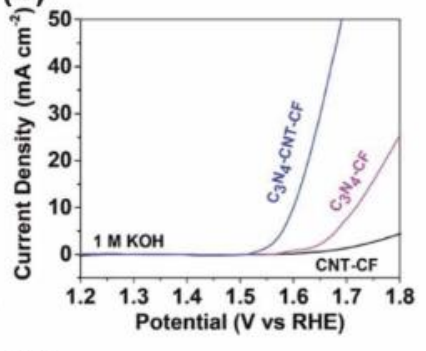

(f)

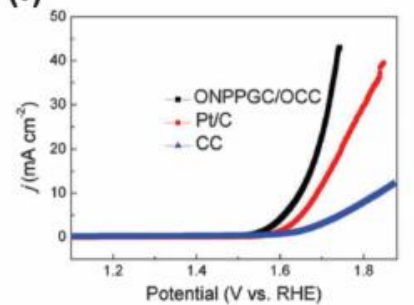

(c)

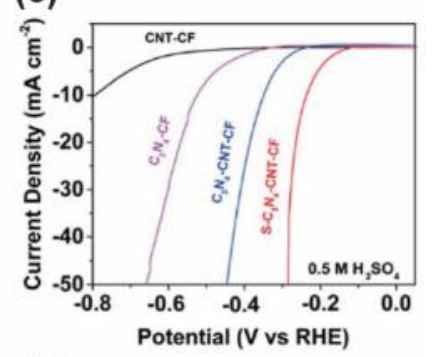

(g)

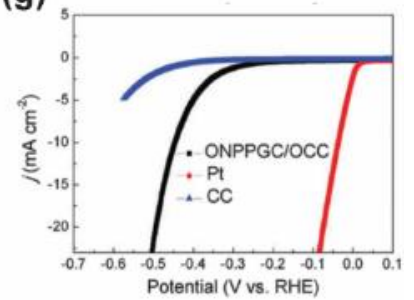

Figure 17. Self-supported metal-free 3D structured carbon fiber electrodes prepared with and without $S$ doping for water splitting. (a) Schematic illustration of the synthesis process of the self-supported $C_{3} N_{4}$ based metal free electrolyzer, (b) LSV curves of $C_{3} N_{4}, C N T-C F$ and $\mathrm{C}_{3} \mathrm{~N}_{4}-\mathrm{CNT}-\mathrm{CF}$ in $1 \mathrm{M} \mathrm{KOH}, 5 \mathrm{mV} \mathrm{s}^{-1}$, (c) LSV of CNT-CF, $\mathrm{C}_{3} \mathrm{~N}_{4}-\mathrm{CF}, \mathrm{C}_{3} \mathrm{~N}_{4}-\mathrm{CNT}-\mathrm{CF}, \mathrm{S}-\mathrm{C}_{3} \mathrm{~N}_{4}-$ CNT-CF and Pt in 0.5M H $\mathrm{H}_{2} \mathrm{SO}_{4}, 5 \mathrm{mV} \mathrm{s}^{-1}$. LSV data of the homologous $\mathrm{C}_{3} \mathrm{~N}_{4}-\mathrm{CNT}-\mathrm{CF} \| \mathrm{S}-\mathrm{C}_{3} \mathrm{~N}_{4}-$ CNT-CF metal free water splitting system in (d) $1 \mathrm{M} \mathrm{KOH}$ and (e) $0.5 \mathrm{M} \mathrm{H}_{2} \mathrm{SO}_{4},{ }^{[397]}$ (Copyright 2016, RSC) LSV curves for ONPPGC/OCC, bare CC, and Pt/C (f) for OER, $1 M \mathrm{KOH}, 2 \mathrm{mV} \mathrm{s}$ ${ }^{1}$ and (g) for HER, 1M KOH, $2 \mathrm{mV} \mathrm{s}^{-1} .{ }^{[398]}$ (Copyright 2016, RSC) 


\section{WILEY-VCH}

(a)
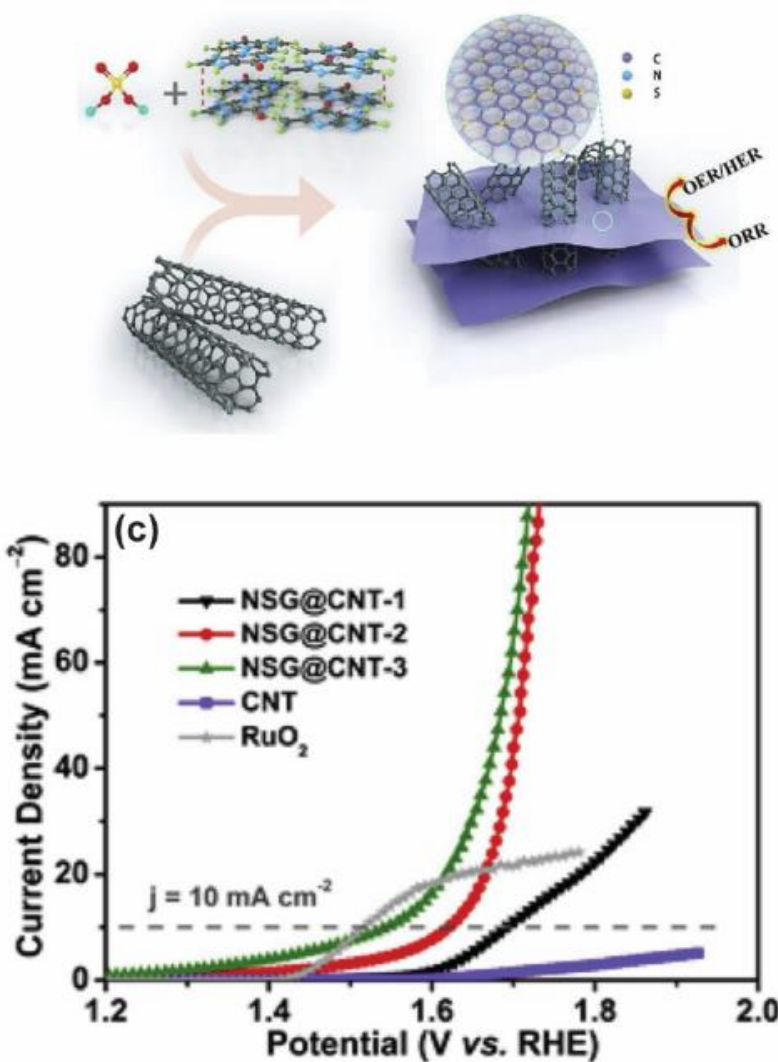
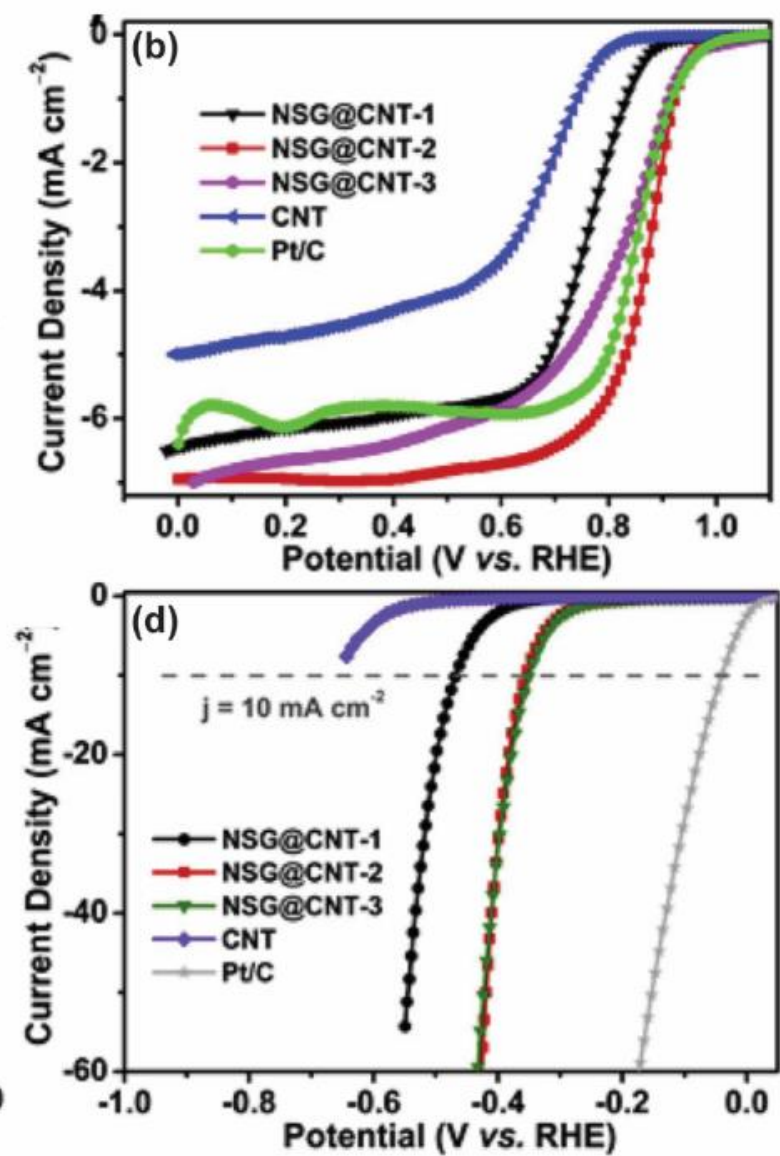

Figure 18. Template-free synthesis of 3D N,S-codoped carbon electrocatalysts for trifunctional catalysis. (a) Illustration of the synthetic route to CNT-graphene, (b) Comparisons of the RDE polarization curves in $\mathrm{O}_{2}$-saturated $0.1 \mathrm{M} \mathrm{KOH}$ at $1600 \mathrm{rpm}$ with 10 $m V s^{-1}$, (c) LSV curves for OER with $5 \mathrm{mV} \mathrm{s}^{-1}$, (d) LSV curves for HER with $5 \mathrm{mV} \mathrm{s}^{-1}$, [406] (Copyright 2019, Elsevier)

((For Essays, Feature Articles, Progress Reports, and Reviews, please insert up to three author biographies and photographs here, max. 100 words each)). Author Photograph(s) ((40 $\mathrm{mm}$ broad, $50 \mathrm{~mm}$ high, gray scale)) 


\section{WILEY-VCH}

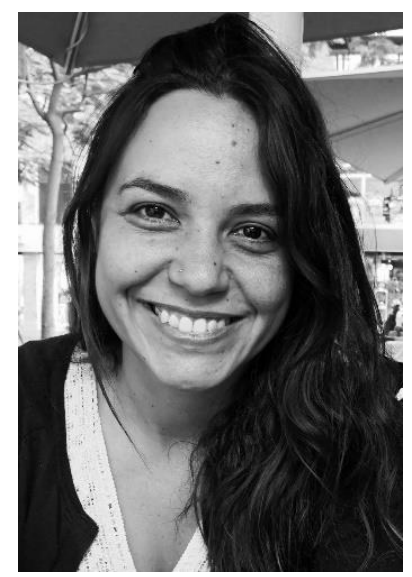

Ana Belen Jorge graduated in Chemistry in Canary Islands in 2004. She obtained her PhD in Materials Science from the Instituto de Ciencia de Materiales - Universidad Autonoma de Barcelona in 2009. After some time in industry, she came back to academia in 2011, taking up a postdoctoral position at University College London investigating new graphitic carbon nitrides for energy applications. Since 2016, she is a Lecturer in Energy Materials at Queen Mary University of London. Her research focuses in creating new sustainable materials for energy, including oxygen electrocatalysts, redox flow battery electrodes and photoanodes for water oxidation.

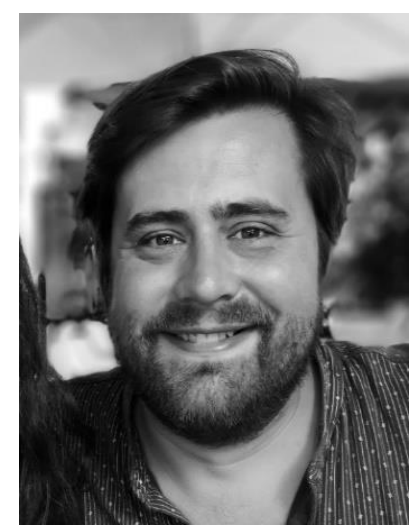

Rhodri Jervis graduated from Balliol College, Oxford in Chemistry in 2008 and after a short time working for a medical research spinout in his home town of Swansea obtained his $\mathrm{PhD}$ in fuel cell catalysis from University College London in 2015. After a post-doctoral research position in redox flow batteries he took up a position as lecturer in Chemical Engineering in UCL in 2018. He is currently the project lead for the Faraday Institution fast-start on Li ion battery degradation. His research interests focus on studying energy materials using a combination of electrochemical and x-ray techniques.

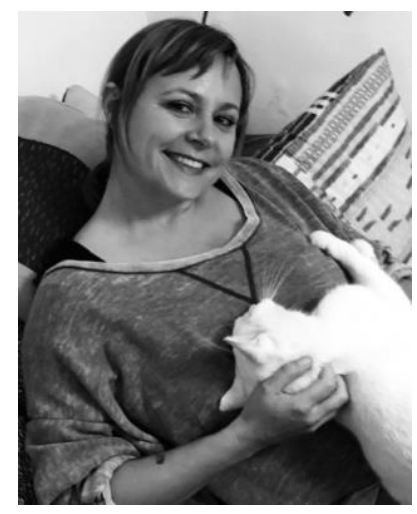




\section{WILEY-VCH}

Magda Titirici has a PhD from University of Dortmund (2005). She then did a PostDoc and become later a group leader at the Max-Planck Institute of Colloids and Interface. She then worked as a Reader and later Professor at Queen Mary University of London and is currently a Chair in Sustainable Energy Materials at Imperial College London. She has published over 200 papers on carbon materials for energy storage and conversion.

Keywords 3D porous carbons, electrocatalysis, OER, ORR, HER, energy storage and conversion

Ana Belen Jorge*, Rhodri Jervis, Arun Prakash Periasamy, Mo Qiao, Jingyu Feng, Linh Ngoc Tran, Maria-Magdalena Titirici*

Title Three-Dimensional Carbon Materials for Efficient Oxygen and Hydrogen

\section{Electrocatalysis}

Metal - free carbon - based materials with a three - dimensional porous architecture are earmarked to be the platform for the next generation of electrocatalysts in energy conversion and storage technologies. This review highlights the latest findings in 3D porous carbon nanostructured materials, main challenges and future directions for further development of these exciting materials into highly performing oxygen and hydrogen electrocatalysts.

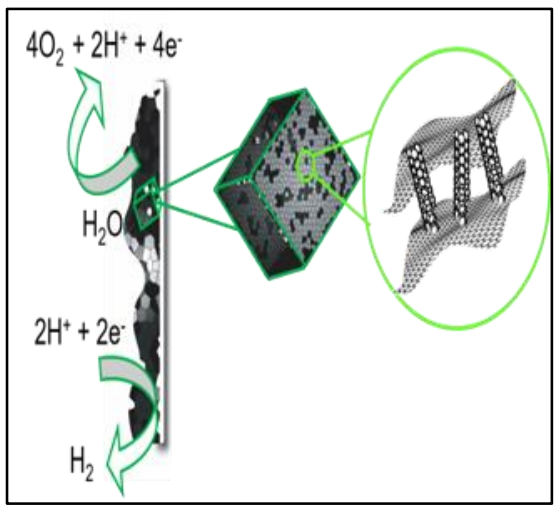

